TECHNICAL REPORT STANDARD TITLE PAGE

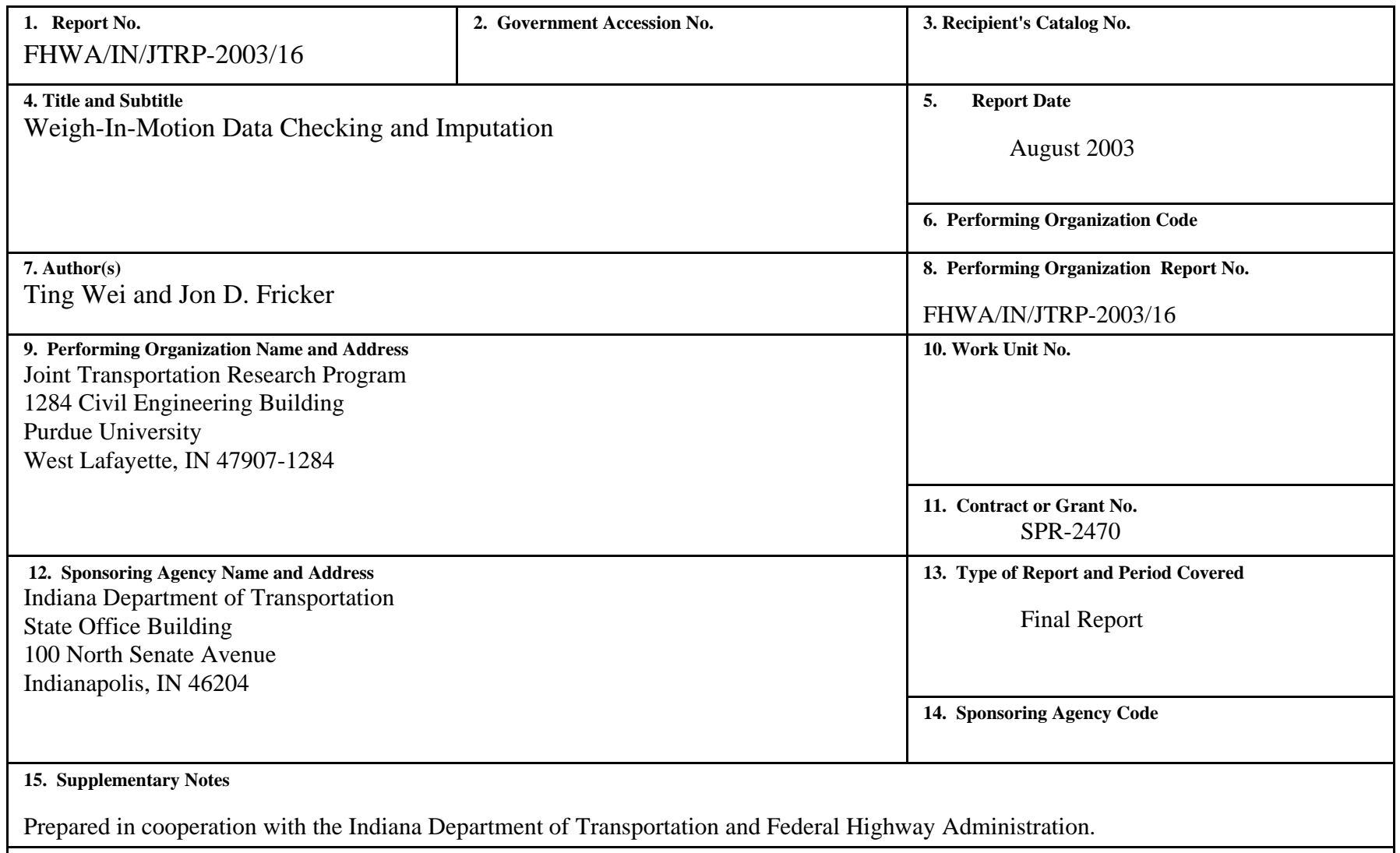

\title{
16. Abstract
}

There are about 46 weigh-in-motion (WIM) stations in Indiana. When operating properly, they provide valuable information on traffic volumes, vehicle classifications, and axle weights. Because there are great amounts of WIM data collected everyday, the quality of these data should be monitor without further delay. The first objective of this study is to develop effective and efficient methods to identify missing or erroneous WIM data. The second objective is to develop a data imputation method to update the missing or erroneous data.

This report describes the WIM data checking process on both a monthly and a daily basis. The Weigh-In-Motion Daily Data Checking (WDDC) program is introduced. The whole procedure requires very little human intervention, and provides a convenient way to check daily summary data. This report also describes several imputation methods in the experiment of imputing 7-day data.

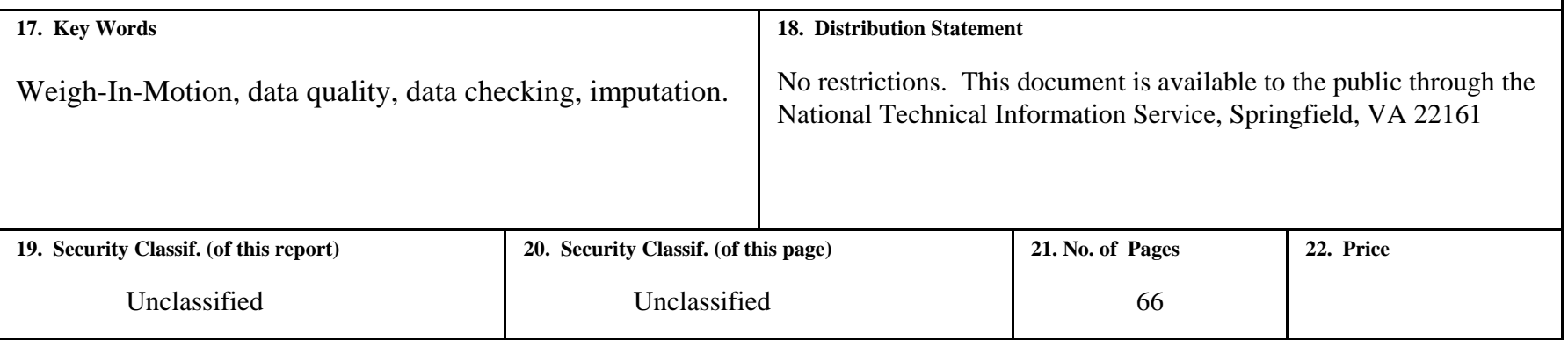




\section{TECHNICAL Summary}

INDOT Research

Technology Transfer and Project Implementation Information

\section{Weigh-In-Motion Data Checking and Imputation}

\section{Introduction}

WIM systems are usually used to detect illegally overweight vehicles and to collect traffic data for highway planning and management purposes. The purpose of this study is to identify missing or erroneous data and to develop a data imputation method to update these data. WIM data from the year of 1997 to 2001 for sites 4260 and 4270 are used in the analysis.

\section{Findings}

WIM data checking should be conducted on both a monthly basis and a daily basis. The three methods using unclassified vehicle rate, front axle distribution and Class 9 vehicle GVW are widely accepted. The WDDC (Weigh-In-Motion Daily Data Checking) program is developed for
INDOT to facilitate the daily checking process.

In the experiment of imputing 7-day data, the MAPE for the factor method and regression methods are within the range of 15-20 percent.

\section{Implementation}

Throughout the data analysis for this project, we realize how much important information the Weigh-In-Motion system can provide. However, the data quality often suffers from equipment problems. In addition, this project has been hampered by the lack of historical data. As more historical data can be retrieved, the ability to impute data can be more comprehensively assessed.
In the meantime, the data checking procedures developed in this project should facilitate the prompt detection of apparent data anomalies and the application of appropriate connective action. In the process, the amount of poor data can be reduced, with a corresponding reduction in the need for data imputation. 


\section{Contacts}

For more information:

Prof. Jon Fricker

Principal Investigator

School of Civil Engineering

Purdue University

West Lafayette IN 47907

Phone: (765) 494-2205

Fax: (765) 496-7996

E-mail: fricker@ecn.purdue.edu

\section{Indiana Department of}

Transportation

Division of Research

1205 Montgomery Street

P.O. Box 2279

West Lafayette, IN 47906

Phone: (765) 463-1521

Fax: (765) 497-1665

Purdue University

Joint Transportation Research Program

School of Civil Engineering

West Lafayette, IN 47907-1284

Phone: (765) 494-9310

Fax: (765) 496-7996 
Final Report

FHWA/IN/JTRP-2003/16

Weigh-In-Motion Data Checking and Imputation

By

Ting Wei

Graduate Research Assistant

and

Jon D. Fricker

Professor

School of Civil Engineering

Purdue University

Joint Transportation Research Program

Project No: C-36-17FFF

File No: 8-4-58

SPR-2470

Conducted in Cooperation with the

Indiana Department of Transportation

and the

U.S. Department of Transportation

Federal Highway Administration

The contents of this report reflect the views of the authors, who are responsible for the facts and the accuracy of the data presented herein. The contents do not necessarily reflect the official views or policies of the Indiana Department of Transportation or the Federal Highway Administration at the time of publication.

The report does not constitute a standard, specification, or regulation.

Purdue University

West Lafayette, IN 47907

August 2003 
Table of Contents

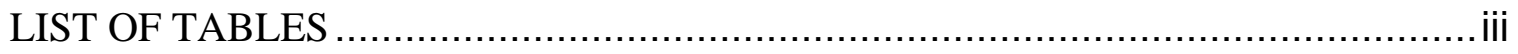

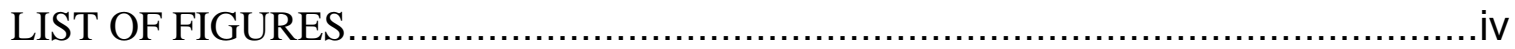

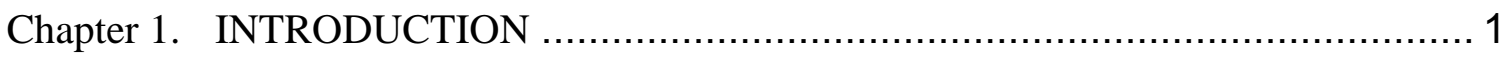

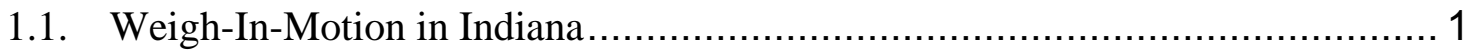

1.2. Definition of WIM Data Quality Problem ............................................ 3

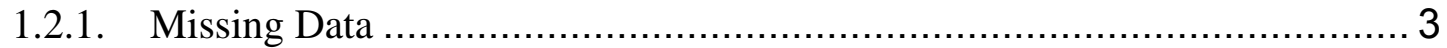

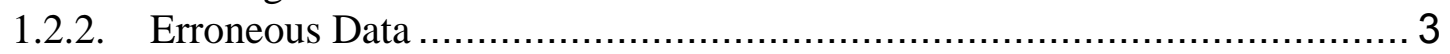

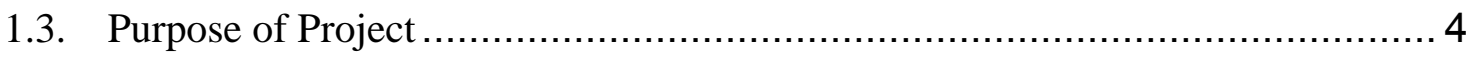

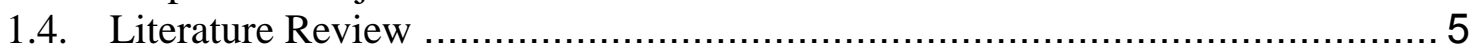

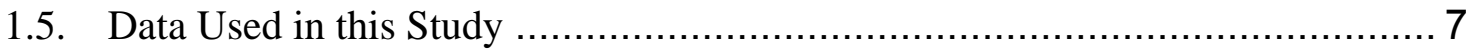

Chapter 2. MONTHLY CHECKING FOR WIM DATA …............................... 12

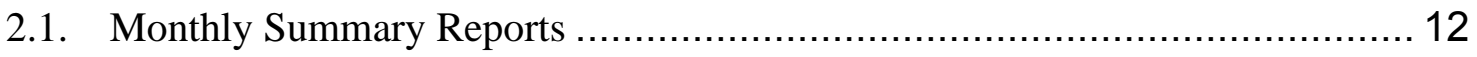

2.1.1. Selection of Monthly Summary Reports ........................................ 12

2.1.2. Generating Monthly Summary Reports.......................................... 15

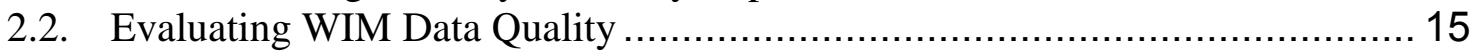

2.2.1. Using Unclassified Vehicle Rates ................................................ 15

2.2.2. Using Front Axle Weight Distribution ............................................ 17

2.2.3. Using Average Gross Vehicle Weight ………............................... 19

Chapter 3. DAILY CHECKING FOR WIM DATA ....................................... 21

3.1. Introduction to the WDDC Program..................................................... 21

3.2. Procedure for Using the WDDC Program ............................................. 22

Chapter 4. IMPUTATION FOR WIM DATA ……….................................... 31

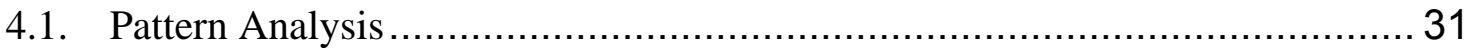

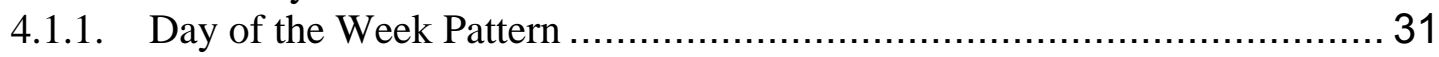

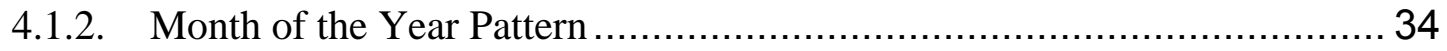

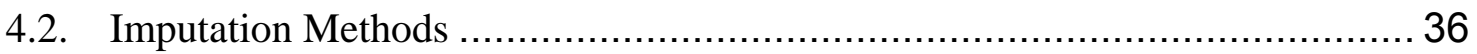

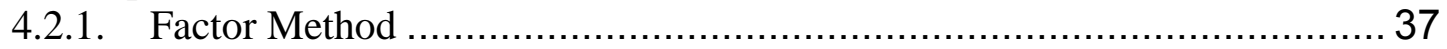

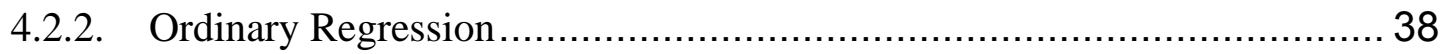

4.2.3. Regression with Autocorrelated Errors ............................................. 39

4.2.4. Other Time Series Forecasting Methods ......................................... 41

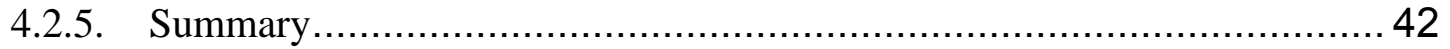

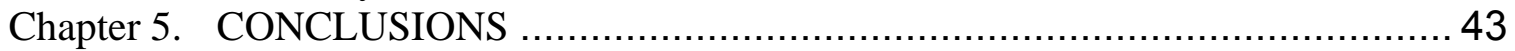

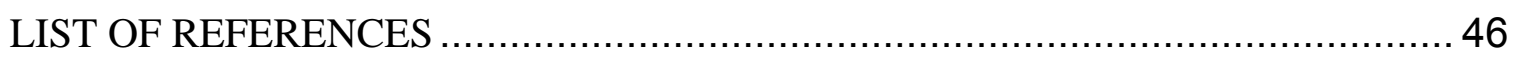

Appendix A. FHWA VEHICLE CLASSIFICATION SCHEME.............................. 49

Appendix B. DATA USED FOR PATTERN ANALYSIS …............................... 51

Appendix C. DATA USED FOR IMPUTATION METHODS …….......................... 60 


\section{LIST OF FIGURES}

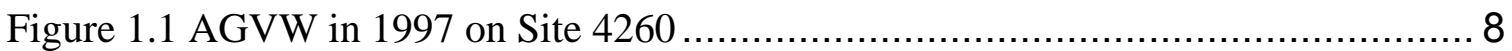

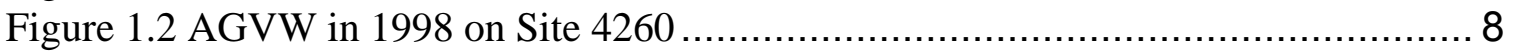

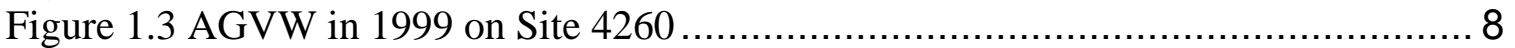

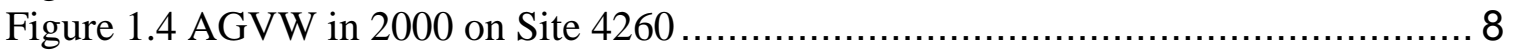

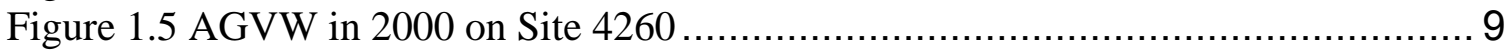

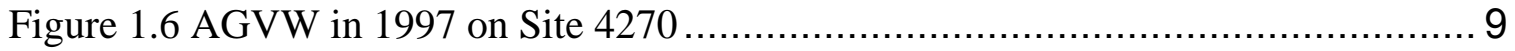

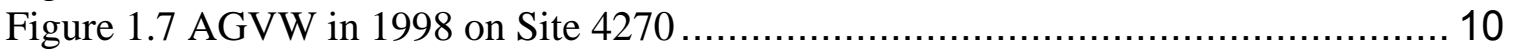

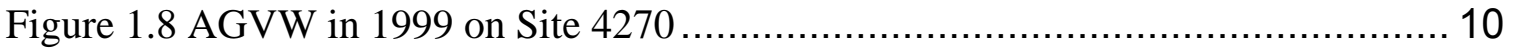

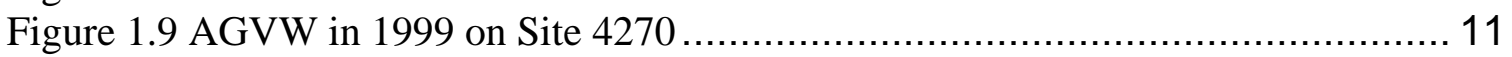

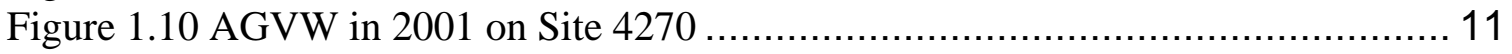

Figure 2.1 Vehicle Passage Information by IRD Office ................................... 12

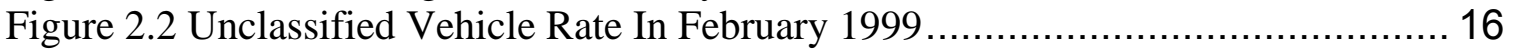

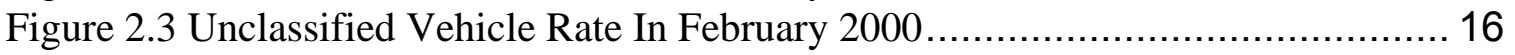

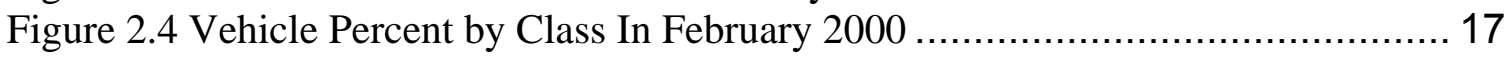

Figure 2.5 Front Axle Load Distribution for Site 4110 in March 1996 ...................... 18

Figure 2.6 Front Axle Load Distribution for Site 4260 in April 1999 ....................... 18

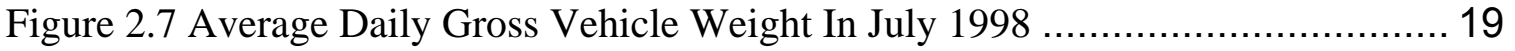

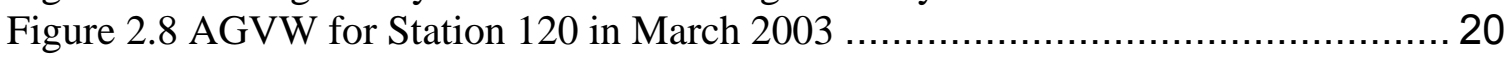

Figure 3.1 Step by Step Daily Checking Procedure ........................................ 23

Figure 3.2 The "Summary” Worksheet ( Part ) .......................................... 27

Figure 3.3 The "Hourly Counts” Worksheet (Part) ....................................... 28

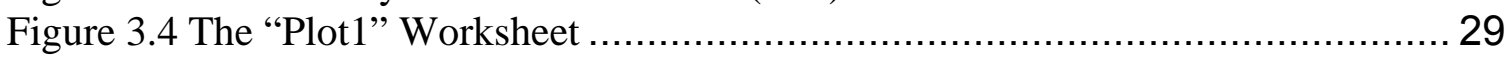

Figure 3.5 The "Plot2" Worksheet (Part) ............................................... 30

Figure 4.1 Output of ANOVA for Day of the Week Analysis ............................... 32

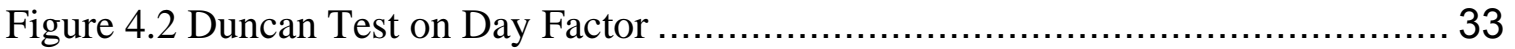

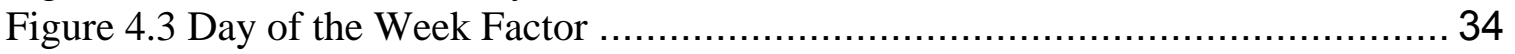

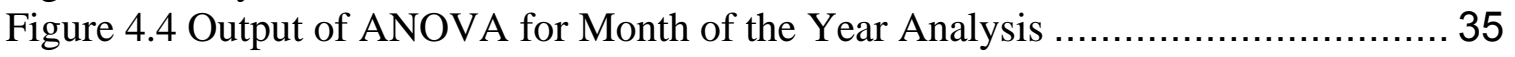

Figure 4.5 Duncan Test on Month Factor................................................. 35

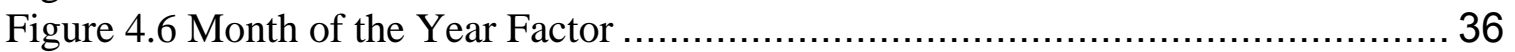

Figure 4.7 Output of the REG Analysis ................................................. 39

Figure 4.8 Output of Ordinary Least Squares Estimates.................................. 40

Figure 4.9 Output of Maximum Likelihood Estimates ................................. 41 


\section{LIST OF TABLES}

Table 1.1 Comparison of Common WIM Technologies....................................... 2

Table 2.1 List of Available Report Formats................................................... 13

Table 2.2 Example of Site Summary Report............................................... 14

Table 3.1 Files in the WDDC Program .................................................. 22

Table 3.2 Site Extensions Supported in WDDC Program................................... 25

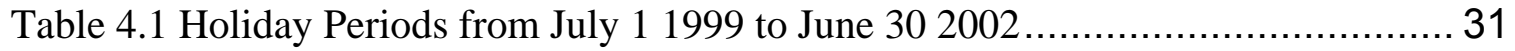

Table 4.2 Day of the Week Factor................................................................. 33

Table 4.3 Month of the Year Factor ............................................................. 36

Table 4.4 ESAL Values Estimated by Factor Method................................... 37

Table 4.5 ESAL Values Estimated by Ordinary Regression ............................... 39

Table 4.6 ESAL Values Estimated by Regression with Autocorrelated Errors .............41

Table 4.7 Results for Time Series Forecasting Methods ................................... 42 


\section{CHAPTER 1. INTRODUCTION}

\subsection{Weigh-In-Motion in Indiana}

Weigh-in-Motion (WIM) is defined as "the process of measuring the dynamic tire

forces of a moving vehicle and estimating the corresponding tire loads of the static vehicle" by ASTM (1994). WIM systems serve two very important functions:

1. Detection of illegally overweight vehicles

2. Data collection for highway planning and management purposes

It is widely accepted that heavy trucks cause major damage to highways. Weigh stations with static scales have traditionally been used to weigh commercial carriers using the highways. When a weigh station is in operation, all passing trucks are required to stop at the weigh station and have their weights recorded. Based on the industry standard cost of one dollar per minute of delay at a weigh station, it was estimated that weigh station stops could cost the nation's trucking industry over 10 billion dollars (Bergana et al. 1998).

A WIM system automatically weighs trucks when they are traveling at highway speed, so it can be an important enforcement tool for screening trucks and targeting potential violators. Because only suspected trucks are directed to a static scale, WIM can focus enforcement resources by concentrating on noncompliant trucks, while reducing the delay costs to compliant trucks. Green et al. (2002) described some enforcement practices using a "Virtual Weigh Station" by Indiana State Police. 
Another advantage of WIM systems is that they can be used to collect traffic data at all times, even when static weigh station is closed. Drivers of overweight vehicles may try to find the operation schedule of weigh station and delay their travel until the station is closed. However, if a WIM system is installed near the weigh station, the overweight trucks will be recorded.

The data continuously collected from WIM systems has proven to be valuable information for highway planning and management. Indiana has about 46 WIM stations on major highways, forming a statewide WIM data collection system. When operating properly, they provide valuable information on traffic volumes, vehicle classifications, and axle weights. This information is an important part of the data collected for the Highway Performance Monitoring System (HPMS) and is a key element of INDOT's warranty projects. The WIM data are also collected for the nationwide Long-Term Pavement Performance (LTPP) project. Gulen et al. (2000) updated the ESAL values for single unit trucks and multiple unit trucks, using the 1998 and 1999 traffic data collected from Indiana WIM stations.

There are three common technologies used in WIM systems: bending plates, piezoelectric sensors, and load cells. Bushman and Pratt (1998) compared the three types of technologies with respect to accuracy, life span and cost, as summarized in Table 1.1.

Table 1.1 Comparison of Common WIM Technologies

\begin{tabular}{|c|c|c|c|}
\hline & Piezoelectric & Bending Plate & Single Load Cell \\
\hline Accuracy (95\% confidence) & $\pm 15 \%$ & $\pm 10 \%$ & $\pm 6 \%$ \\
\hline Expected Life & 4 Years & 6 Years & 12 Years \\
\hline Initial Installation Cost & $\$ 9000$ & $\$ 21500$ & $\$ 48700$ \\
\hline Annual Life Cycle Cost & $\$ 4750$ & $\$ 6400$ & $\$ 8300$ \\
\hline
\end{tabular}

Most of Indiana WIM stations are using piezoelectric sensors or single load cells. INDOT has contracts with International Road Dynamics (IRD), Inc. for all the WIM systems in Indiana. IRD also provides a software package for INDOT to 
download the vehicle record files from remote WIM sites and to process the data to generate summary reports.

\subsection{Definition of WIM Data Quality Problem}

There are two kinds of data quality problems discussed in this report: missing data and erroneous data.

\subsubsection{Missing Data}

It is not unusual for a WIM site to fail to record any data for a specific period. This kind of problem can be caused by a power outage or a loop malfunction. Because INDOT downloads the vehicle record file on a daily basis, if the situation lasts a whole day, there will no file for this day; if the situation lasts for a few hours in a day, the file will only have the records for the other hours of the day.

\subsubsection{Erroneous Data}

Erroneous data is defined as the data that don't reflect the actual traffic conditions. By "erroneous", we mean the WIM data differ significantly from what we expect from a properly performing WIM station. There are many possible reasons for erroneous data, such as pavement condition, improper calibration, or lack of calibration.

In order to detect data that are present but erroneous, we can convert the raw data to some kind of summary report, and look for suspicious values of representative variables (e.g., gross vehicle weight). An extreme situation can be that a WIM site records all vehicles with 0 gross vehicle weight. Such a situation can be easily characterized as erroneous. In real life, we may see other situations with suspiciously high or low gross vehicle weights, and we have to conduct further analysis before making a conclusion. 


\subsection{Purpose of Project}

There are two major objectives of this study. The first objective is to develop effective and efficient methods to identify missing or erroneous WIM data. Because highway planners and designers rely on WIM data, the quality of the WIM data must be assured. Currently INDOT personnel inspect only the monthly summary report to identify possible data quality problems, because daily checking would require more time than is available to the personnel responsible.

In this report, we will explore the techniques used in monthly data checking (Chapter 2) and the methods possible for daily data checking (Chapter 3). As a result of the checking process, all suspicious data should be flagged for appropriate action. The second objective is to develop a data imputation method

to update the missing or erroneous data. We will test and compare several candidate methods in data imputation.

There has been much debate about data imputation and base data integrity. AASHTO Guidelines for Traffic Data Programs states: "Some current traffic editing programs estimate missing or edit rejected data. This practice, termed 'imputation,' is not recommended" (AASHTO 1992). This recommendation is based on the concern of base data integrity and the justification that imputing missing values introduces "errors which cannot be quantified" (AASHTO 1992).

However, leaving gaps where the missing data and erroneous data are identified may cause the whole data set to be far from complete, and may introduce biases. The Mobility Monitoring Program of the Texas Transportation Institute (TTI) reports that, after screening erroneous data, Transportation Management System (TMS) data archives can be anywhere from 16 percent to 93 percent complete. The median value in this study was 67 percent (Lomax et al. 2001).

The use of the remaining undiscarded data can introduce bias into the incomplete data set, because the data that have been discarded may represent a 
certain kind of traffic pattern that doesn't exist in the remaining dataset. For example, if we estimate average annual daily ESAL for a WIM station that has good data through the year except in January and December, the ESAL value could be higher than the actual value, because January and December are the two months that have the least truck traffic during the year.

Although INDOT has been using ESAL values for pavement design, INDOT currently doesn't employ any techniques for "replacing" missing or erroneous data. In a recent effort to update the average ESAL estimate values for multiple unit trucks and single unit trucks for INDOT, WIM data were refined by deleting the data based on several quality criteria (Gulen et al. 2000).

\subsection{Literature Review}

It has been recognized that the quality of WIM data can affect pavement design dramatically. It was reported (FHWA 1998) that the basic trend is that every 1 percent error by which a scale is under-calibrated results in slightly more than a 3 percent under-estimation of the true ESAL value. Every 1 percent overestimation in axle weight represents a 4.5 percent over-estimation of ESAL values. Thus, even an over-calibration of only 10 percent would result in a 45 percent error in estimated damage.

Therefore, it is important to do the system calibration properly. The American Society for Testing and Materials (1994) has published standard specifications for the calibration procedure for highway WIM system, which includes the acceptance and initial calibration processes. States' Successful Practices WeighIn-Motion Handbook (McCall and Vodrazka 1997) also provides a standardized step-by-step procedure for WIM calibration.

Moreover, calibration must be done routinely because electronics do drift over time. Zhi et al. (1999) evaluate the performance of a WIM system in Manitoba, 
Canada, and found that about 90 percent of truck weights were underestimated and the degree of underestimation was higher than 50 percent of the static weights, due to the reasons of unstandardized calibration procedures and a drift in calibration over time. This finding highlights the importance of quality control and corrections on WIM data prior to their use in research or engineering practice.

In order to detect possible WIM data quality problems, there are two kinds of methods used to check WIM data. The first type involves comparing data values to a confirmed range. For example, the WIM axle-spacing data sets should fall with the range specified by ASTM Standard E1572. There are other variables that can be selected, such as front axle weight or gross vehicle weight (GVW).

The second type involves plotting data values of a specified period for serial check or graphic inspection. Generally we can use daily GVW or ESAL. Schmoyer and Hsu (1997) used a change-point algorithm based on the statistic:

$$
T=200 \times\left|\frac{\text { mean for } 2 \text { weeks post }- \text { mean for } 2 \text { weeks prior }}{\text { mean for } 2 \text { weeks post }+ \text { mean for } 2 \text { weeks prior }}\right|
$$

Schmoyer and Hsu stated that, "A change in the series is suggested at any point for which the mean for the last two weeks is appreciably different from the mean for the next two weeks. "Appreciably different" must be defined, of course, and should achieve a reasonable balance of false positives and false negatives." The advantage of this method is to avoid the reliance on human eyes to do the serial check.

There is a large amount of research related to missing values. In the book Statistical Analysis with Missing Data, Little and Rubin (2002) summarized most of the up-to-date approaches that handle missing data. There is some research addressing how missing data are handled by transportation practitioners. Nihan and Holmesland (1980) used Box-Jenkins techniques to predict short-term traffic for urban freeways. Their model was able to predict average weekday volumes 
for two months, in which entire monthly data was missing. Zhong et al. (2002) analyzed the data from Alberta DOT and Minnesota DOT, and found that genetically designed regression models based on data from before and after the failure had the most accurate results. Average errors for refined models were lower than 1 percent, and the 95th percentile errors were below 2 percent for counts with stable patterns. Smith et al. (2003) provided a comparison of heuristic techniques and statistical techniques and indicated that the more sophisticated statistical techniques may generate better imputations. Smith et al. also suggested that the transportation profession seriously reconsider the AASHTO "policy" of not imputing traffic data in order to provide the user as much information as possible.

\subsection{Data Used in this Study}

In order to analyze the characteristics and patterns of WIM data, it has been recognized that there must be enough WIM data available, especially for several continuous years. INDOT provided us with 5 years (from 1997 to 2001) of WIM data for Stations 4260 and 4270 . These data were used throughout the study. The following figures are the plots of the average daily GVW for class 9 vehicles from summary reports.

For station 4260, as we can see in Figure 1.1-1.5, there are a few periods that have missing data or zero GVW. The year of 1998 seems to have the most complete data set. However, there is a big change happening during July 1998 (Figure 1.2). This kind of change also happened in March 1999 and July 2001. 


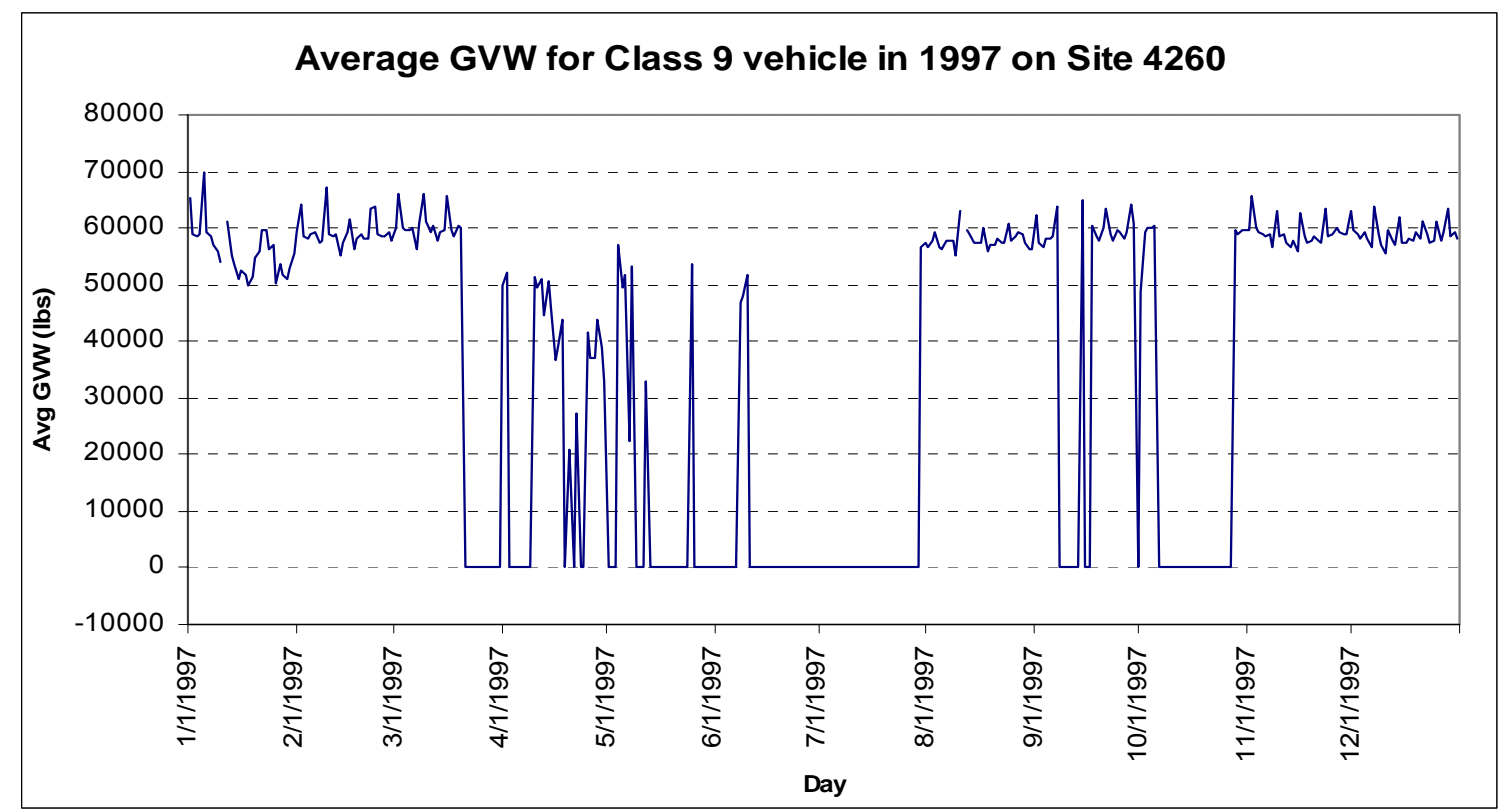

Figure 1.1 AGVW in 1997 on Site 4260

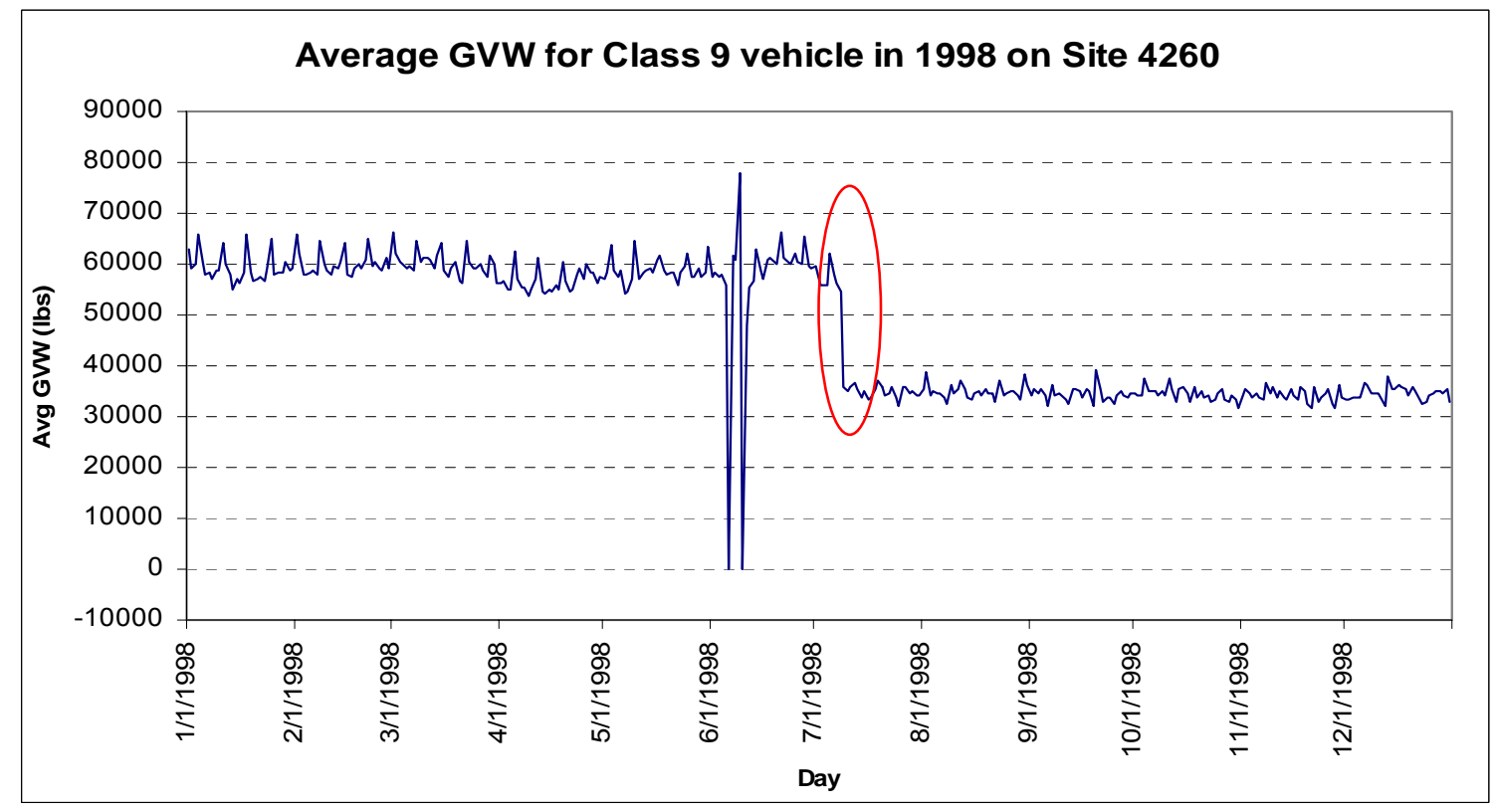

Figure 1.2 AGVW in 1998 on Site 4260 


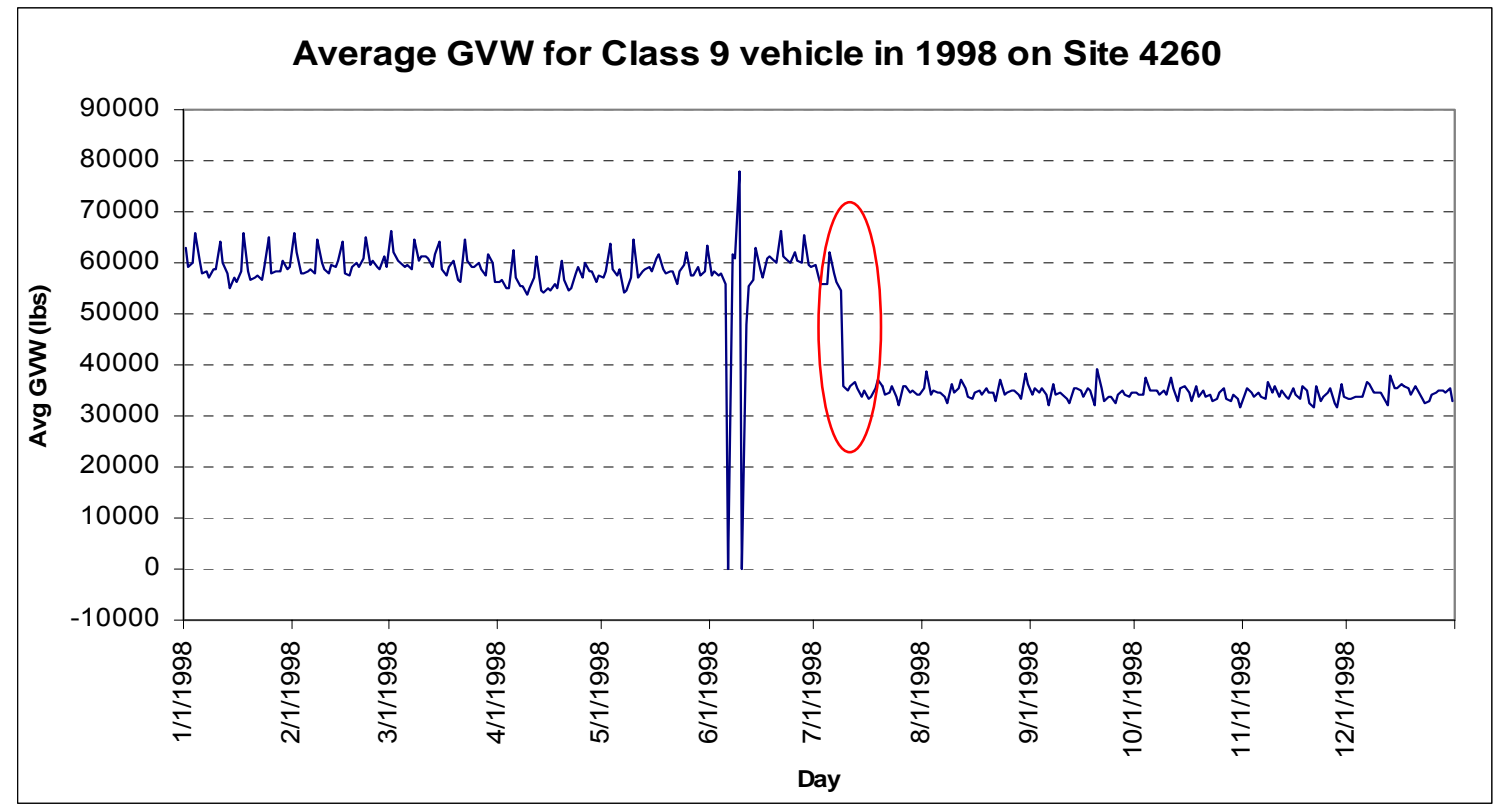

Figure 1.3 AGVW in 1999 on Site 4260

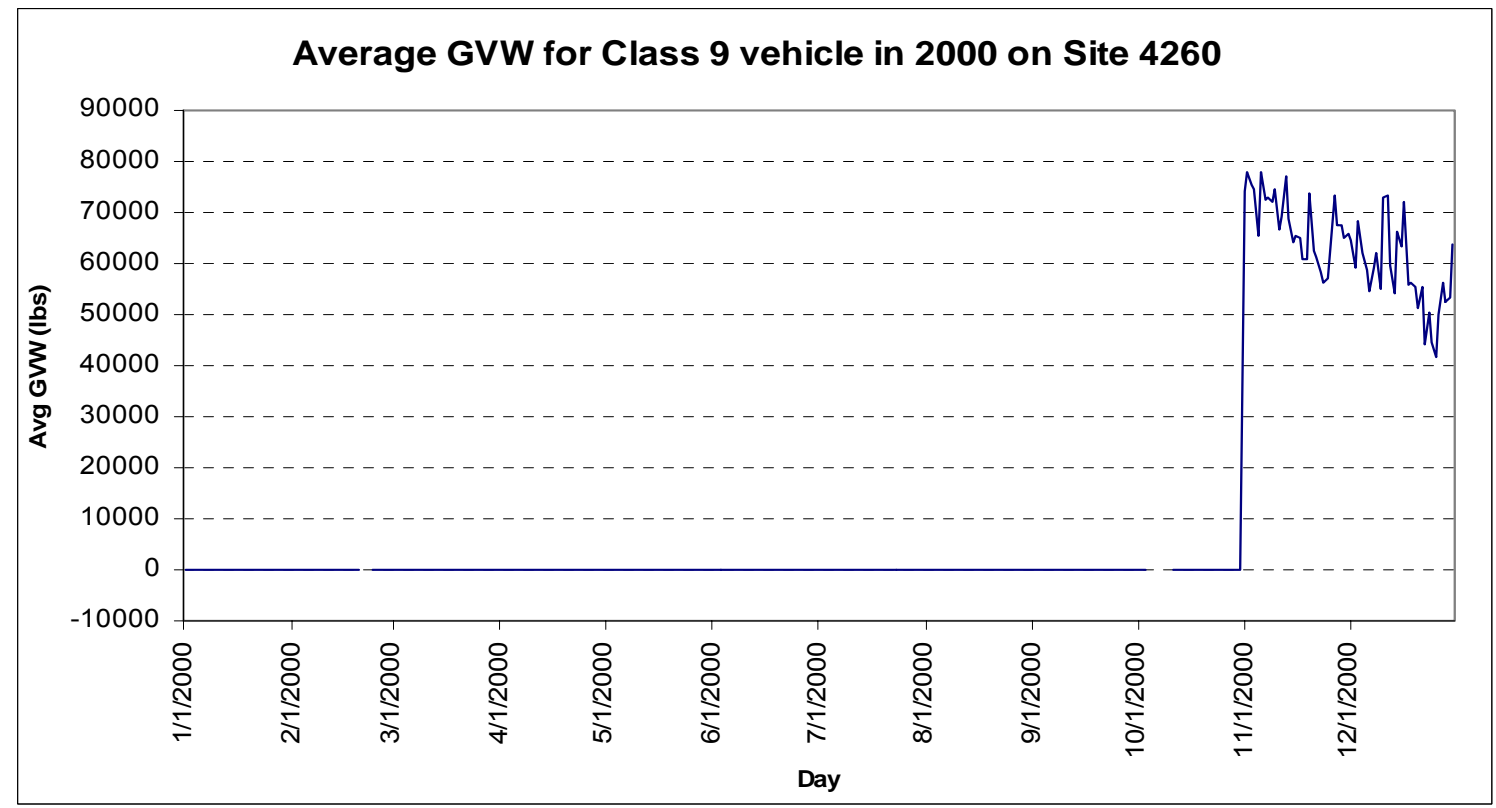

Figure 1.4 AGVW in 2000 on Site 4260

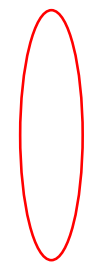




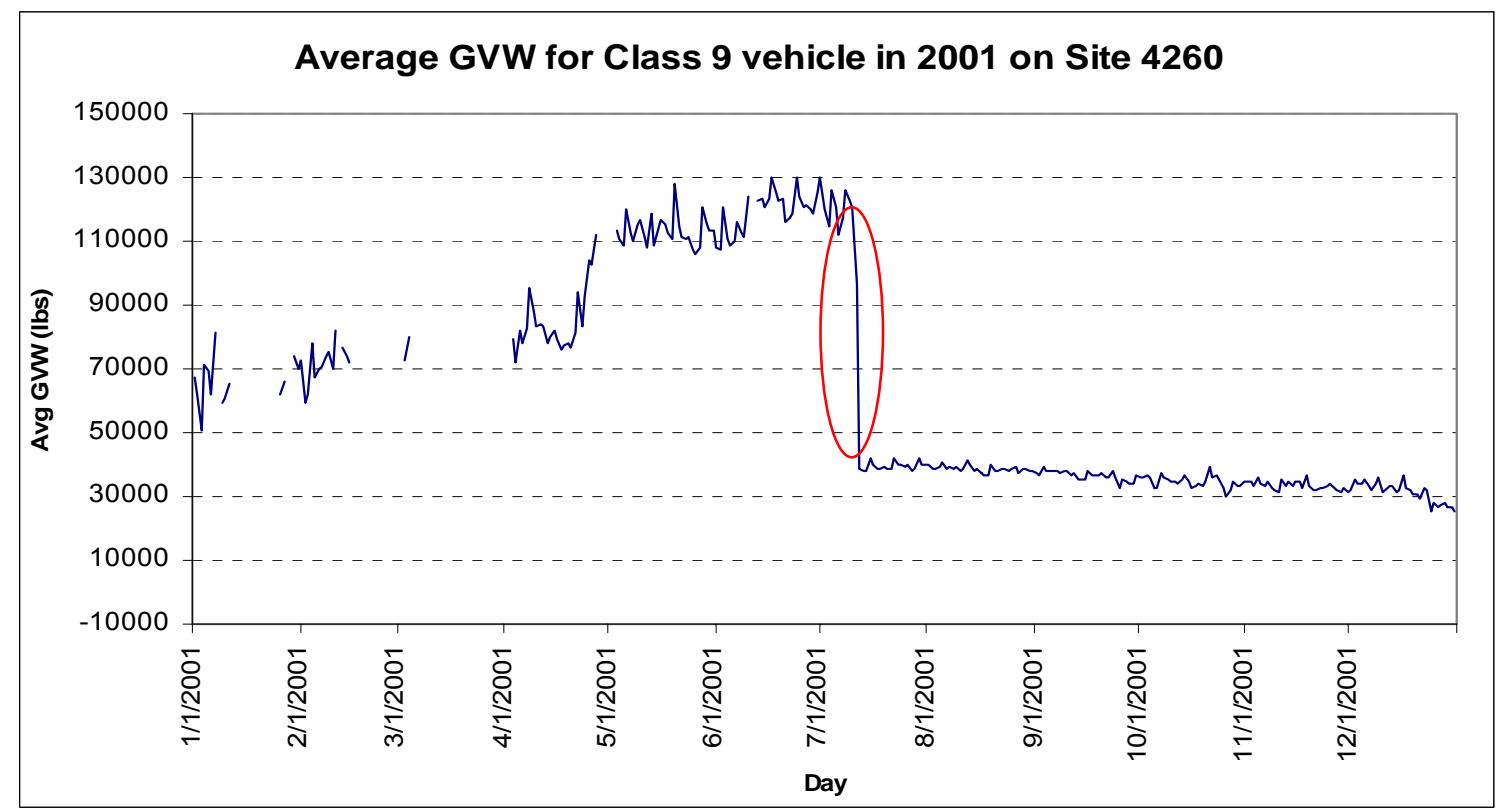

Figure 1.5 AGVW in 2000 on Site 4260

For station 4270, as we can see in Figures 1.6-1.10, the WIM data has overall better quality, except a 5-month period of zero GVW (Figures 1.7 and 1.8) and a 2-month period of missing data (Figure 1.10).

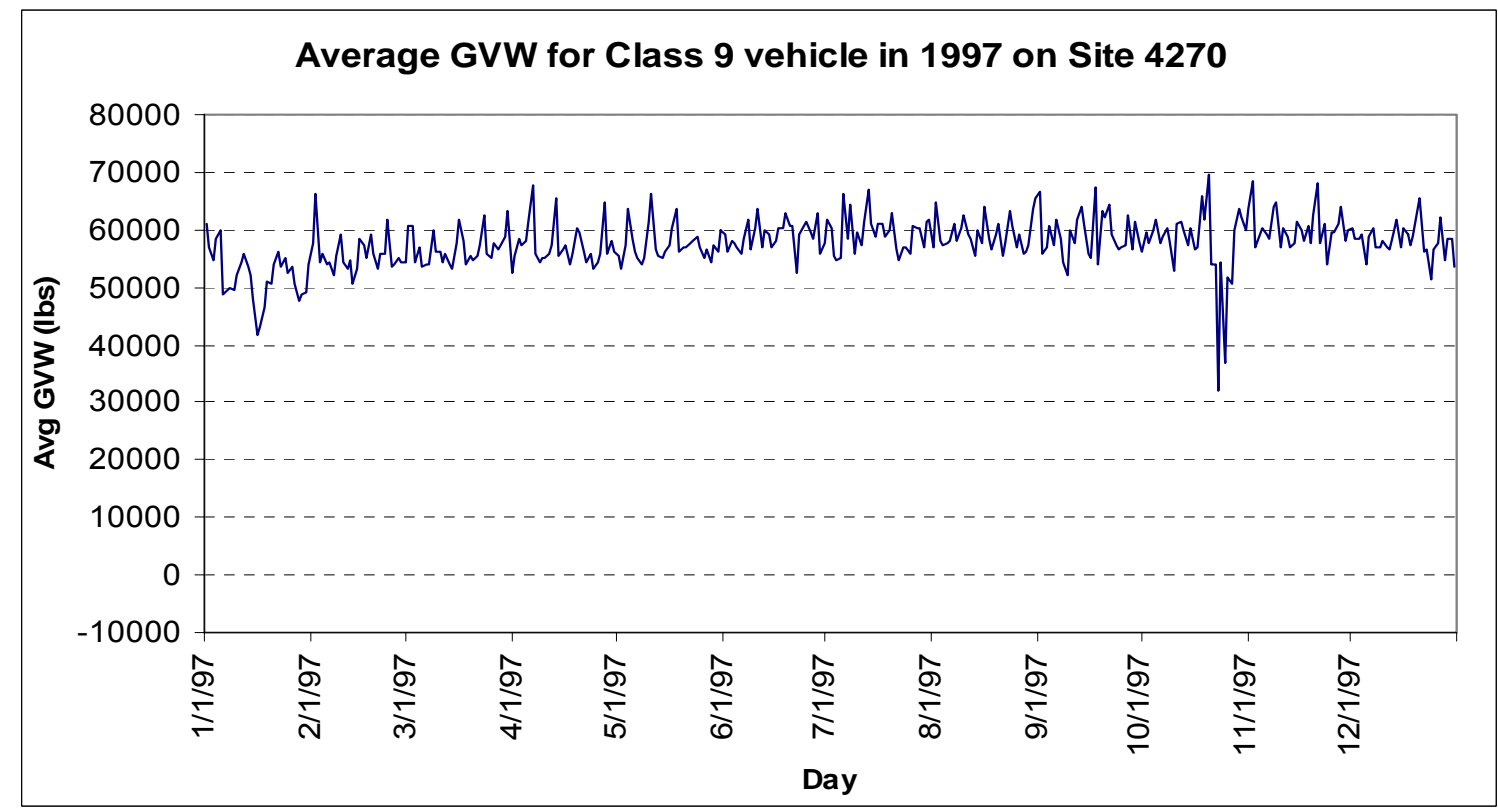

Figure 1.6 AGVW in 1997 on Site 4270 


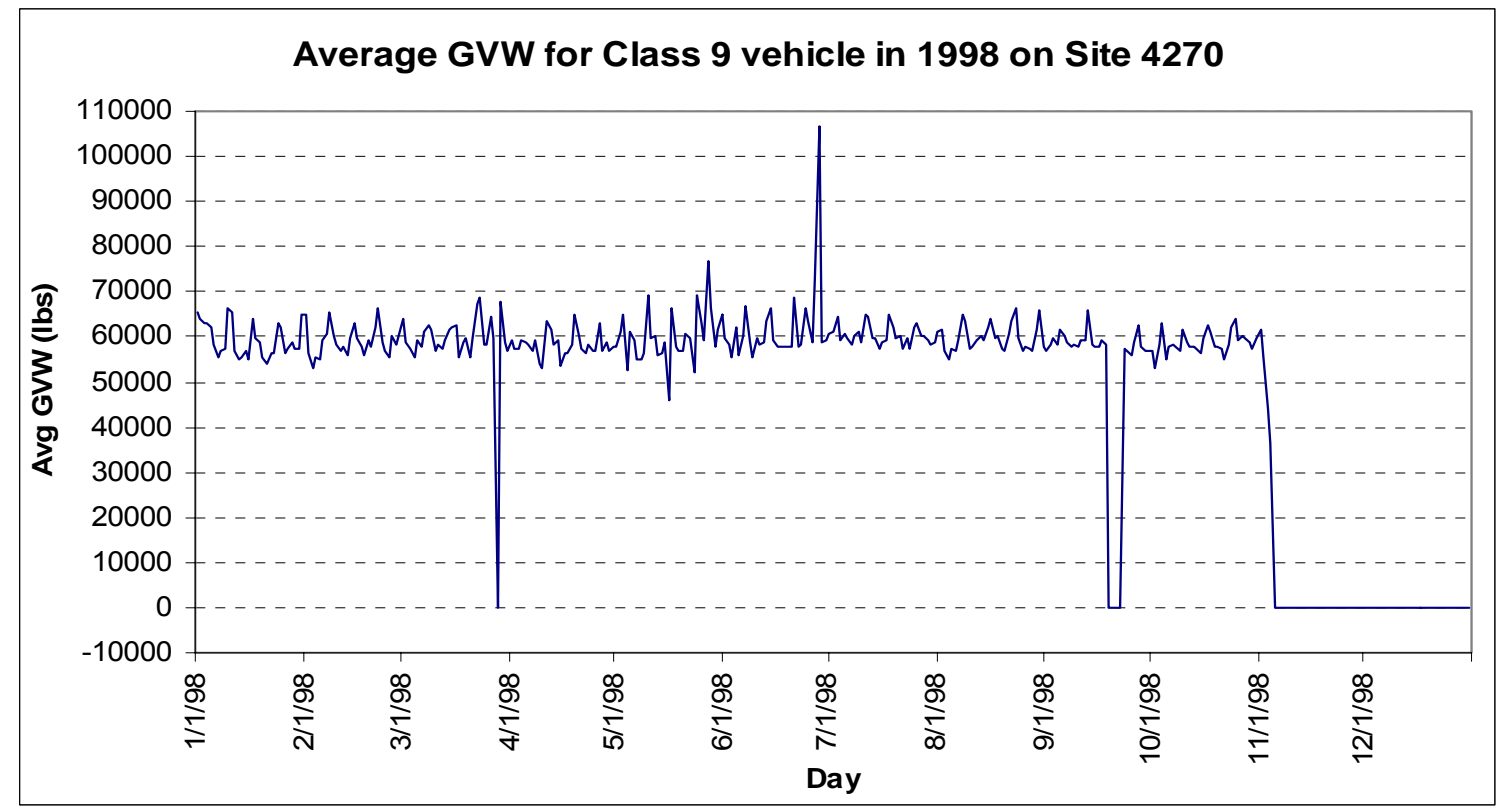

Figure 1.7 AGVW in 1998 on Site 4270

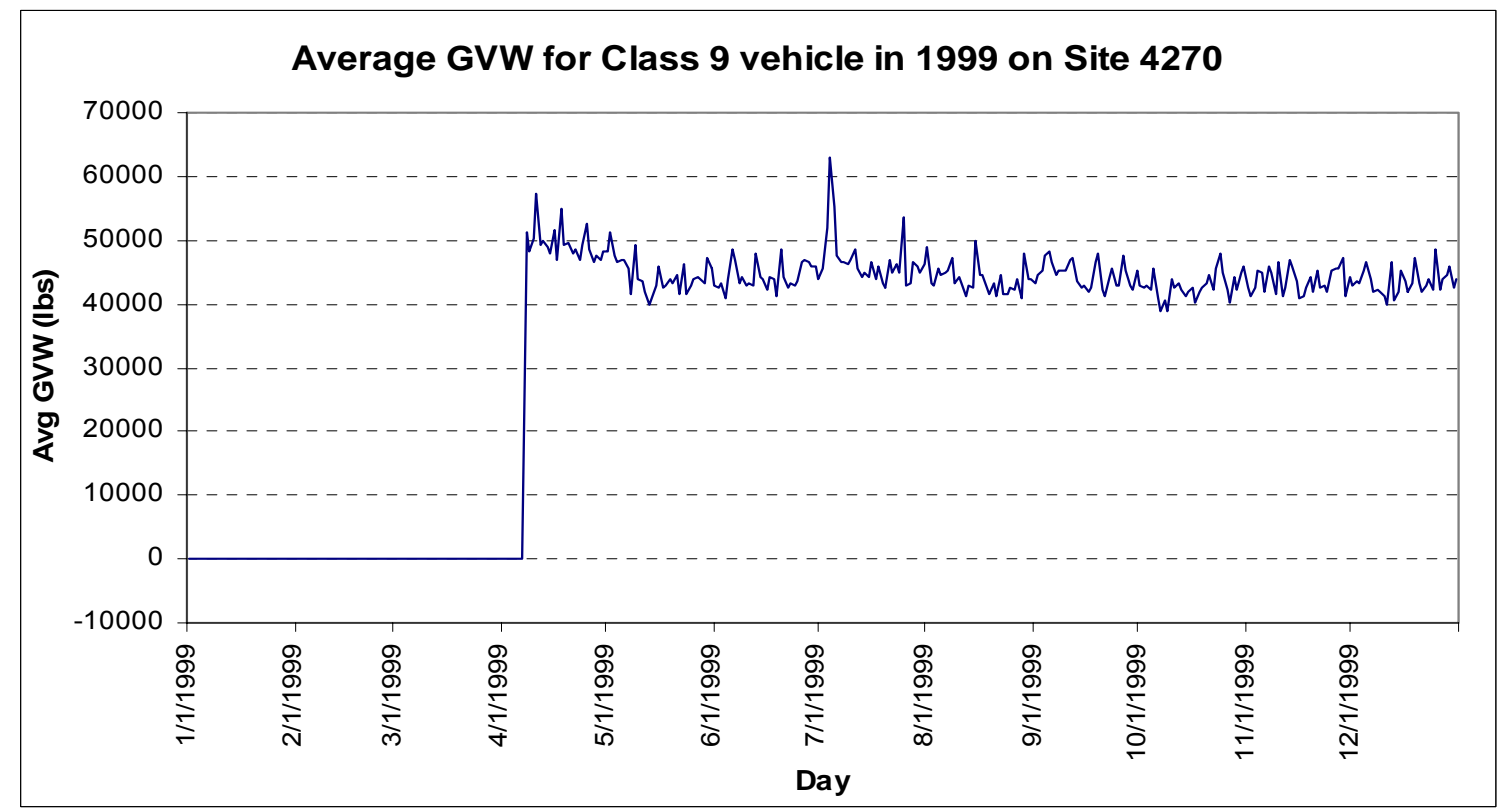

Figure 1.8 AGVW in 1999 on Site 4270 


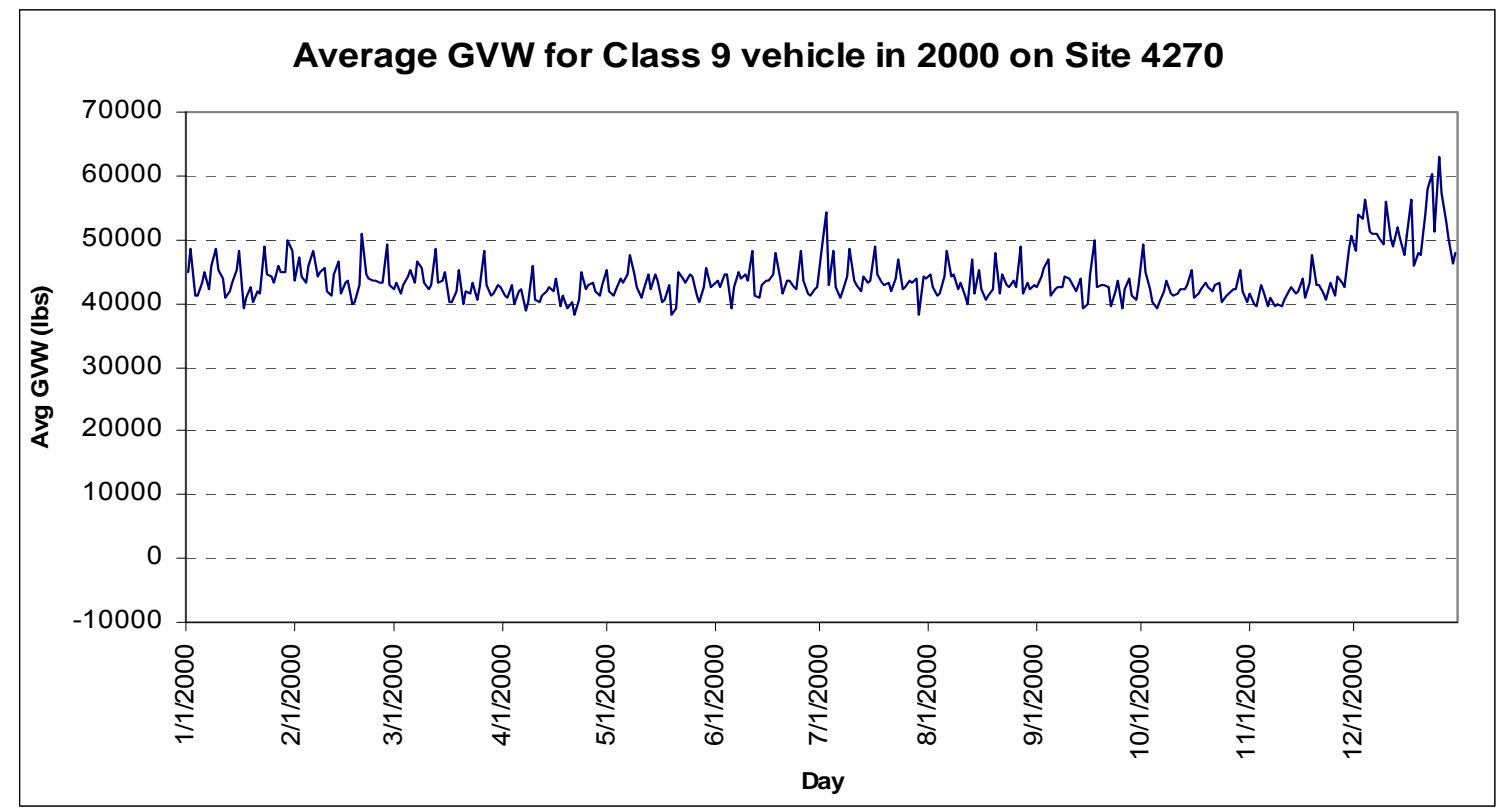

Figure 1.9 AGVW in 1999 on Site 4270

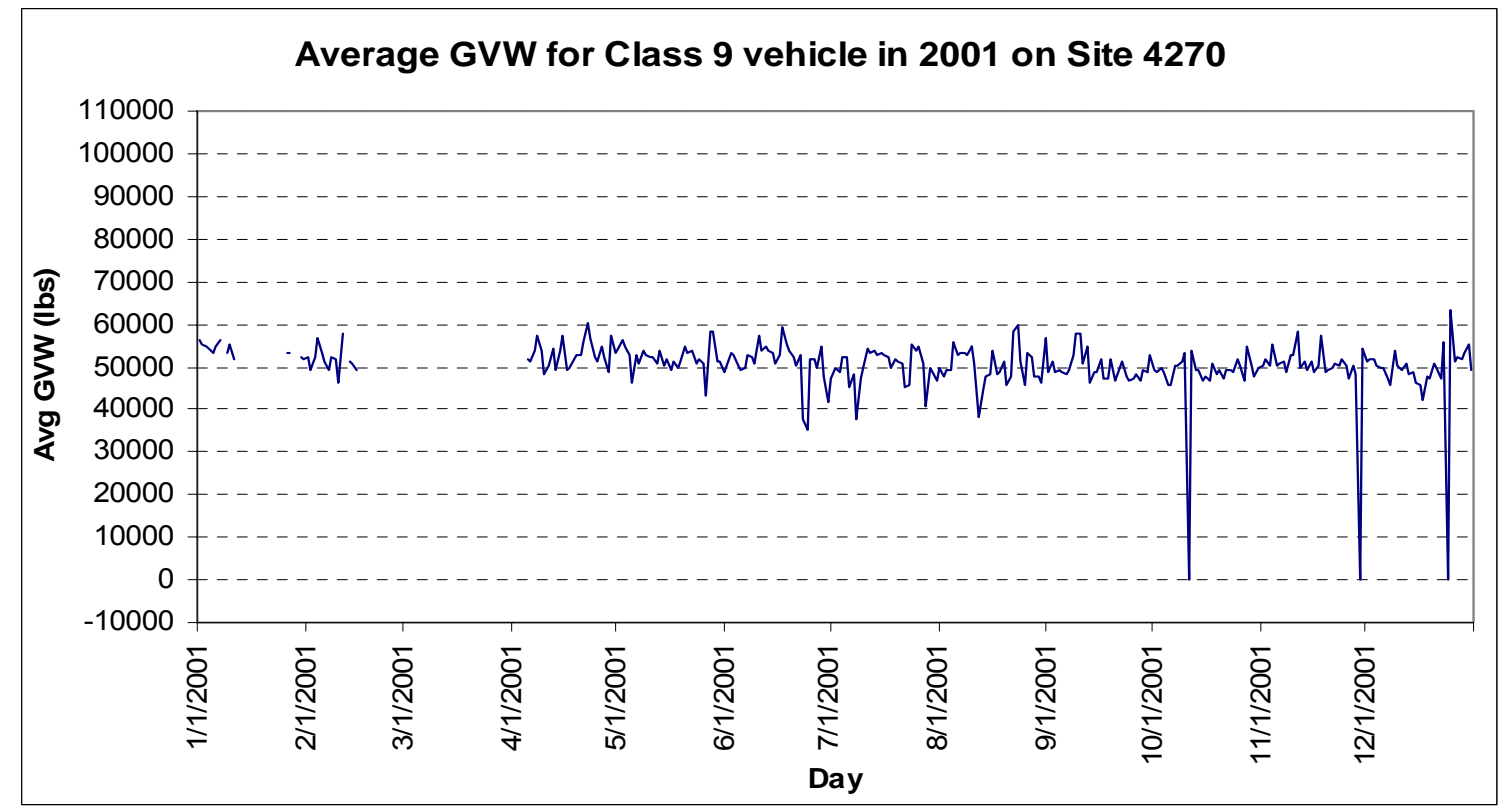

Figure 1.10 AGVW in 2001 on Site 4270

During the year of 2002, INDOT began to continuously provide WIM data for all Indiana WIM stations to Professor Darcy Bullock at Purdue University. The use of these data will be discussed in the following chapters. 


\section{CHAPTER 2. MONTHLY CHECKING FOR WIM DATA}

\subsection{Monthly Summary Reports}

\subsubsection{Selection of Monthly Summary Reports}

The raw data downloaded from WIM stations have been encrypted by IRD, and can't be viewed directly. In this project, we use the IRD Office (version 7.5.0) to process these data, focusing on truck information. One way to do this is to retrieve vehicle-by-vehicle information, as shown in Figure 2.1.

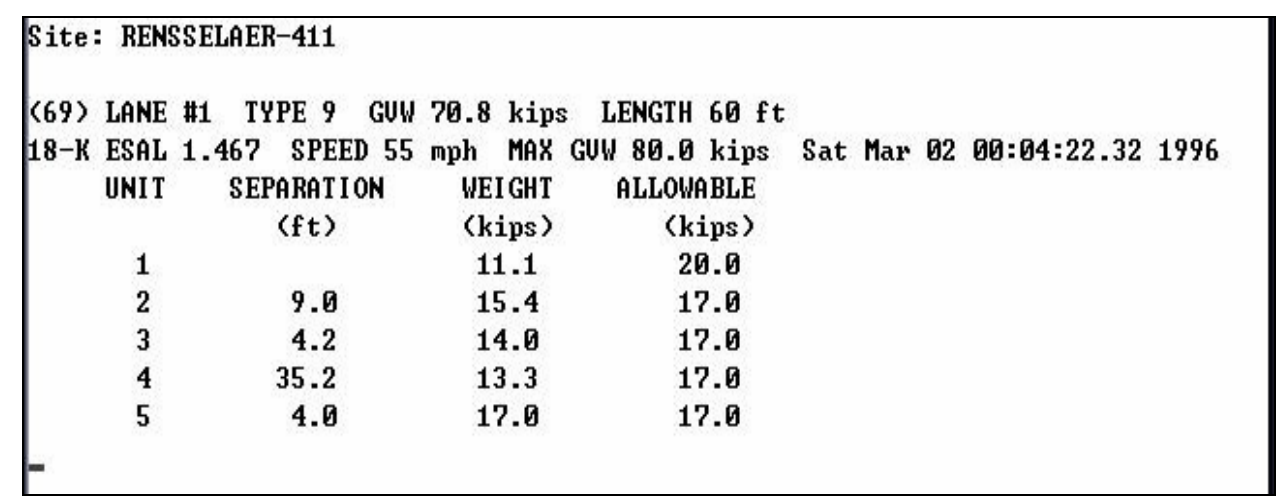

Figure 2.1 Vehicle Passage Information by IRD Office

We can now view all the information the WIM system has recorded for each individual truck. The ESAL is automatically calculated using the AASHTO load equivalency table or formula (selected by user) in the AASHTO Guide for Design of Pavement Structures, 1986 (IRD 1993).

Another way to retrieve the truck information is to generate customized summary reports. In this project, because we are specifically interested in daily statistics, we only use summary reports. The user can select a preferred format and appropriate variables. Table 2.1 lists the report formats provided by IRD Office: 
Table 2.1 List of Available Report Formats

\begin{tabular}{|c|c|}
\hline Class by Hour & FHWA TMG Card Reports \\
\hline Speed by Hour & Autocalibration \\
\hline Lane by Hour & Site Summary \\
\hline Lane by Class & IRD ASCII Vehicles Records \\
\hline Error Vehicle by Hour & Single Axles \\
\hline Class by Day of Month & Tandem Axles \\
\hline Truck Count by Day of Month & Tridem Axles \\
\hline Class by Front Axle Weight & Quadrem Axles \\
\hline $\begin{array}{c}\text { Class by Gross Vehicle } \\
\text { Weight }\end{array}$ & Axle Count by Axle Weight \\
\hline Class by Overweight Vehicles & Site History \\
\hline Weight Violations by Hour & Power Log \\
\hline 18 KIP ESALs by Hour & Calibration Log \\
\hline
\end{tabular}

Users can select any combination of these formats in their summary report according to their needs. In this project, "site summary" contains most of the information we need. Table 2.2 is an excerpt of a site summary report: 
Table 2.2 Example of Site Summary Report

\begin{tabular}{|c|c|c|c|c|c|c|c|c|}
\hline \multicolumn{9}{|c|}{ Site Summary Report } \\
\hline $\begin{array}{c}\text { Site: RENSSELAER- } \\
411\end{array}$ & \multicolumn{2}{|c|}{ Lanes: \#1 } & & & & & & \\
\hline \multicolumn{3}{|c|}{ Classification: FHWA } & \multicolumn{5}{|c|}{ Start Class 0 End Class 16} & \\
\hline \multicolumn{9}{|c|}{ FROM: Wed Jan 01 00:00:00 1997 TO: Thu Jan 02 00:00:00 1997} \\
\hline \multicolumn{9}{|c|}{ Classification } \\
\hline & 0 & 1 & 2 & ....... & 9 & $\ldots$ & 13 & Total \\
\hline Veh Cnt & 1496 & 0 & 509 & $\ldots \ldots$ & 547 & ....... & 196 & 6334 \\
\hline$\%$ Count & 23.6 & 0 & 8 & $\ldots \ldots$ & 8.6 & $\ldots \ldots$ & 3.1 & 100 \\
\hline Recorded & 2024 & 165 & 803 & $\ldots \ldots$ & 470 & $\ldots \ldots$ & 33 & 4911 \\
\hline Warn Cnt & 315 & 6 & 10 & $\ldots \ldots$ & 233 & $\ldots \ldots$ & 19 & 781 \\
\hline \% Warn & 15.6 & 3.6 & 1.2 & $\ldots \ldots$ & 49.6 & $\ldots \ldots$ & 57.6 & 15.9 \\
\hline Valid Wt & 1709 & 159 & 793 & & 237 & & 14 & 4130 \\
\hline TGW(000) & 27074 & 845 & 7105 & & 6314 & & 657 & 59976 \\
\hline Avg GVW & 15842 & 5317 & 8960 & & 26641 & & 46955 & 14522 \\
\hline Tot ESAL & 89.2 & 0.4 & 2.4 & & 59.1 & $\ldots \ldots$ & 3.4 & 189.9 \\
\hline Avg ESAL & 0.05 & 0 & 0 & & 0.25 & & 0.25 & 0.05 \\
\hline Ovrwt & 0 & 0 & 0 & $\ldots$ & 8 & ....... & 0 & 11 \\
\hline$\%$ Ovrwt & 0 & 0 & 0 & & 3.4 & & 0 & 0.3 \\
\hline \multicolumn{9}{|c|}{ Vehicle records used in this report include: } \\
\hline Good + Warning + & Error & vehicle & & & & & & \\
\hline \multicolumn{9}{|c|}{ Total Counts As Defined By Report Parameters: } \\
\hline Error $\quad \mathrm{W}$ & arning & & ored & & Total & & & \\
\hline $842(13.3 \%)$ & $781(1$ & $2.3 \%)$ & & $3(90.8$ & & 6334 & & \\
\hline
\end{tabular}

In Table 2.2, we can see that IRD Office uses the FHWA classification scheme to classify vehicles (see Appendix A). If a vehicle doesn't fit any of the 13 classes, it will be assigned to class 0 vehicle.

The summary reports can be generated for the intervals of $5 \mathrm{~min}, 15 \mathrm{~min}$, hourly, daily, weekly, and monthly, depending on the user's needs. 


\subsubsection{Generating Monthly Summary Reports}

There are two ways to generate summary reports. One is to use IRD Office's menu system; the other is to use a batch file. In this project, we use a batch file to generate summary reports, because a batch file can handle the data from all sites, while the menu system can handle only one site's data at a time. For detailed instructions on how to generate summary reports, refer to IRD Software User's Manual, 1993.

The summary reports generated are stored in ASCII files with file extensions corresponding to the station numbers minus the last zero. For example, the summary reports for station 7340 will be stored in an ASCII file as *. 734 . If we generate a monthly summary report using daily interval, the ASCIl file will have all the reports of each day in the month, unless the data are missing.

\subsection{Evaluating WIM Data Quality}

In the rest of this chapter, we will explore how to evaluate the WIM data quality by reviewing the monthly summary reports.

\subsubsection{Using Unclassified Vehicle Rates}

Unclassified vehicles, or class 0 vehicles, can be used to represent how well the WIM system is working. If the rates of unclassified vehicles exceed a specified level, say 10 percent, for several continuous days, this is evidence of possible malfunctioning of the WIM site. For example, during February 1999 (Figure 2.2), the unclassified vehicle rates for station 4270 are all below 10 percent. However, during February 2000 (2.3), there are several days that have unclassified vehicle rates over 30 percent. By inspecting unclassified vehicle rates, we find the data from February 2000 for station 4270 are suspicious. 


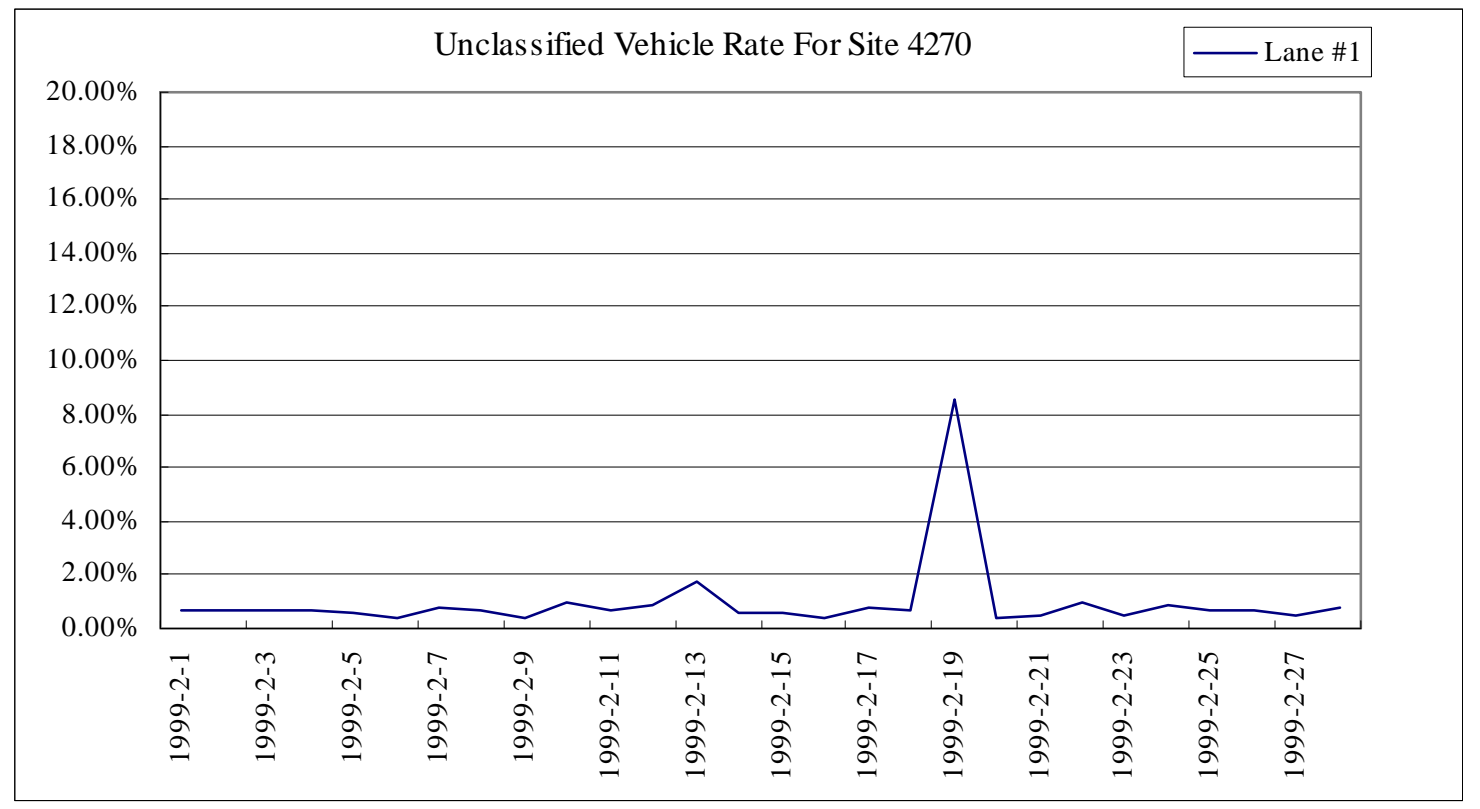

Figure 2.2 Unclassified Vehicle Rate In February 1999

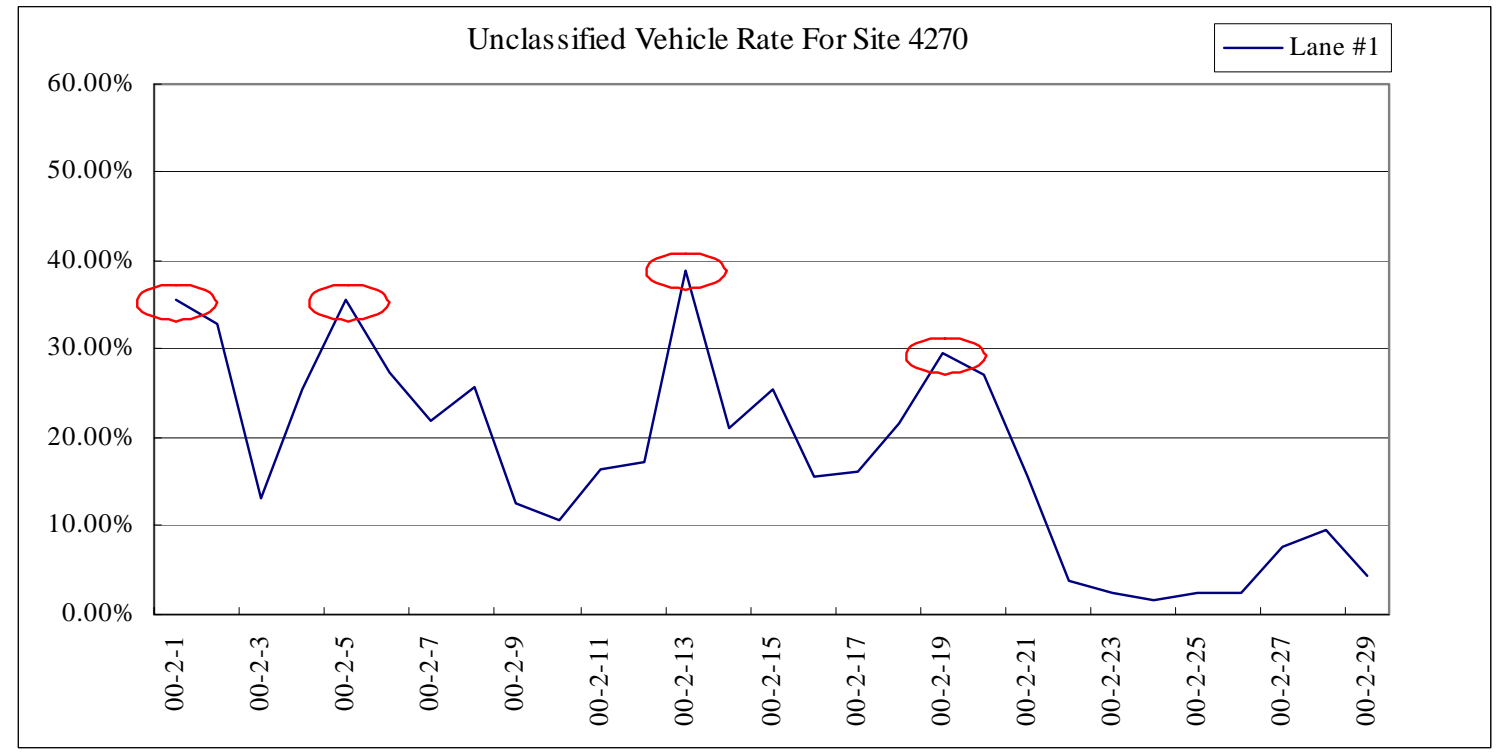

Figure 2.3 Unclassified Vehicle Rate In February 2000

As we further our analysis on the data in February 2000. We find that the changes in the unclassified vehicle rates are often related to the changes of class 2 and class 9 vehicle rates. 


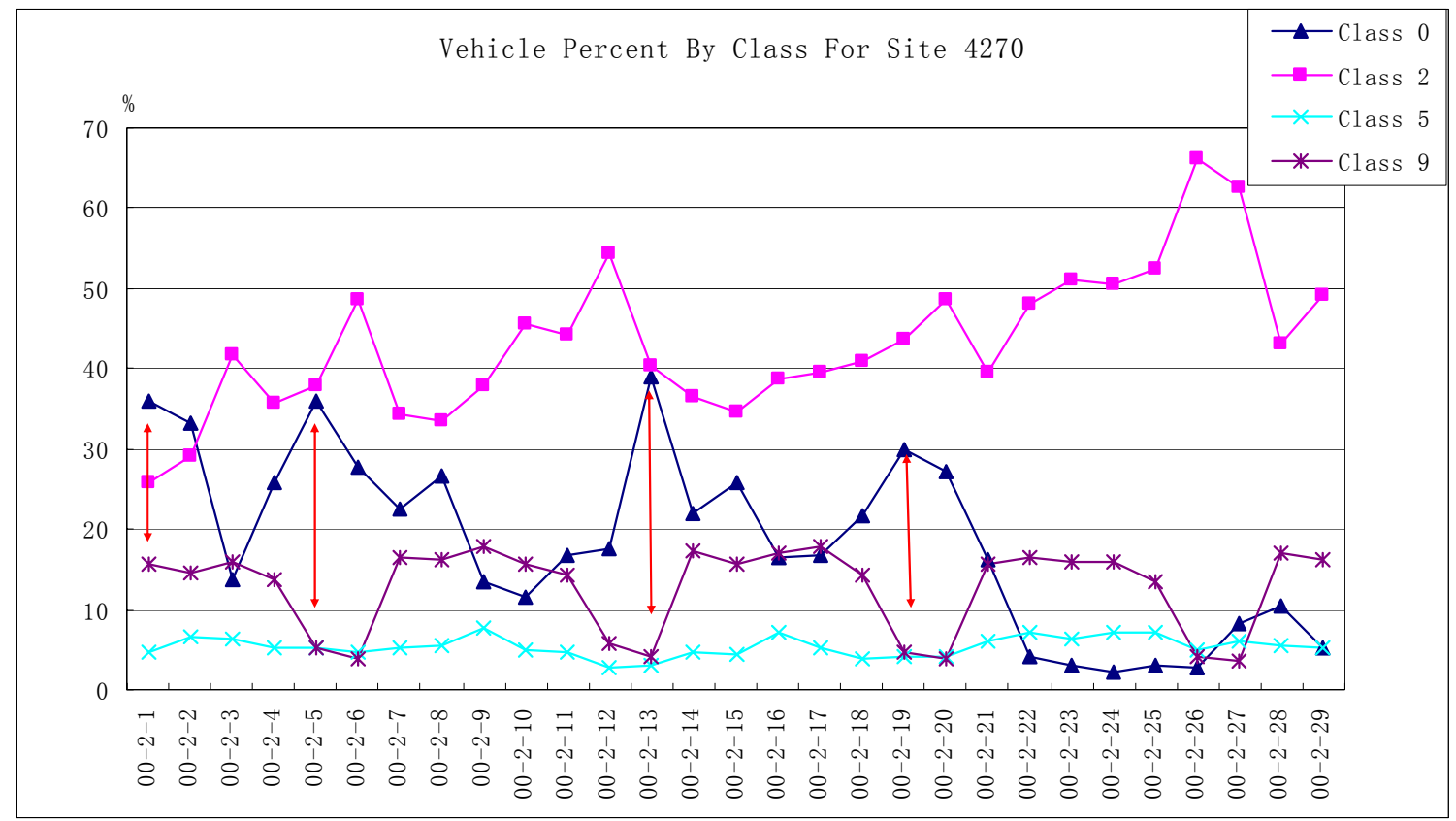

Figure 2.4 Vehicle Percent by Class In February 2000

As we can see in Figure 2.4, the class 0 vehicle rates often reach peaks during the weekends. Because the class 2 vehicle rates also have high values during weekends, it is possible that the increase of unclassified vehicles is from class 2 vehicles.

\subsubsection{Using Front Axle Weight Distribution}

For a properly working WIM station, the front axle weight of most class 9 vehicles should fall within the 8-12 kip range. Based on this criterion, we can inspect the front axle weight distribution, as shown in Figure 2.5 and Figure 2.6. 


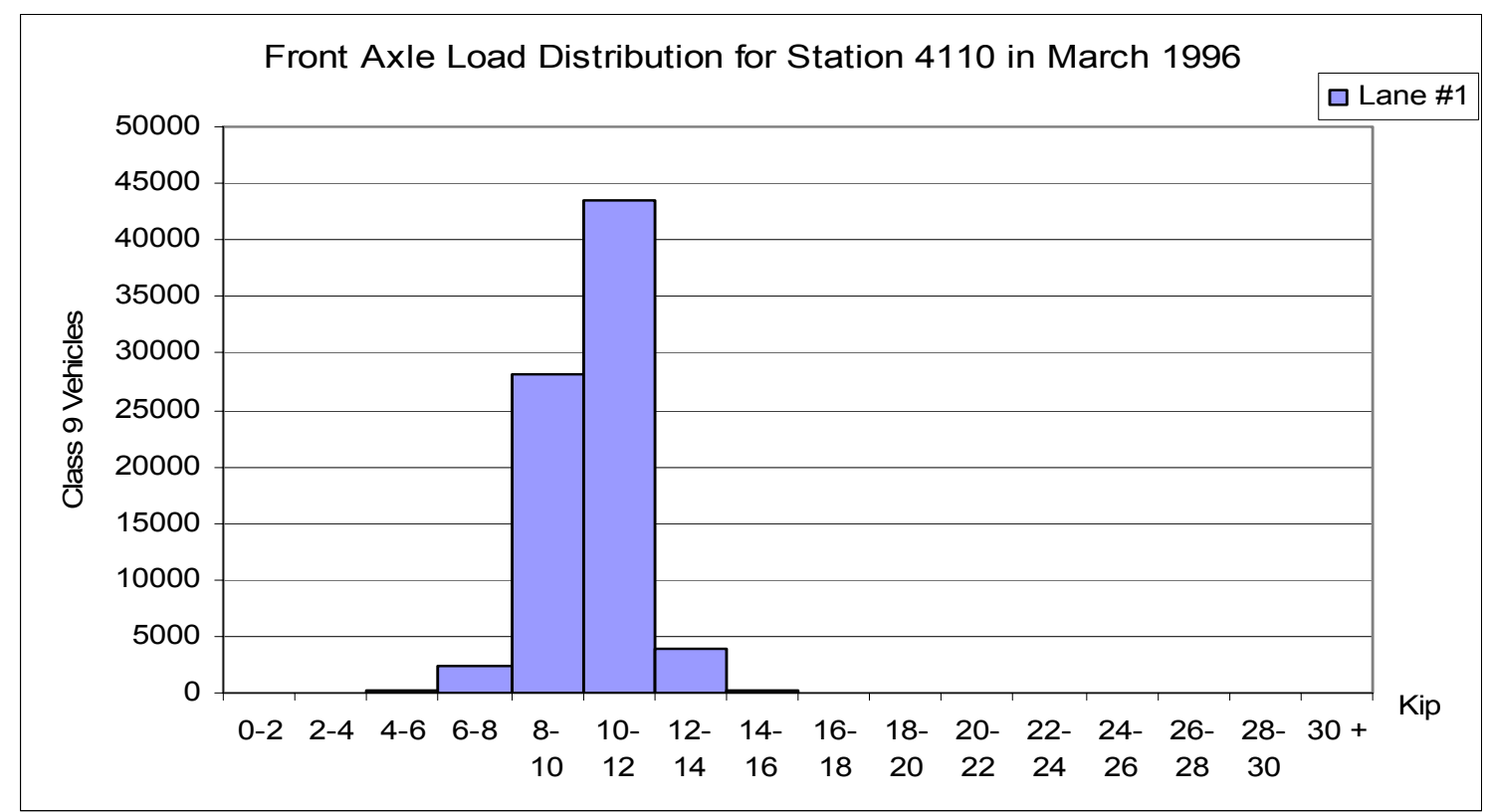

Figure 2.5 Front Axle Load Distribution for Site 4110 in March 1996

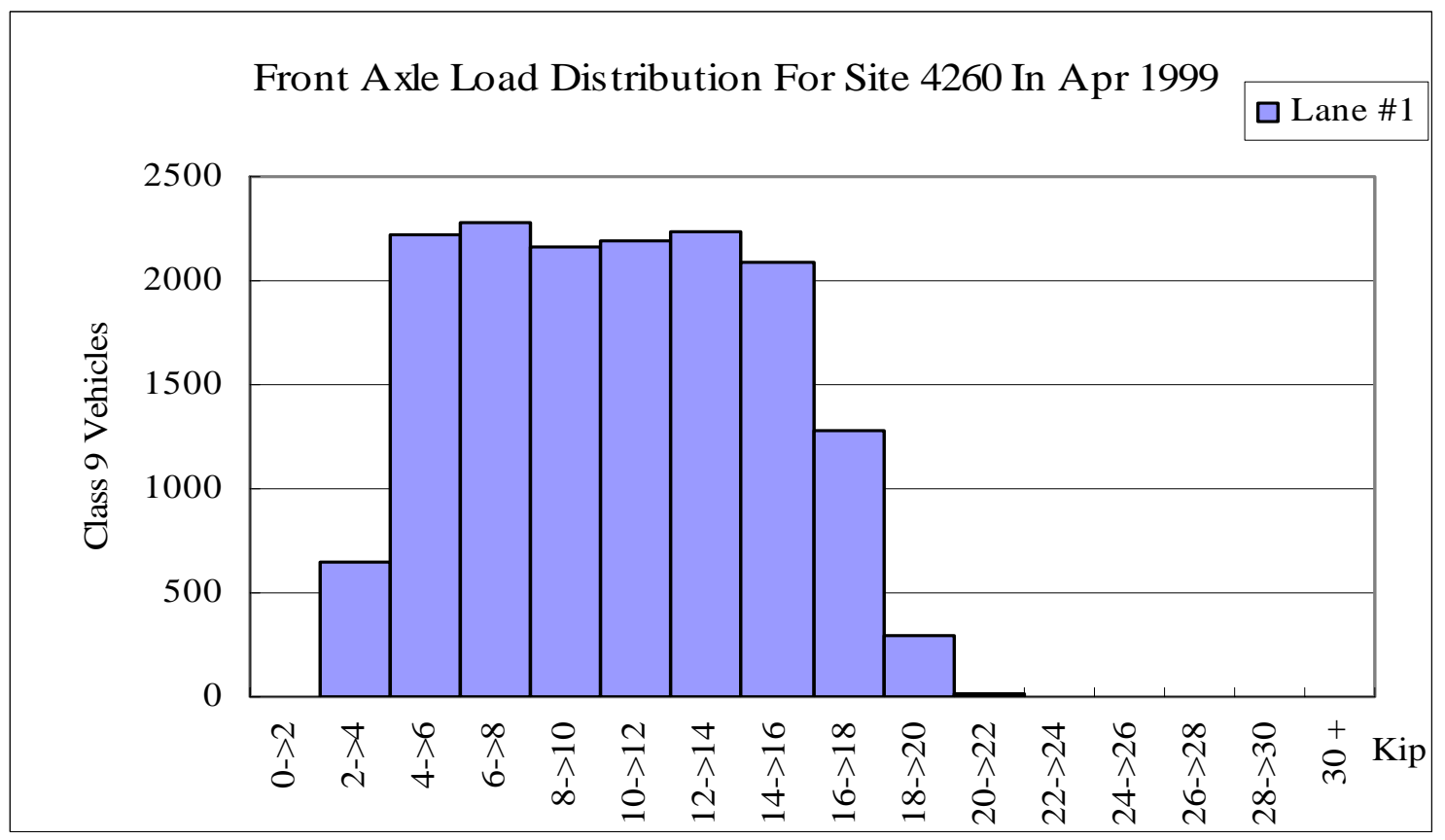

Figure 2.6 Front Axle Load Distribution for Site 4260 in April 1999

Figure 2.5 fits the criterion very well, while the data in Figure 2.6 look suspicious. Because the distribution expand to both lower and higher ranges, we suspect that the problem can be related to the sensor installed. 


\subsubsection{Using Average Gross Vehicle Weight}

The average daily GVW for class 9 vehicles is plotted over the month. The average gross vehicle weight of class 9 vehicles should fall within the range of $25-80 \mathrm{kip} .80 \mathrm{~K}$ is the legal limit; $25 \mathrm{kip}$ is the weight that even an unloaded class 9 vehicle should exceed. In the plots, we can look for any appreciable changes in GVW, which may indicate a situation that needs immediate investigation.

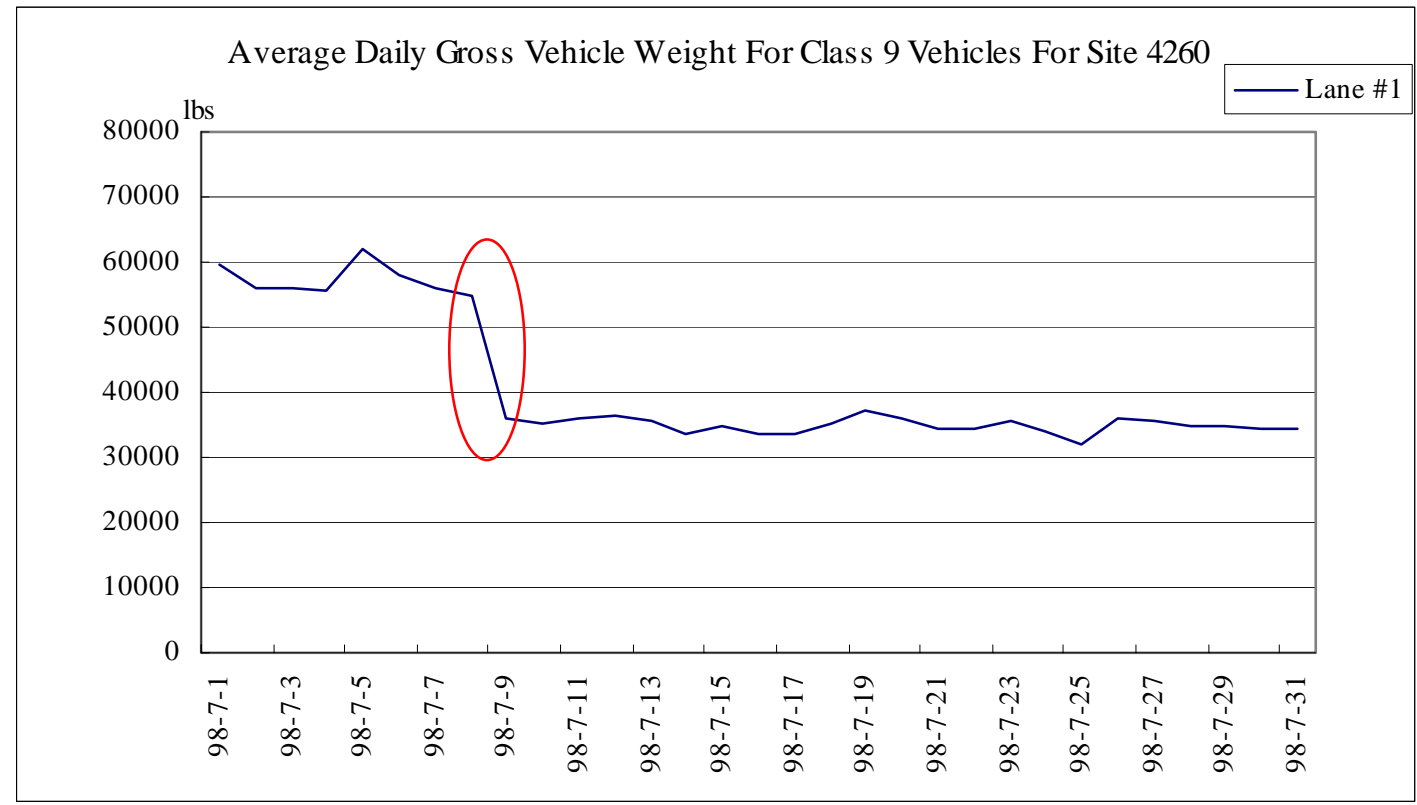

Figure 2.7 Average Daily Gross Vehicle Weight In July 1998

As we see in Figure 2.7, on July 9th 1998, the GVW decreased from the 50k-60k range to the $30 \mathrm{k}-40 \mathrm{k}$ range. This change is more than 40 percent.

For some situations, a shift in GVW patterns may not be immediately detected by a manual inspection. For example, the daily GVW values may be a function of the day of the week. The fluctuations between workdays and weekends may hinder a manual inspection to identify a shift. In this case, we would recommend calculating the 7-day average for each day i:

$$
\overline{\mathrm{GVW}}_{\mathrm{i}}=\frac{1}{7} \times\left(\mathrm{GVW}_{\mathrm{i}-6}+\mathrm{GVW}_{\mathrm{i}-5}+\mathrm{GVW}_{\mathrm{i}-4}+\mathrm{GVW}_{\mathrm{i}-3}+\mathrm{GVW}_{\mathrm{i}-2}+\mathrm{GVW}_{\mathrm{i}-1}+\mathrm{GVW}_{\mathrm{i}}\right)
$$

Where $\overline{G V W}_{i}$ is the weekly average GVW for the 7 days ending with day $i$. 
The results of using this method are shown in Figure 2.8.

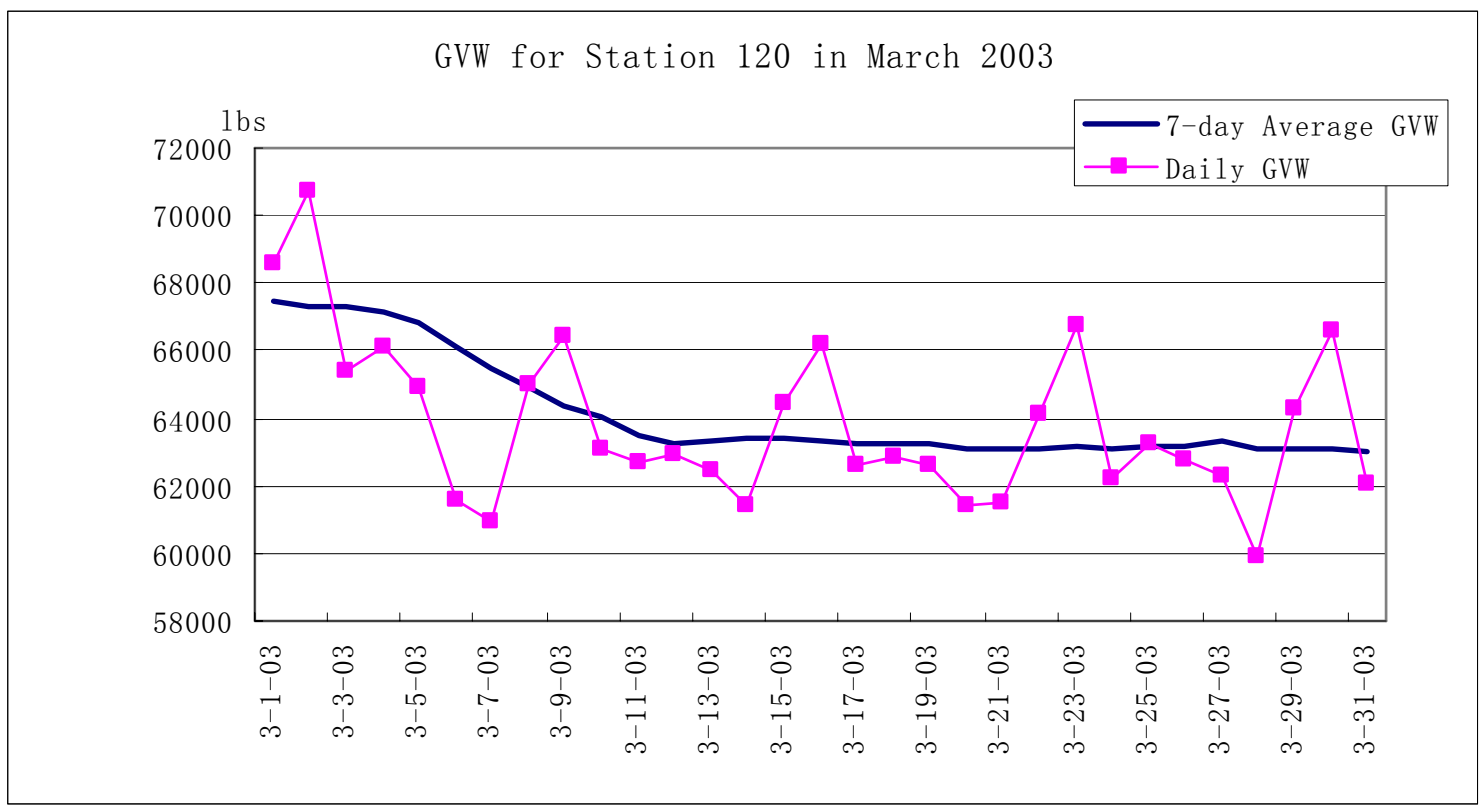

Figure 2.8 AGVW for Station 120 in March 2003

In this way, we can observe that the values decrease from the $6600-6800$ range to the 62000-64000 range during March 2003. 


\title{
CHAPTER 3.DAILY CHECKING FOR WIM DATA
}

\begin{abstract}
3.1. Introduction to the WDDC Program
In Chapter 2, we have discussed the WIM data checking on a monthly basis. When we analyze the data at the end of a month, it is possible that a data quality problem has existed for several weeks before we find it. To improve the data quality, it is desirable to detect the problem soon after it happens, and fix the problem as soon as possible. Daily checking for WIM data can provide a way to achieve this objective. Instead of waiting until the current month ends, we can check the data from yesterday or the day before yesterday. If the daily checking procedure is to be repeated each day, it should involve as little human effort as possible, and preferably be an automated program.
\end{abstract}

The Weigh-In-Motion Daily Data Checking (WDDC) program was specifically developed in this project to facilitate the daily checking process for INDOT. This program should be run on a PC with Microsoft Excel and IRD Office software installed. Microsoft Excel version 2002 and IRD Office version 7.5.0 were used during the program development.

Table 3.1 listed the functional files in the WDDC program. 
Table 3.1 Files in the WDDC Program

\begin{tabular}{|c|c|c|}
\hline File & Location & Function \\
\hline “Dailychecking.bat & C:IIrd|Ird|Dataanalysis $1750^{*}$ & Generate batch reports \\
\hline "Dailychecking.xls & C:ITemplIrd & $\begin{array}{c}\text { Import the summary } \\
\text { reports }\end{array}$ \\
\hline $\begin{array}{l}\text { Report parameter } \\
\text { files }\end{array}$ & $\begin{array}{c}\text { C:IIrdIIrd|Dataanalysis|750|Report } \\
\mathrm{s}^{*}\end{array}$ & Specify the report formats \\
\hline $\begin{array}{l}\text { Site parameter } \\
\text { files }\end{array}$ & $\underset{\mathrm{s}^{*}}{\mathrm{C}: \mathrm{Ird} \text { IIrdIDataanalysis|750|Param }}$ & $\begin{array}{l}\text { Provide the site } \\
\text { configurations }\end{array}$ \\
\hline
\end{tabular}

\subsection{Procedure for Using the WDDC Program}

The procedure for using the WDDC program is described in Figure 3.1. 


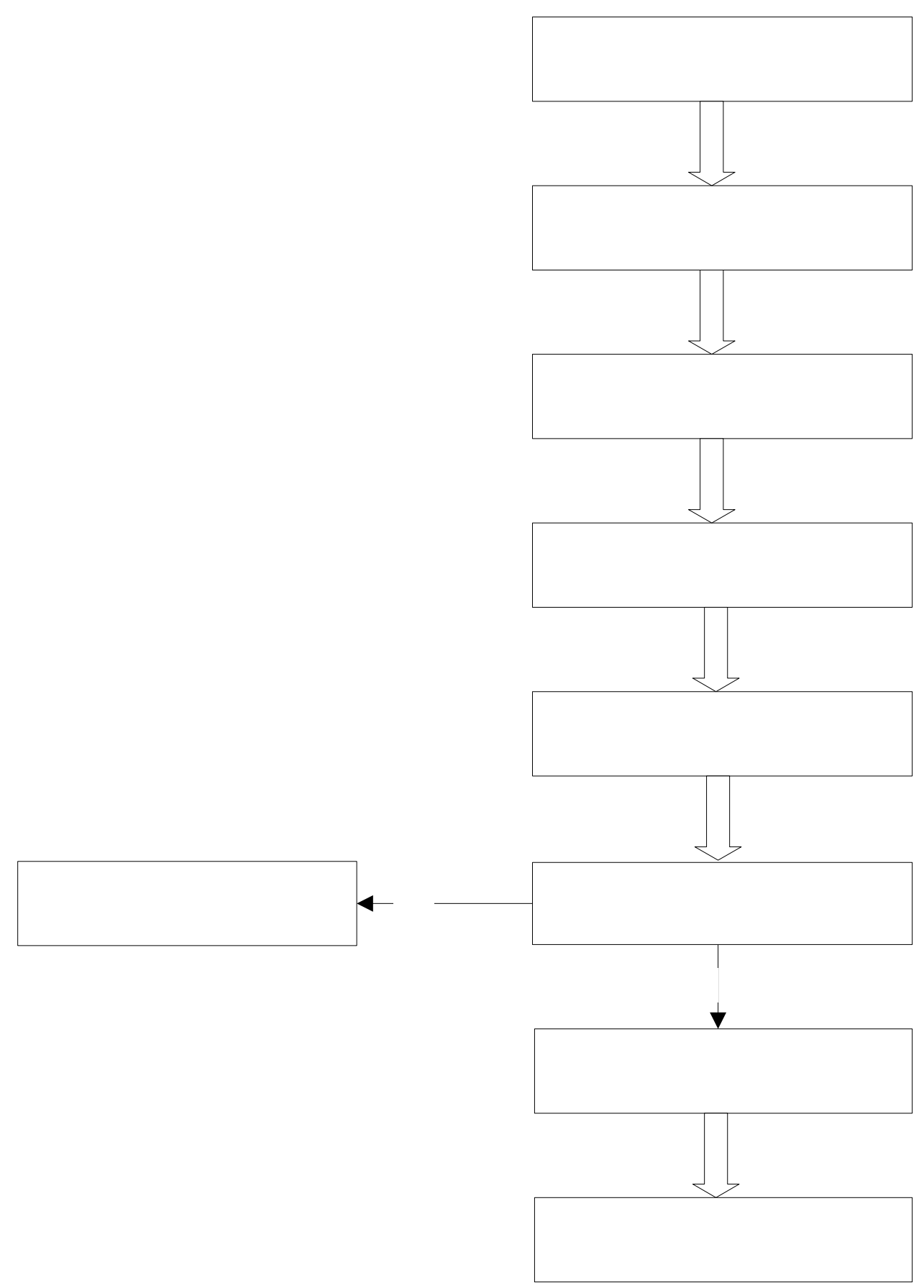

Figure 3.1 Step by Step Daily Checking Procedure

Step 1: The folder "newdata" is for holding IRD-encrypted raw data files, and should be placed in the same folder as "office.exe" (current location: C:IIRDIIRDIDATAANALYSISI750). If it is the first time to use the WDDC 
program, please create this folder. Before proceeding to Step 2, please delete all data files in this folder.

Step 2: Copy the data files for the day of interest for each site into the folder "newdata". Let us say that we are interested in WIM data for the day November 20,2002 . All the files in the folder "newdata" should have a name like "11202002." (where * is called the site extension). Actually, the site extensions are the WIM station number without the last zero. For example, 11202002.240 is the raw data file from WIM Station 2400 . The program currently can handle 45 sites. Table 3.2 shows the list of these sites. 
Table 3.2 Site Extensions Supported in WDDC Program

\begin{tabular}{|c|c|c|c|c|c|c|}
\hline Stations & Lane \#1 & Lane \#2 & Lane \#3 & Lane \#4 & Lane \#5 & Lane \#6 \\
\hline 100 & $\mathrm{Y}$ & $\mathrm{N}$ & $*$ & * & $*$ & * \\
\hline 110 & $\bar{Y}$ & $\mathrm{~N}$ & $\mathrm{Y}$ & $\mathrm{N}$ & * & * \\
\hline 120 & $\mathrm{Y}$ & $\mathrm{Y}$ & $\mathrm{Y}$ & $\mathrm{Y}$ & * & * \\
\hline 130 & $\bar{Y}$ & $\mathrm{~N}$ & $\bar{Y}$ & $\mathrm{~N}$ & * & * \\
\hline 200 & $\mathrm{Y}$ & $Y$ & $Y$ & $Y$ & * & * \\
\hline 210 & $\bar{Y}$ & $\bar{Y}$ & $\bar{Y}$ & $\bar{Y}$ & * & * \\
\hline 220 & $\mathrm{Y}$ & $\mathrm{N}$ & $\mathrm{N}$ & $\mathrm{N}$ & * & * \\
\hline 230 & $\bar{Y}$ & $\mathrm{~N}$ & $\mathrm{~N}$ & $\bar{N}$ & * & * \\
\hline 240 & $\mathrm{Y}$ & $\mathrm{Y}$ & * & * & * & * \\
\hline 300 & $\bar{Y}$ & $\mathrm{~N}$ & $\bar{Y}$ & $\mathrm{~N}$ & * & * \\
\hline 310 & $\mathrm{~N}$ & $\mathrm{~N}$ & $\mathrm{Y}$ & $\mathrm{N}$ & * & * \\
\hline 320 & $\mathrm{Y}$ & $\bar{Y}$ & $\bar{Y}$ & $\bar{Y}$ & * & * \\
\hline 330 & $\mathrm{Y}$ & $\mathrm{Y}$ & $\mathrm{Y}$ & $\mathrm{Y}$ & $\mathrm{Y}$ & $\mathrm{Y}$ \\
\hline 340 & $\bar{Y}$ & $\bar{Y}$ & $\bar{Y}$ & $\bar{Y}$ & $\bar{Y}$ & $\bar{Y}$ \\
\hline 350 & $\mathrm{Y}$ & $\mathrm{Y}$ & $\mathrm{Y}$ & * & * & * \\
\hline 351 & $\bar{Y}$ & $\bar{Y}$ & $\bar{Y}$ & * & * & * \\
\hline 352 & $\mathrm{Y}$ & $\mathrm{Y}$ & $\mathrm{Y}$ & * & * & * \\
\hline 353 & $\bar{Y}$ & $\bar{Y}$ & $\bar{Y}$ & * & * & * \\
\hline 360 & $\mathrm{Y}$ & $\mathrm{Y}$ & $\mathrm{Y}$ & $\mathrm{Y}$ & * & * \\
\hline 370 & $\mathrm{Y}$ & $\mathrm{Y}$ & $\bar{Y}$ & $\bar{Y}$ & * & * \\
\hline 400 & $\mathrm{Y}$ & $\mathrm{Y}$ & $\mathrm{Y}$ & $\mathrm{Y}$ & * & * \\
\hline 401 & $\bar{Y}$ & $\bar{Y}$ & $\bar{Y}$ & $\bar{Y}$ & * & * \\
\hline 410 & $\mathrm{Y}$ & $\mathrm{N}$ & $\mathrm{Y}$ & $\mathrm{N}$ & * & * \\
\hline 420 & $\mathrm{Y}$ & $\mathrm{Y}$ & $\mathrm{Y}$ & * & * & * \\
\hline 421 & $\mathrm{Y}$ & $\mathrm{Y}$ & $\mathrm{Y}$ & * & * & * \\
\hline 430 & $\mathrm{Y}$ & $\mathrm{Y}$ & $\mathrm{Y}$ & $\mathrm{Y}$ & $\mathrm{Y}$ & $\mathrm{Y}$ \\
\hline 440 & $\bar{Y}$ & $\bar{Y}$ & $\bar{Y}$ & $\bar{Y}$ & $\bar{Y}$ & $\bar{Y}$ \\
\hline 450 & $\mathrm{~N}$ & $\mathrm{~N}$ & $\bar{Y}$ & $\mathrm{~N}$ & * & * \\
\hline 460 & $\bar{Y}$ & $\bar{N}$ & $\bar{N}$ & $\mathrm{~N}$ & * & * \\
\hline 470 & $\bar{Y}$ & $\bar{Y}$ & $\bar{Y}$ & $\bar{Y}$ & * & * \\
\hline 500 & $\bar{Y}$ & $\mathrm{~N}$ & $\mathrm{~N}$ & $\mathrm{~N}$ & * & * \\
\hline 510 & $\bar{Y}$ & $Y$ & $\mathrm{Y}$ & $\mathrm{Y}$ & * & * \\
\hline 520 & $\bar{Y}$ & $\bar{Y}$ & * & * & * & * \\
\hline 530 & $Y$ & $\mathrm{~N}$ & $\mathrm{Y}$ & $\mathrm{N}$ & * & * \\
\hline 540 & $Y$ & $\mathrm{~N}$ & $Y$ & $\mathrm{~N}$ & * & * \\
\hline 600 & $\bar{Y}$ & $\bar{Y}$ & $\mathrm{~N}$ & $\mathrm{~N}$ & * & * \\
\hline 610 & $\bar{Y}$ & $\mathrm{~N}$ & $Y$ & $\bar{N}$ & * & * \\
\hline 620 & $\bar{Y}$ & $\mathrm{~N}$ & * & * & * & * \\
\hline 630 & $Y$ & $\mathrm{~N}$ & $\mathrm{~N}$ & $\mathrm{~N}$ & * & * \\
\hline 640 & $\bar{Y}$ & $\mathrm{Y}$ & $\mathrm{Y}$ & $\mathrm{Y}$ & * & * \\
\hline 650 & $\bar{Y}$ & $\bar{N}$ & $\bar{Y}$ & $\mathrm{~N}$ & * & * \\
\hline 660 & $\mathrm{~N}$ & $\mathrm{~N}$ & $\mathrm{Y}$ & $\mathrm{N}$ & * & * \\
\hline 730 & $\bar{Y}$ & $\bar{Y}$ & $\bar{Y}$ & $\bar{Y}$ & * & * \\
\hline 732 & $\bar{Y}$ & $\mathrm{Y}$ & $\mathrm{Y}$ & $\mathrm{Y}$ & * & * \\
\hline 734 & $\bar{Y}$ & $\bar{Y}$ & $\bar{Y}$ & $\bar{Y}$ & * & * \\
\hline
\end{tabular}


Step 3. "Dailychecking.bat" is the batch file that will call "office.exe" and create batch reports. This file has been created for this program and should be placed in the same folder as "office.exe" (current location:

C:IIRDIIRDIDATAANALYSISI750). As long as we put only one day's data in the folder "newdata", there is no need to change the batch file. In order to get output files, there must be corresponding site parameter files located in: C:IIRDIIRDIDATAANALYSISI750IPARAMS for each site. Otherwise, there will be no output files for this site. The output files generated are named as "Output1." and "Output2." (" is the site extension), and they will be located in: C:ITemplIRD. All report parameters have been set in "WDDC1A(B,C,D).rpt" and "WDDC2A(B,C,D).rpt", which should be placed in: C:IIRDIIRDIDATAANALYSISI750IREPORTS.

Step 4. "Dailychecking.xIs" is an EXCEL file that has pre-imported the output files "Output1." and "Output2." (* is the site extension) in a fixed format and provides some summarized data for checking. Each time "Dailychecking.xls" is opened, the pre-imported data will be automatically updated with the new output files. Currently there are 50 worksheets in this EXCEL file. The "Summary" worksheet provides all the important variables for daily checking. The "Hourly Counts" worksheet records the class 9 vehicle counts for each hour of the day. The preimported output files are stored in the worksheets named as "Site ${ }^{*}\left({ }^{*}\right.$ is the site extension). For example, the output file for Site 240 is stored in the "Site240" worksheet. "Plot1" and "Plot2" worksheets compare the Average Gross Vehicle Weight (GVW) for Class 9 Vehicle for the day of interest with the historical data, which consist of 6 months' data in 2002 (May, June, September, October, November and December). These are the only data available to us during the program development. All the historical data are stored in the "Historical" worksheet. 
Step 5. The "Summary" worksheet has four columns with summarized data. Column $\mathrm{A}$ is the site extension. Column $\mathrm{F}$ is the start time linked from the imported output file. Column B contains the unclassified vehicle rates and Column D shows the Avg GVW for Class 9 Vehicles during the specified period. We should check first whether Column F in the "Summary" worksheet is the date we are interested in. For example, let's say in Step 2 we have copied raw data for November 20, 2002 into the folder "newdata". When we proceed to Step 5, we find all the sites show "Nov 20, 2002" at Column F except that Site 410 shows "Nov 19, 2002", which means the "Dailychecking.bat" doesn't generate output file for Site 410 for November 20, 2002. Generally, this is because Site 410 doesn't have the raw data for November 20, 2002 in the folder "newdata". In this way, we can be alerted to sites that have missing data for the day of interest.

Step 6. Columns B and D in the "Summary" worksheet use two easy criteria to check the reliability of the data. Criterion 1 is to check if the number of unclassified vehicles exceeds $10 \%$. If the unclassified vehicle rates at a site are over $10 \%$ for several consecutive days, the WIM system at that site may need to be checked out. Criterion 2 is to check if the Average GVW for Class 9 Vehicle is out of the 25,000-80,000 pounds range. As we can see in Figure 3.2, all the data exceeding the limits will be highlighted.

\begin{tabular}{|c|c|c|l|}
\hline & Column B & Column D & \multicolumn{1}{|c|}{ Column F } \\
\hline Stations & Unclassified Vehicle Rate & Class 9 Avg GVW & From: \\
\hline $100 \# 1$ & $56.0 \%$ & 0 & Wed Nov 20 00:00:00 2002 \\
\hline $110 \# 1$ & $8.0 \%$ & 47163 & Wed Nov 20 00:00:00 2002 \\
\hline $120 \# 1$ & $11.7 \%$ & 75260 & Wed Nov 20 00:00:00 2002 \\
\hline $130 \# 1$ & $32.3 \%$ & 39502 & Wed Nov 20 00:00:00 2002 \\
\hline $200 \# 1$ & $100.0 \%$ & 0 & Wed Nov 20 00:00:00 2002 \\
\hline
\end{tabular}

Figure 3.2 The "Summary" Worksheet ( Part )

Step 7. It is possible that a WIM station may work improperly only a few hours in a day. The "Hourly Counts" worksheet provides a way we can check the hourly counts for class 9 vehicles. As we can see in Figure 3.3, all the hourly counts with zero will be highlighted. 


\begin{tabular}{|c|c|c|c|c|c|}
\hline \multicolumn{6}{|c|}{ Site } \\
\hline Hours & $100 \# 1$ & $110 \# 1$ & 120\#1 & 130\#1 & 200\#1 \\
\hline $0-1$ & 0 & 198 & 105 & 84 & 0 \\
\hline $1-2$ & 0 & 221 & 97 & 86 & 0 \\
\hline $2-3$ & 0 & 192 & 77 & 54 & 0 \\
\hline $3-4$ & 0 & 203 & 60 & 79 & 0 \\
\hline $4-5$ & 0 & 188 & 71 & 75 & 0 \\
\hline $5-6$ & 0 & 175 & 85 & 98 & 0 \\
\hline $6-7$ & 0 & 178 & 87 & 87 & 0 \\
\hline $7-8$ & 0 & 177 & 111 & 80 & 0 \\
\hline $8-9$ & 0 & 218 & 131 & 104 & 0 \\
\hline $9-10$ & 0 & 286 & 130 & 95 & 0 \\
\hline $10-11$ & 0 & 270 & 147 & 127 & 0 \\
\hline $11-12$ & 0 & 253 & 138 & 123 & 0 \\
\hline $12-13$ & 0 & 293 & 156 & 110 & 0 \\
\hline $13-14$ & 0 & 291 & 145 & 119 & 0 \\
\hline $14-15$ & 0 & 248 & 153 & 118 & 0 \\
\hline $15-16$ & 0 & 232 & 144 & 146 & 0 \\
\hline $16-17$ & 0 & 283 & 146 & 115 & 0 \\
\hline $17-18$ & 0 & 292 & 158 & 131 & 0 \\
\hline $18-19$ & 0 & 265 & 160 & 124 & 0 \\
\hline $19-20$ & 0 & 249 & 168 & 116 & 0 \\
\hline $20-21$ & 0 & 246 & 148 & 120 & 0 \\
\hline $21-22$ & 0 & 227 & 151 & 102 & 0 \\
\hline $22-23$ & 0 & 226 & 146 & 118 & 0 \\
\hline $23-24$ & 0 & 233 & 110 & 107 & 0 \\
\hline Total & 0 & 5644 & 3024 & 2518 & 0 \\
\hline
\end{tabular}

Figure 3.3 The "Hourly Counts" Worksheet (Part)

There are some situations in which one day's data may not be enough to judge the performance of a site's WIM system. The comparison of one day's value to historical values can substantially help the user to make the judgment. In the WDDC program, "Dailychecking.xIs" provides several ways to compare the GVW for Class 9 Vehicles for the day of interest to the historical values.

In the "Plot1" worksheet, each data point represents one site, with the $\mathrm{x}$ coordinate as a site's historical average and the y coordinate as the site's value for the day of interest. There are a total of 45 data points in Figure 3.4 (Lane \#1 data only). If we move the cursor to any data point, we can see the name for the series, which is also the site extension for the data. If a data point is above the upper dashed line (blue on the screen), it means the ratio of the GVW for the day 
of interest to the historical average is more than 1.2. If a point is below the lower dashed line (red on the screen), it means the ratio is less than 0.8 . The data points between the two lines have a ratio between 0.8 and 1.2.

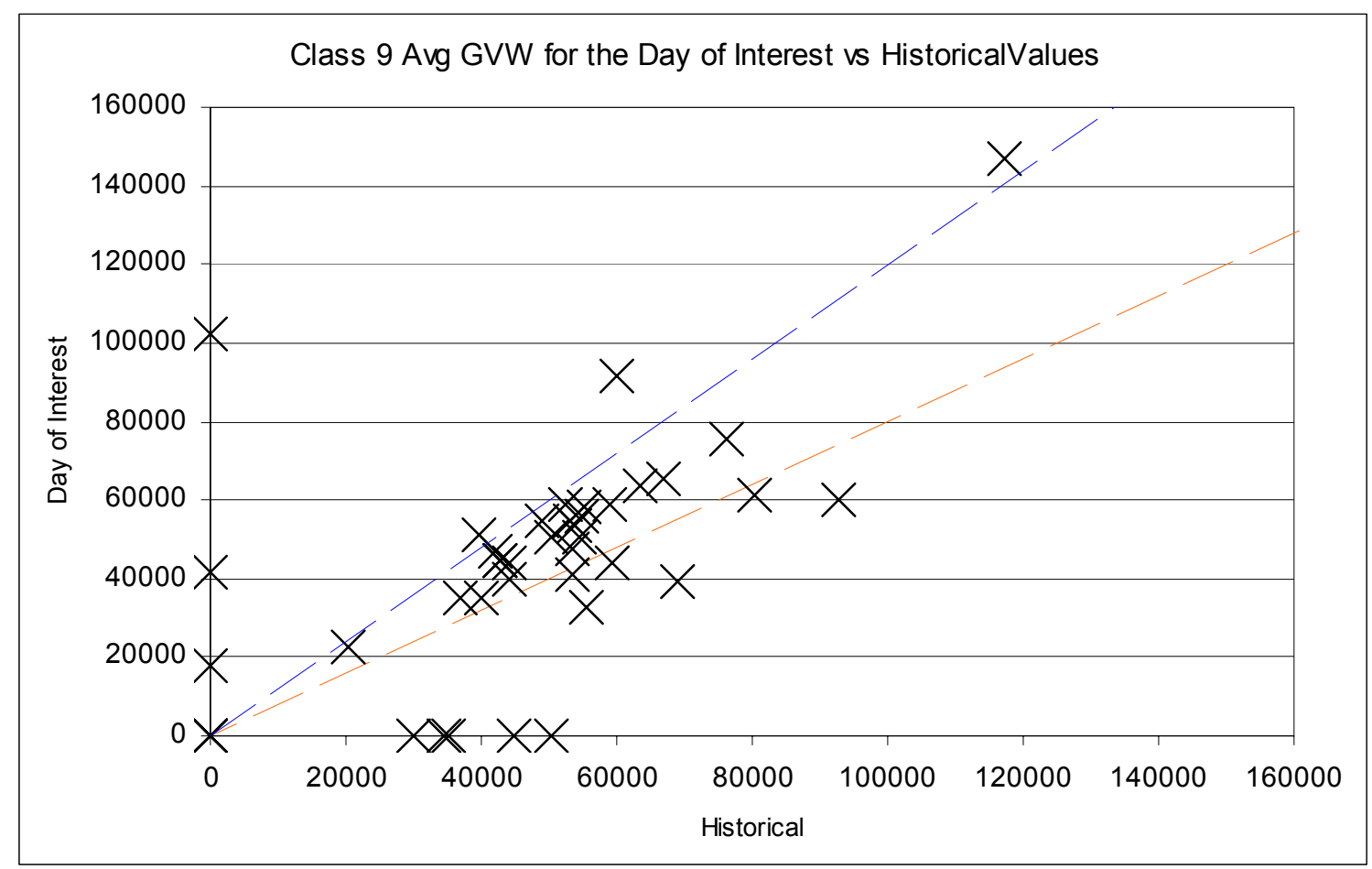

Figure 3.4 The "Plot1" Worksheet

In the "Plot2" worksheet, the confidence intervals $(\alpha=0.05)$ have been added to the historical average for each site, with the $\mathrm{x}$ coordinate as the site extension and y coordinate as GVW. We can then identify the data points that fall within or outside the confidence interval site by site. In Figure 3.5, we can see for the day of November 20, 2002, the average GVW for lane 1 in site 220 is near the lower limit of the confidence interval, while the average GVW for lane 1 in site 130 is far below the lower limit of the interval. 


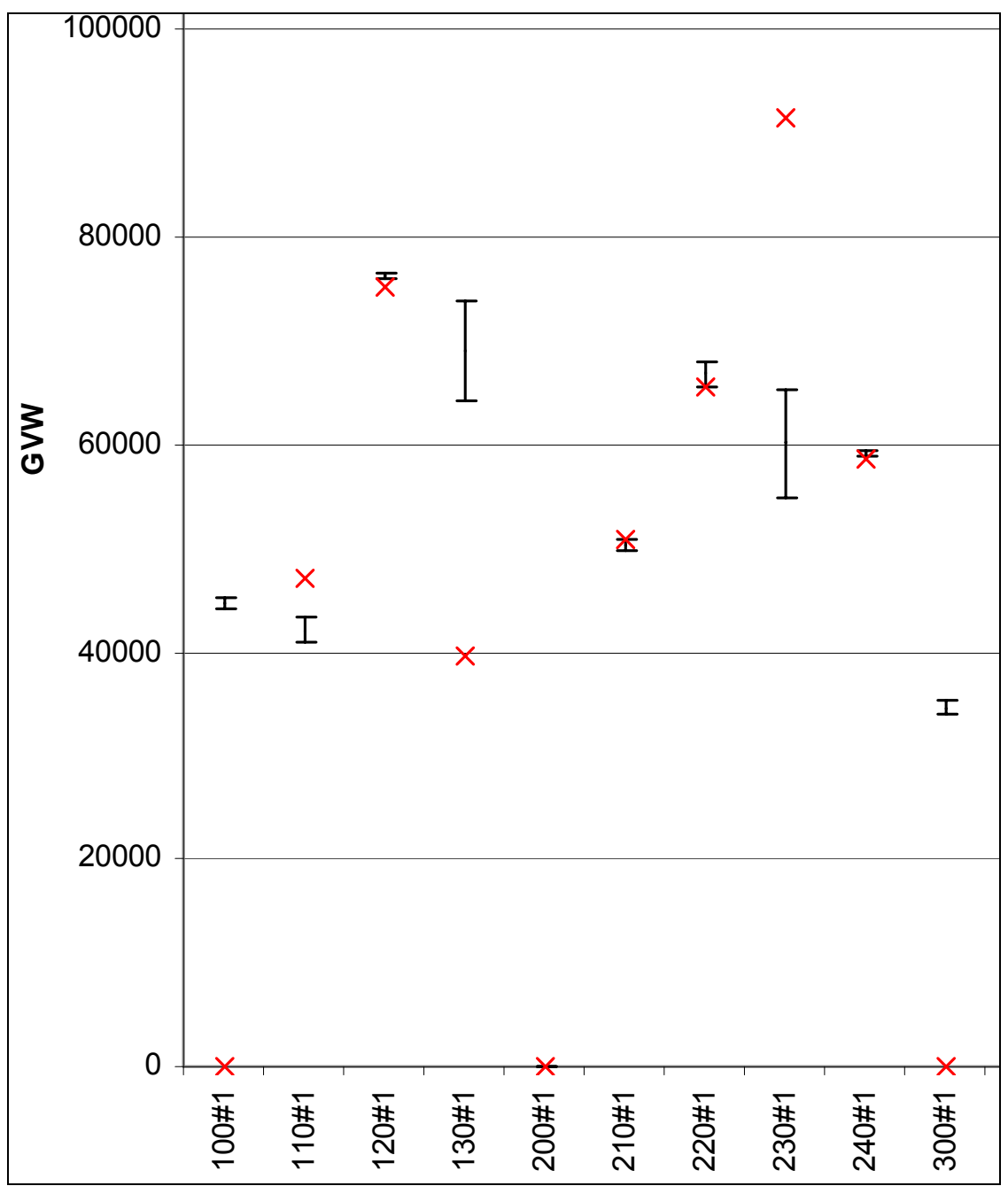

Figure 3.5 The "Plot2" Worksheet (Part)

If we need to check more information for the day of interest, we can go to the output files imported in the spreadsheet or to the original ASCII output files located at: C:ITEMPIIRD. 


\title{
CHAPTER 4. IMPUTATION FOR WIM DATA
}

\begin{abstract}
4.1. Pattern Analysis
In this chapter we will begin to focus on ESALs (Equivalent Single Axle Loads).

The ESAL data may have larger variance than GVWs, because ESAL is calculated based on the damage of the axle weights to the pavement. However, we will use ESALs because ESAL values are used widely in highway maintenance and pavement design.
\end{abstract}

Before we go to data imputation methods, it is desirable to analyze the WIM data to identify any patterns in the data. Pattern analysis is a tool to characterize the variability in WIM data, and provides a basis for data imputation. In order to produce a reasonable result, the data used in this analysis should have good quality throughout a year. After inspecting the WIM data for stations 4260 in the years 4270 from 1997 to 2001, we have select the data from July 1, 1999 to June 30, 2000 for station 4270 (lane \#1) as the basis for our pattern analysis (See Appendix B).

\subsubsection{Day of the Week Pattern}

Generally the daily ESALs on weekdays are higher, because there is more truck activity on highways on the weekdays than on weekends and holidays. The recreational traffic that occurs during weekends and holidays has very little effect on the total ESALs. The daily ESAL data are divided into 8 day groups. Groups

1-7 correspond to Monday, Tuesday, ..., Sunday. Group 8 corresponds to Holidays. In this analysis, Group 8 has a total of 14 days, as listed in Table 4.1 Table 4.1 Holiday Periods from July 11999 to June 302002 


\begin{tabular}{|c|c|}
\hline Holiday & Holiday Period \\
\hline Independence Day & July 4, 5 \\
\hline Labor Day & September 6 \\
\hline Thanksgiving Day & November 25-28 \\
\hline Christmas Day & December 24-26 \\
\hline New Year's Day & December 31, January 1-2 \\
\hline Memorial Day & May 29 \\
\hline
\end{tabular}

The ANOVA model has only one main factor: day (day of the week factor). The model is analyzed using SAS GLM procedure:

\author{
Proc glm data=a1; \\ class day; \\ model TotalEsal=day; \\ means day/duncan;
}

run;

The output is shown in Figure 4.1:

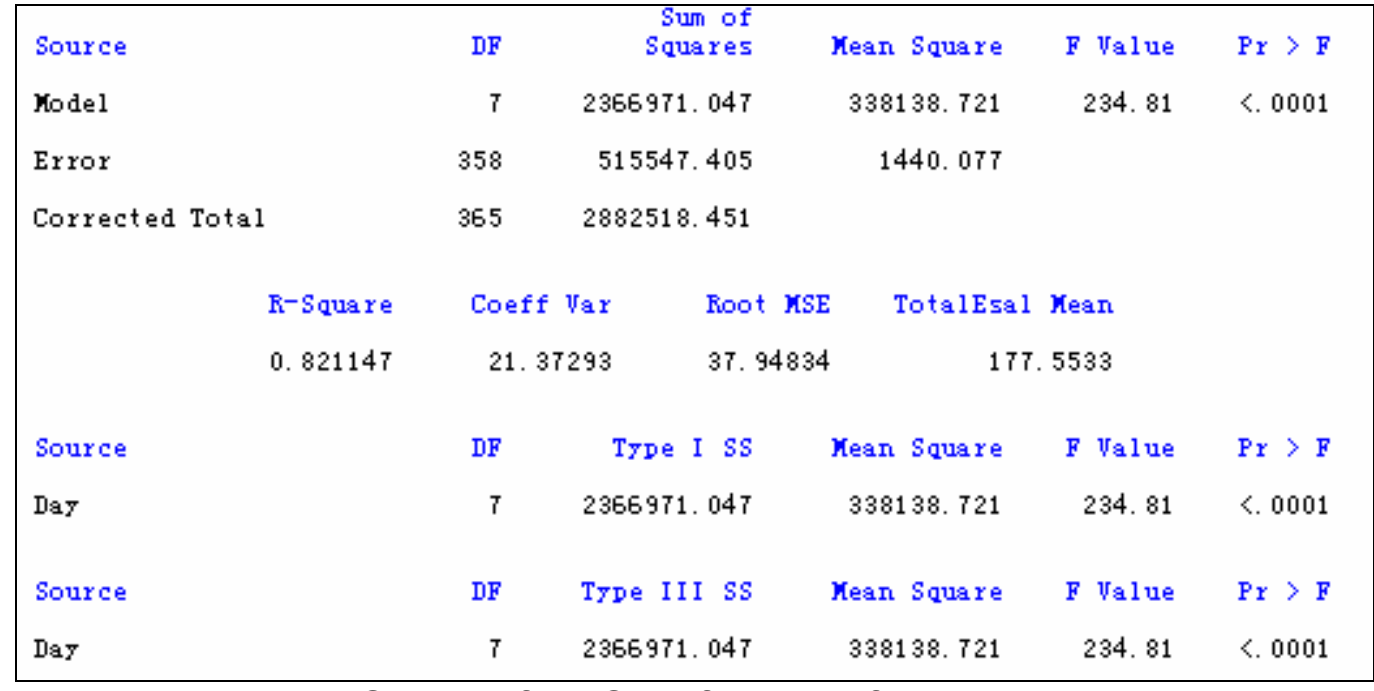

Figure 4.1 Output of ANOVA for Day of the Week Analysis

In Figure 4.1 we can see the factor "day" is significant $(=0.05)$. To further analyze the day factor, we need to look at the output of the Duncan Test in

Figure 4.2. 


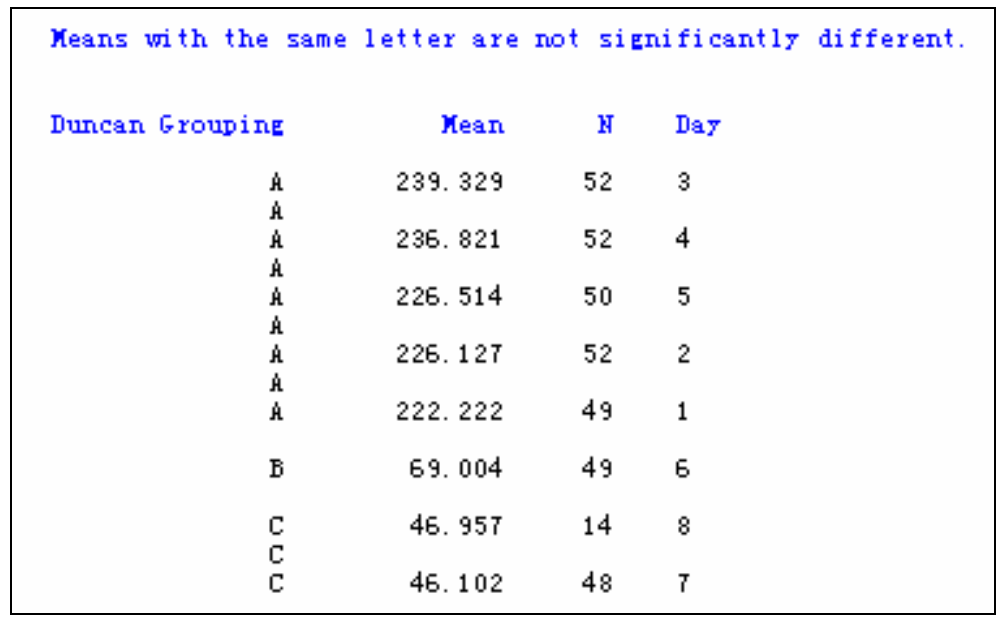

Figure 4.2 Duncan Test on Day Factor

As we can see in Figure 4.2, Wednesday has the highest ESALs, while Sunday has the lowest values. For simplicity, group 8 will be included in group 7 from now on.

The day of the week factor can be defined as:

$$
d_{i}=\frac{M D_{i} \times 7}{\sum_{k=1}^{7} M D_{k}}
$$

Where $d_{i}$ is the day of the week factor

$M D_{i}$ is the mean value of the day group $i$

Table 4.2 and Figure 4.3 show the values of the day of the week factors, based on the mean values in Figure 4.2. Table 4.2 Day of the Week Factor

\begin{tabular}{|c|c|c|c|c|c|c|c|}
\hline Day & 1 & 2 & 3 & 4 & 5 & 6 & 7 \\
\hline $\mathrm{d}_{\mathrm{i}}$ & 1.229 & 1.250 & 1.323 & 1.309 & 1.252 & 0.382 & 0.255 \\
\hline
\end{tabular}




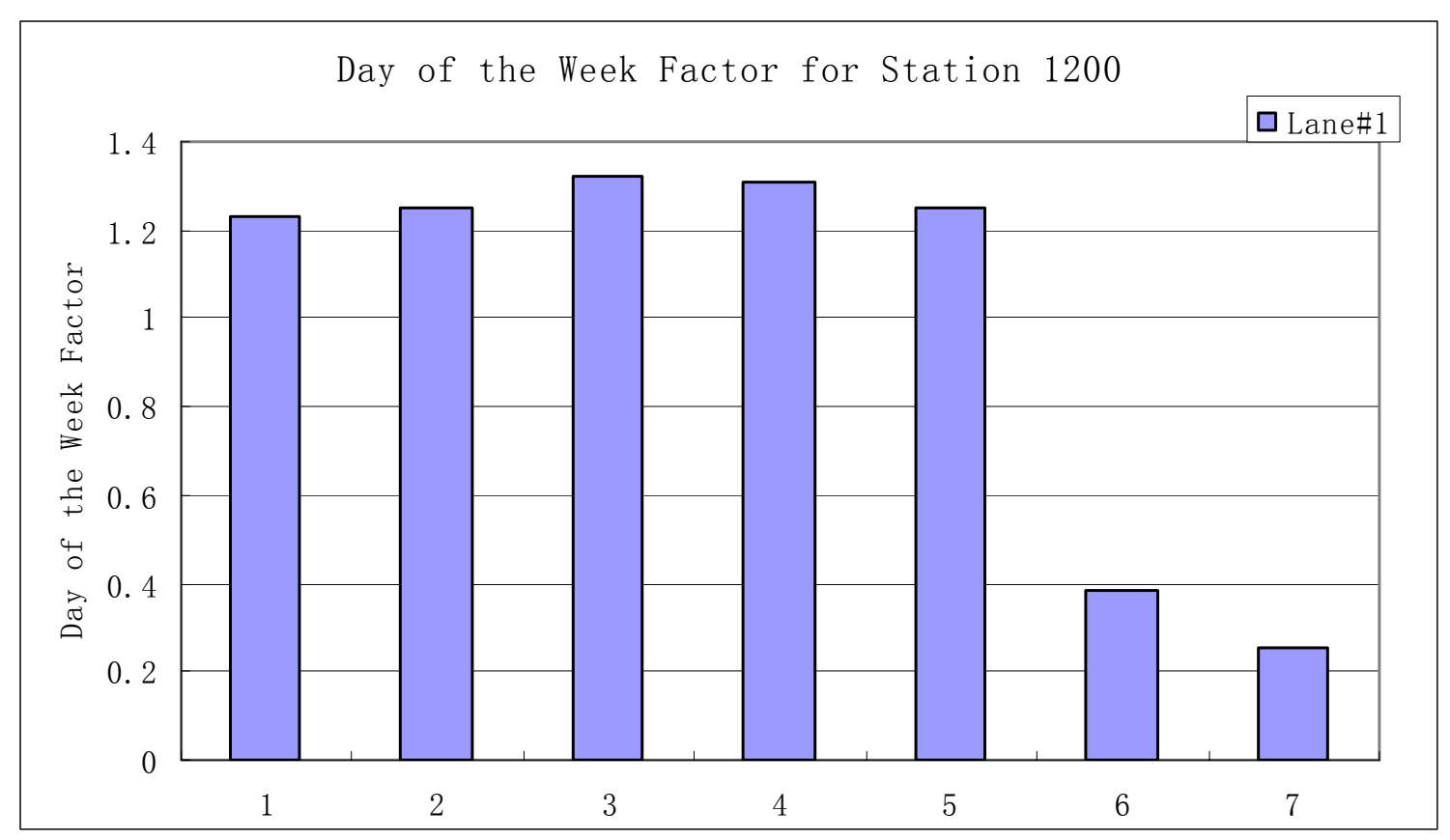

Figure 4.3 Day of the Week Factor

\subsubsection{Month of the Year Pattern}

Because weather can have significant effect on truck activity, we expect that the daily ESALs reflect the yearly weather pattern. Especially in winter, the daily ESALs should be lower, because of the severe weather. The daily ESAL data are divided into 12 monthly groups. These groups correspond to each calendar month. The ANOVA model now has two main factors: day (day of the week factor) and month (month of the year factor). The model is analyzed using SAS GLM procedure:

Proc glm data $=\mathrm{a} 1$;

class day month;

model TotalEsal=day month day*month;

means month/duncan;

run;

The result of ANOVA by SAS is shown in Figure 4.4. 


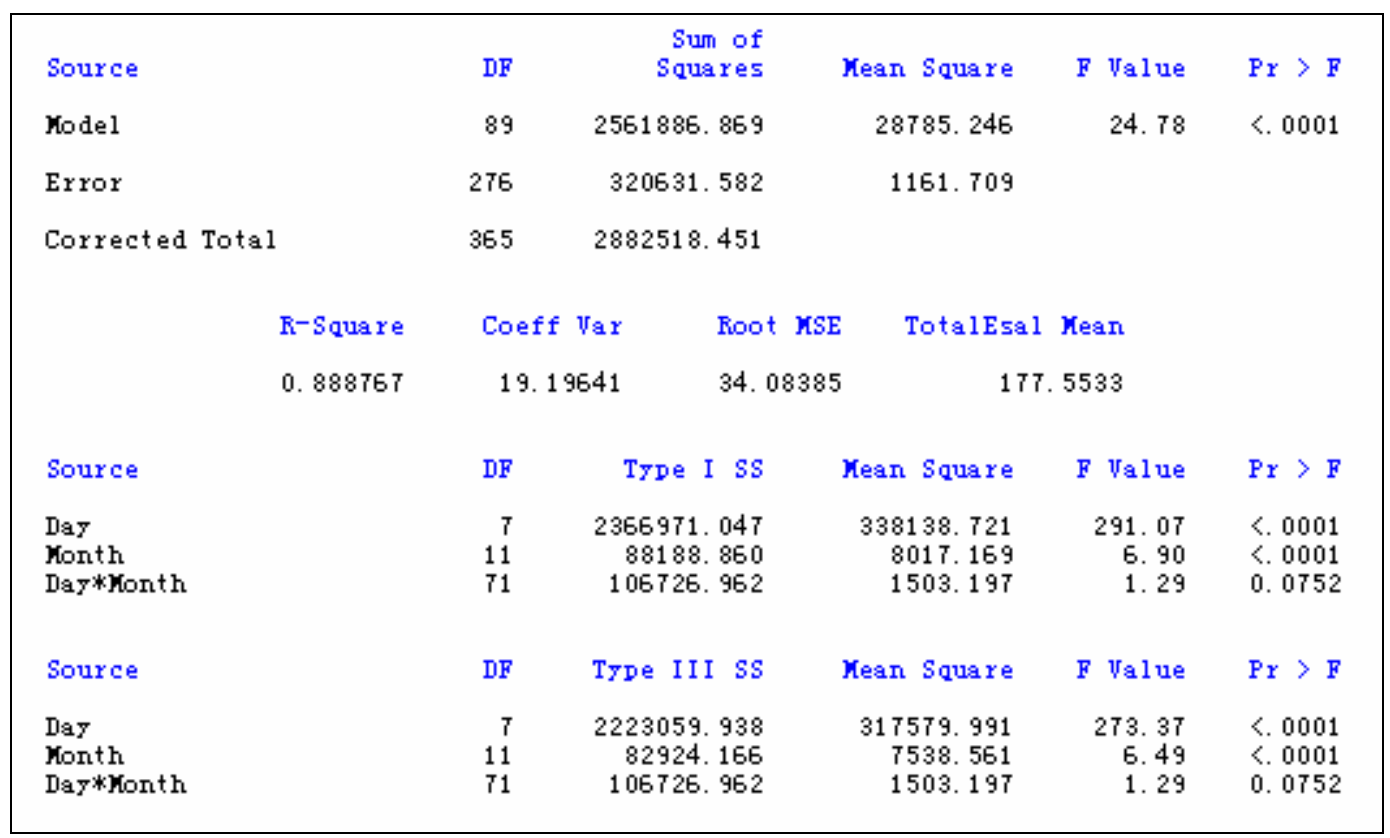

Figure 4.4 Output of ANOVA for Month of the Year Analysis

In Figure 4.4 we can see the factors "day" and "month" are significant, while the interaction factor is not significant $(\alpha=0.05)$. To further analyze the month factor, we need to look at the output of the Duncan Test in Figure 4.5.

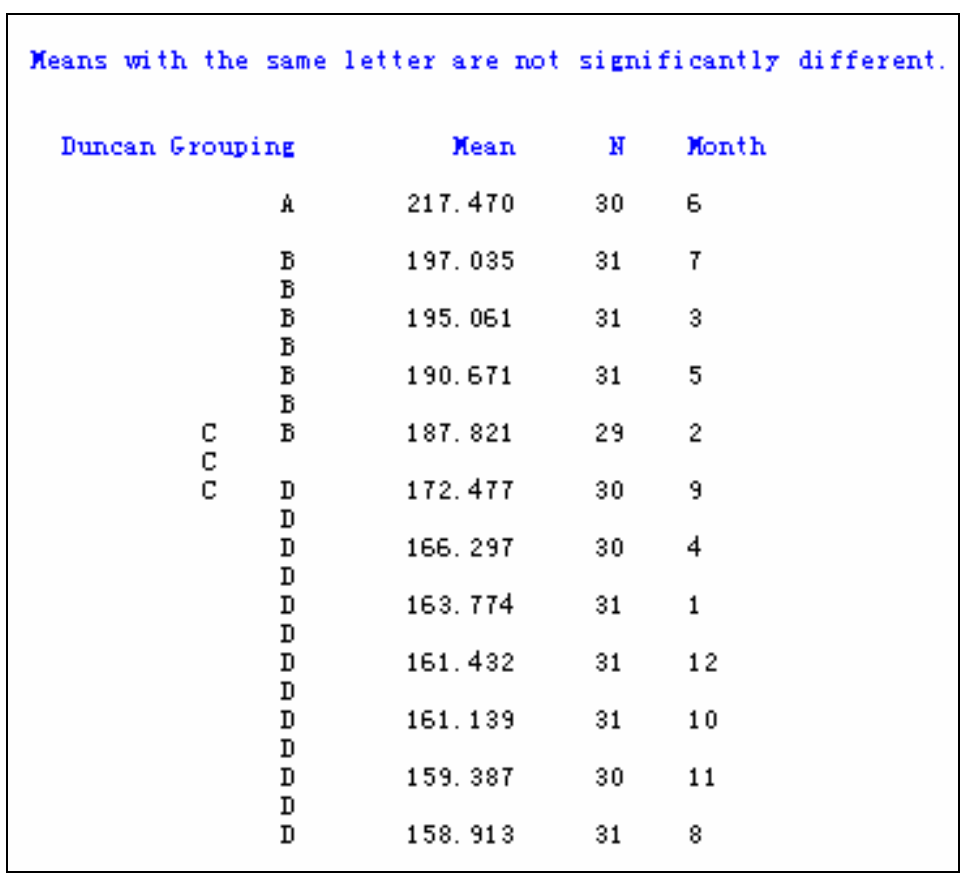

Figure 4.5 Duncan Test on Month Factor

As we can see in Figure 4.5, June has the highest average ESAL values while August has the lowest ESAL values. 
The month of the year factor can be defined as:

$$
m_{i}=\frac{M M_{i}}{M M_{7}}
$$

$m_{i}$ is the month the year factor

$\mathrm{MM}_{\mathrm{i}}$ is the mean values of the month group $\mathrm{i}$

Table 4.3 and Figure 4.6 show the values of the month of the year factors, based on the mean values in Figure 4.5.

Table 4.3 Month of the Year Factor

\begin{tabular}{|c|c|c|c|c|c|c|c|c|c|c|c|c|}
\hline Month & 7 & 8 & 9 & 10 & 11 & 12 & 1 & 2 & 3 & 4 & 5 & 6 \\
\hline $\mathrm{m}_{\mathrm{i}}$ & 1.000 & 0.807 & 0.875 & 0.818 & 0.809 & 0.819 & 0.831 & 0.953 & 0.990 & 0.844 & 0.968 & 1.104 \\
\hline
\end{tabular}

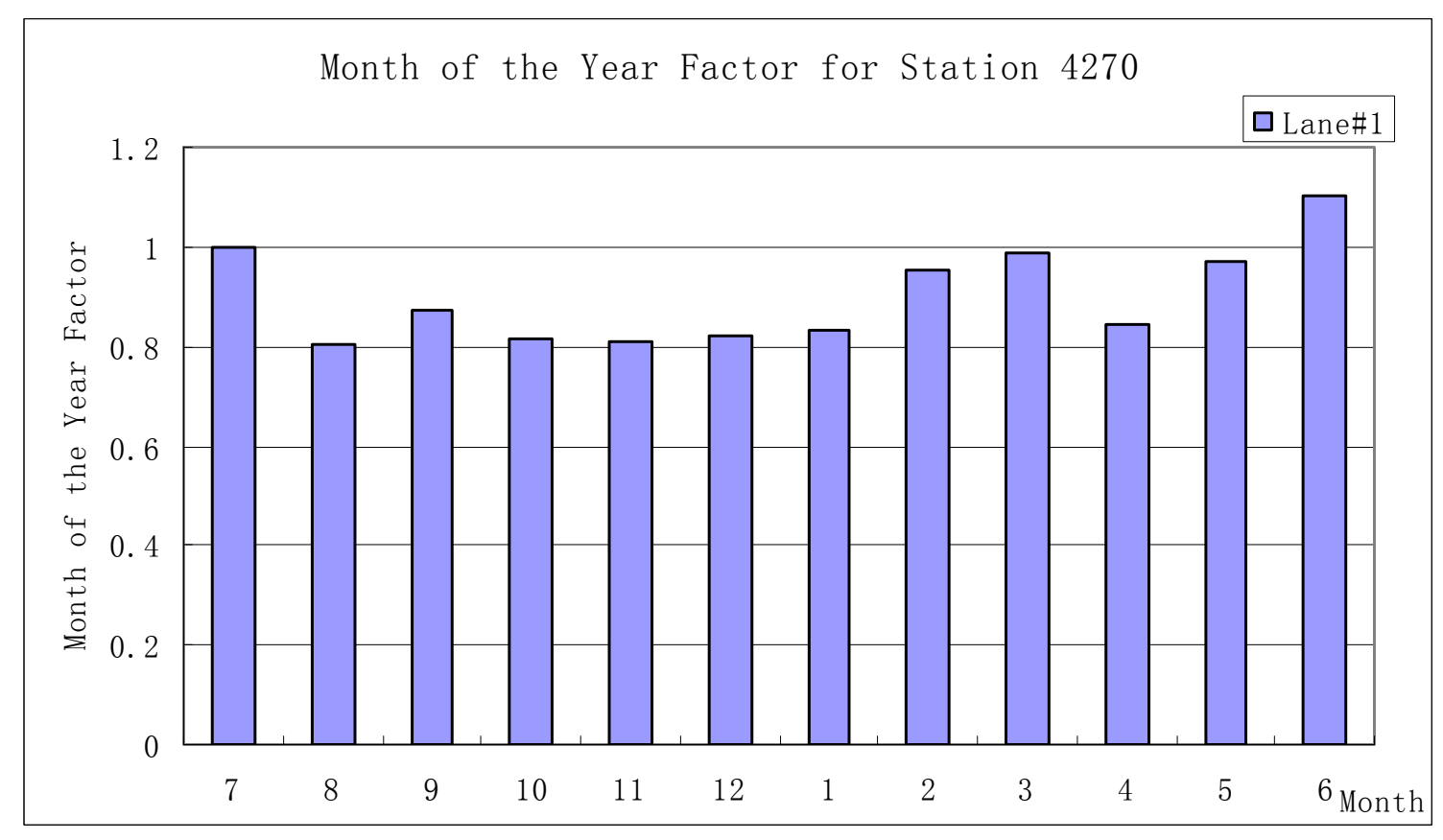

Figure 4.6 Month of the Year Factor

\subsection{Imputation Methods}

In this section, we will discuss several data imputation methods. To compare the candidate methods, we have the WIM data from August 1, 2000 to October 31, 2000 available (See Appendix C). First, we assume that the data from 
September 24, 2000 to September 30, 2000 are missing. Then we will impute the 7 days of "missing" ESAL values and compare the imputed values to their original values.

\subsubsection{Factor Method}

Based on pattern analysis, we can impute the data using the day of week factor and the month of the year factor. For any day, which is the ith day of a week and is in the jth month of a year, the ESAL value for this day can be calculated as:

$$
E S A L_{i j}=M M_{j} \times d_{i}
$$

$d_{i}$ is the day of the week factor.

$M M_{j}$ is the average ESAL value for the month $j$, and can be calculated as:

$$
M M_{j}=m_{j} \times \frac{M M_{j-1}+M M_{j+1}}{m_{j-1}+m_{j+1}}
$$

If $\mathrm{MM}_{\mathrm{j}+1}$ is not available, the equation can be simplified as:

$$
M M_{j}=m_{j} \times \frac{M M_{j-1}}{m_{j-1}}
$$

$m_{i}$ is the month of the year factor.

In this case: $\mathrm{ESAL}_{\mathrm{i} 9}=\mathrm{m}_{9} \times \frac{\mathrm{MM}_{8}+\mathrm{MM}_{10}}{\mathrm{~m}_{8}+\mathrm{m}_{10}} \times \mathrm{d}_{\mathrm{i}}$

Here $\mathrm{j}=9$, and $\mathrm{MM}_{8}=202.26, \mathrm{MM}_{10}=197.45, \mathrm{~d}_{\mathrm{i}}$ and $\mathrm{m}_{\mathrm{i}}$ are in Table 4.2 and 4.3.

The ESAL values are estimated in Table 4.4.

Table 4.4 ESAL Values Estimated by Factor Method

\begin{tabular}{|c|c|c|c|c|c|c|c|}
\hline Date & Sep. 24 & Sep. 25 & Sep. 26 & Sep. 27 & Sep. 28 & Sep. 29 & Sep. 30 \\
\hline i & 7 & 1 & 2 & 3 & 4 & 5 & 6 \\
\hline ESAL(Estimated) & 54.86 & 264.45 & 269.1 & 284.81 & 281.83 & 269.56 & 82.12 \\
\hline ESAL(Actual) & 40.8 & 182.4 & 243.1 & 303.9 & 274.5 & 214.4 & 94.1 \\
\hline
\end{tabular}


There are several performance measures that could be used to evaluate the quality of imputed data. In this report we will use RMSE (Root Mean Squared Error) and MAPE (Mean Absolute Percent Error).

$$
\begin{aligned}
& \text { RMSE }=\sqrt{\frac{\sum e_{i}^{2}}{n}} \\
& \text { MAPE }=\frac{\sum\left|P E_{i}\right|}{n}
\end{aligned}
$$

Here, $P E_{i}=\frac{e_{i}}{V_{i}} \times 100 \%, e_{i}=\hat{V}_{i}-V_{i}, V_{i}$ is the measured variable.

For the factor method, RMSE=40.0, MAPE $=19.7$ percent.

\subsubsection{Ordinary Regression}

As we saw before, the day of the week factor has a very important effect on ESALs. We can use this factor as the only regressor. The basic model is:

$$
\begin{gathered}
E S A L_{i}=\beta_{0}+\beta_{1} X_{i 1}+\beta_{2} X_{i 2}+\beta_{3} X_{i 3}+\beta_{4} X_{i 4}+\beta_{5} X_{i 5}+\beta_{6} X_{i 6}+\varepsilon_{i} \\
\varepsilon_{i} \text { are independent } N\left(0, \sigma^{2}\right)
\end{gathered}
$$

For any day $\bar{x}_{i}$, which is the jth day in a week,

$$
X_{i k}=\left\{\begin{array}{l}
1, k=j \\
0, k \neq j
\end{array}\right\}, k=1,2,3,4,5,6
$$

This model is analyzed using SAS REG procedure:

$$
\text { proc reg data=a1; }
$$

$$
\text { model TotalEsal = d1 d } 2 \text { d3 d4 d5 d6; }
$$

output out=p;

run;

The output is shown in Figure 4.7. 


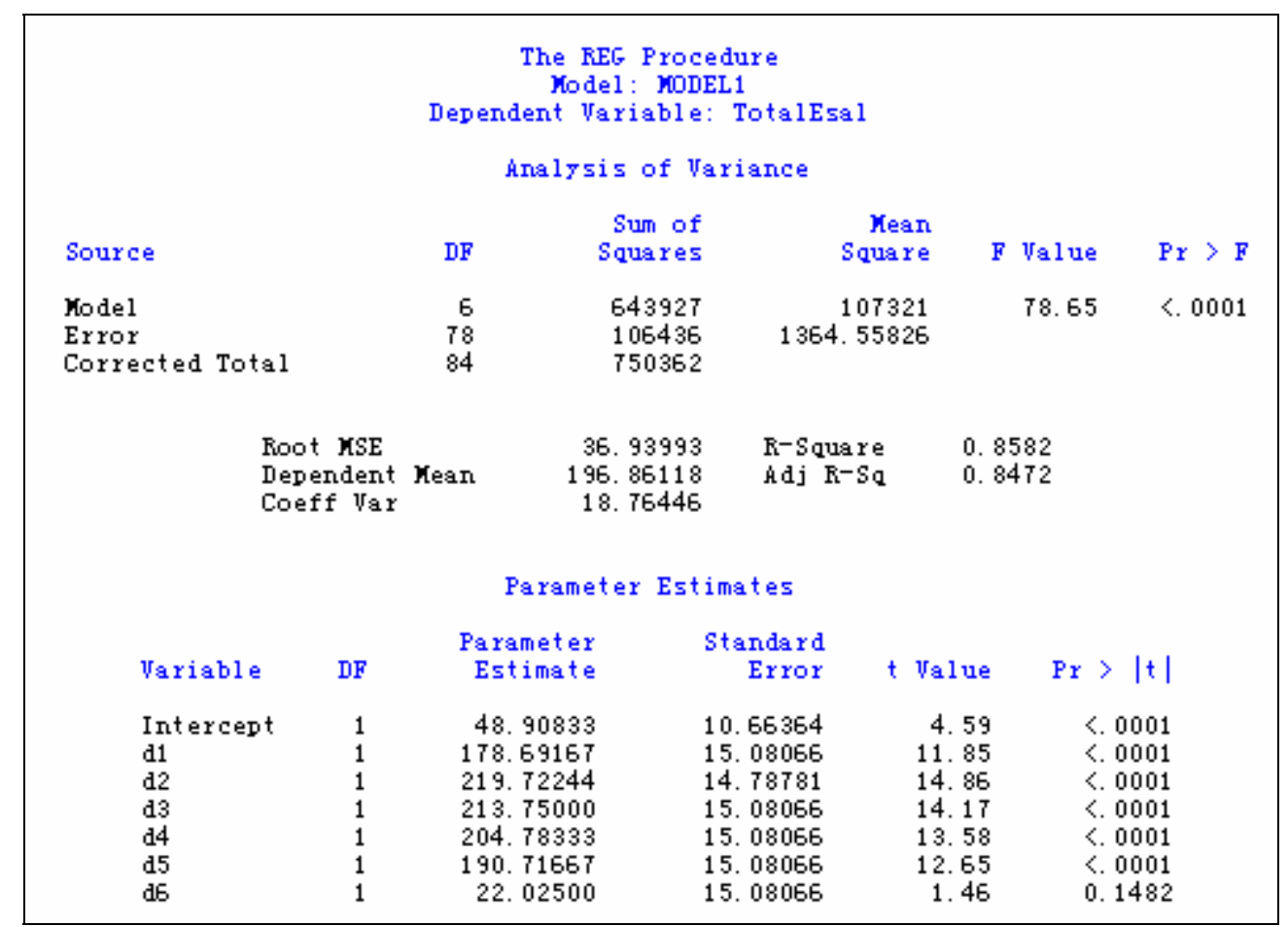

Figure 4.7 Output of the REG Analysis

Based on the parameters in Figure 4.7, the ESAL values can be estimated as shown in Table 4.5.

Table 4.5 ESAL Values Estimated by Ordinary Regression

\begin{tabular}{|c|c|c|c|c|c|c|c|}
\hline Date & Sep. 24 & Sep. 25 & Sep. 26 & Sep. 27 & Sep. 28 & Sep. 29 & Sep. 30 \\
\hline i & 7 & 1 & 2 & 3 & 4 & 5 & 6 \\
\hline ESAL(Estimated) & 48.91 & 227.6 & 268.63 & 262.66 & 253.69 & 239.63 & 70.93 \\
\hline ESAL(Actual) & 40.8 & 182.4 & 243.1 & 303.9 & 274.5 & 214.4 & 94.1 \\
\hline
\end{tabular}

For Ordinary Regression, RMSE=29.4, MAPE=16.1 percent.

\subsubsection{Regression with Autocorrelated Errors}

When a regression is performed on the WIM data, which are also time series data, the errors may not be independent. There is big chance that the errors are correlated, which means each error may be correlated with the error immediately before it. Because one of the assumptions of ordinary regression requires the residuals to be independent, it may be desirable if we can make some correction 
to the ordinary model. The model used in section 4.2.2 can now be modified to be:

$$
\begin{gathered}
\text { ESAL }_{i}=\beta_{0}+\beta_{1} X_{i 1}+\beta_{2} X_{i 2}+\beta_{3} X_{i 3}+\beta_{4} X_{i 4}+\beta_{5} X_{i 5}+\beta_{6} X_{i 6}+\varepsilon_{i} \\
\varepsilon_{i}=\rho \varepsilon_{i-1}+u_{i} \\
u_{i} \text { are independent } N\left(0, \sigma^{2}\right)
\end{gathered}
$$

For any day $\bar{X}_{i}$, which is the jth day in a week,

$$
x_{i k}=\left\{\begin{array}{l}
1, k=j \\
0, k \neq j
\end{array}\right\}, k=1,2,3,4,5,6
$$

This model is analyzed using SAS AUTOREG procedure:

$$
\text { proc autoreg data }=\mathrm{a} 1 \text {; }
$$

model TotalEsal $=\mathrm{d} 1 \mathrm{~d} 2 \mathrm{~d} 3 \mathrm{~d} 4 \mathrm{~d} 5 \mathrm{~d} 6 / \mathrm{nlag}=2$ method=ml; output out=p $p=y$ hat $p m=$ trendhat;

run;

The output is shown in Figure 4.8 and Figure 4.9.

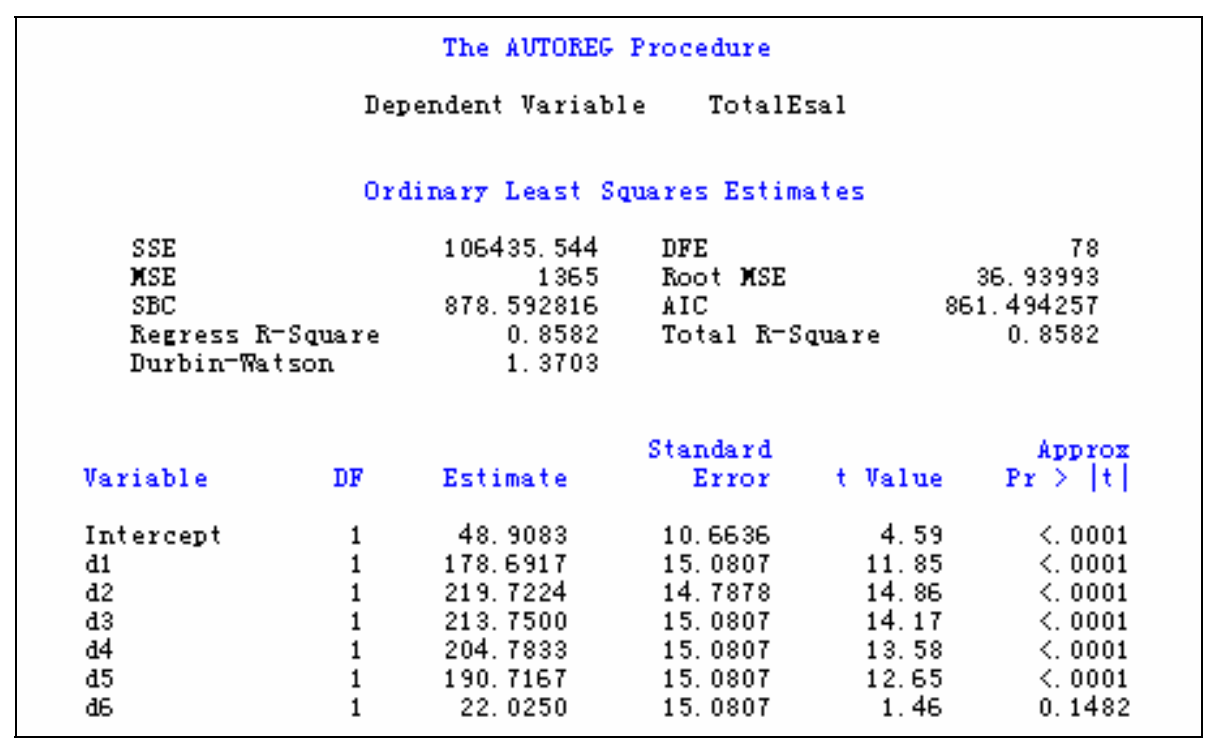

Figure 4.8 Output of Ordinary Least Squares Estimates

In Figure, the Ordinary Least Squares Estimates give the same estimated parameters as in session 4.2.2. The $D$ value for the Durbin-Watson test is 1.3703 , which indicates the errors are correlated. 


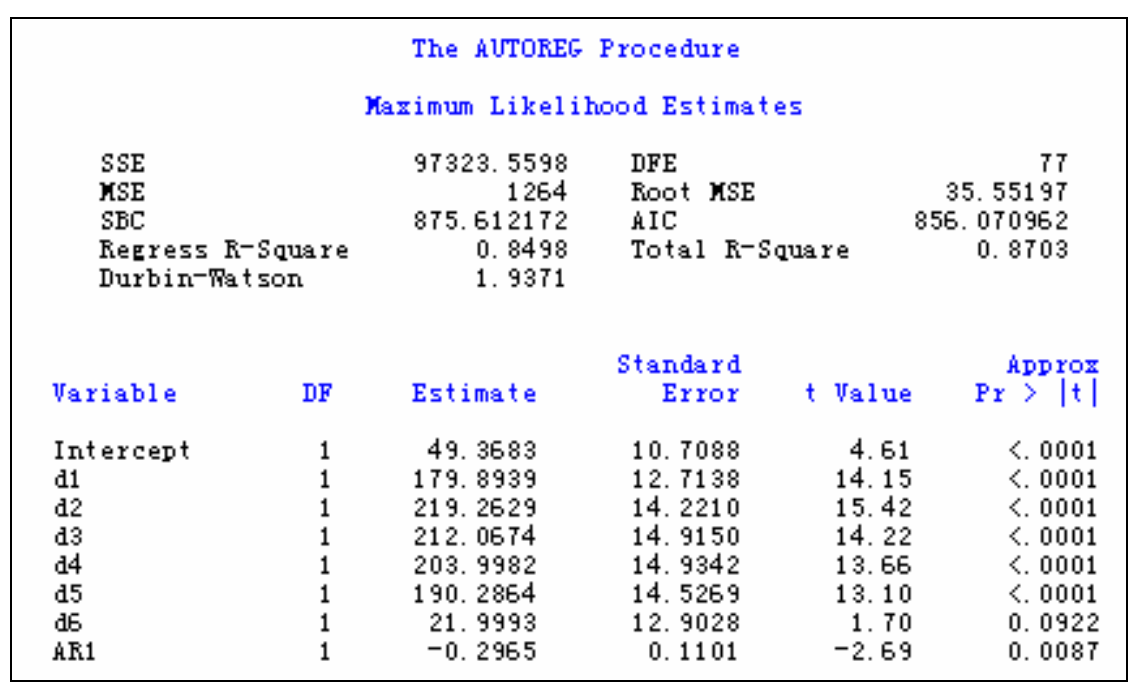

Figure 4.9 Output of Maximum Likelihood Estimates

The results show that AR1 is significant $(\alpha=0.05)$. Based on the parameters given in Figure 4.9, the ESAL values can be estimated as in Table 4.6.

Table 4.6 ESAL Values Estimated by Regression with Autocorrelated Errors

\begin{tabular}{|c|c|c|c|c|c|c|c|}
\hline Date & Sep. 24 & Sep. 25 & Sep. 26 & Sep. 27 & Sep. 28 & Sep. 29 & Sep. 30 \\
\hline i & 7 & 1 & 2 & 3 & 4 & 5 & 6 \\
\hline ESAL(Estimated) & 49.05 & 229.17 & 268.60 & 261.43 & 253.36 & 239.65 & 71.37 \\
\hline ESAL(Actual) & 40.8 & 182.4 & 243.1 & 303.9 & 274.5 & 214.4 & 94.1 \\
\hline
\end{tabular}

For Regression with autocorrelated errors, RMSE=30.0, MAPE=16.3 percent.

\subsubsection{Other Time Series Forecasting Methods}

In some situations, we can use time series forecasting methods to update the missing values. These methods are usually more advanced, and can give a more accurate prediction for time series data. Table 4.7 lists a few forecasting methods in time series analysis. Their prediction errors are calculated based on the data from September 24 to September 30, 2000. The data used to train models are from August 1, 2000 to September 23, 2000. These models are analyzed by 
Table 4.7 Results for Time Series Forecasting Methods

\begin{tabular}{|c|c|c|}
\hline Model & RMSE & MAPE \\
\hline Seasonal Exponential Smoothing & 26.8 & $15.9 \%$ \\
\hline Winters Method-Additive & 26.7 & $15.3 \%$ \\
\hline ARIMA(2,0,0)(1,0,0)s & 28.8 & $20.5 \%$ \\
\hline Log Seasonal Exponential Smoothing & 27.7 & $15.2 \%$ \\
\hline Log Winters Method-Additive & 27.7 & $15.2 \%$ \\
\hline Log ARIMA(2,0,0)(1,0,0)s & 25.2 & $17.5 \%$ \\
\hline
\end{tabular}

\subsubsection{Summary}

The factor method is simple and easy to apply. However, it may be difficult to find enough good data to develop the month of the year factor, and there is no guarantee that the factor will not change year-to-year. So errors in imputation are likely to be caused by inappropriate factors.

Compared to the factor method, regression methods use only "local" data to develop the regression model. The results are better. Regression with autocorrelated errors accounts for data that are correlated, and incorporates the correlation into the error terms, which makes the model suitable for time series data.

Although some time series forecasting methods can produce a lower RMSE and MAPE, it is not recommended to use these methods in most situations. Imputation is different from forecasting: imputation can use the data before and after a gap; forecasting uses only the data before a gap. 


\section{CHAPTER 5. CONCLUSIONS}

WIM data checking should be conducted on both a monthly basis and a daily basis. Chapter 2 discusses the methods that can be used in monthly checking. Although different states use different methods, the three methods using unclassified vehicle rate, front axle distribution and Class 9 vehicle GVW are widely accepted. In Chapter 3, the WDDC (Weigh-In-Motion Daily Data Checking) program is introduced. The WDDC program is developed for INDOT to facilitate the daily checking process. This program can automatically process the raw data to produce daily reports using IRD Office. The reports will then be imported into EXCEL. The whole procedure requires very little human intervention, and provides a convenient way to check daily summary data.

There are debates about data imputation and data integrity. In the experiment in Chapter 4, the factor method and regression methods can do imputation with a MAPE from 15 percent to 20 percent. Due to a lack of data from more WIM sites, we have not been able to test these models extensively and make recommendations. These tests should be carried out as data are made available.

Throughout the data analysis for this project, we realize how much important information the Weigh-In-Motion system can provide. However, the data quality

often suffers from equipment problems. In addition, this project has been hampered by the lack of historical data. As more historical data can be retrieved, the ability to impute data can be more comprehensively assessed. 
In the meantime, the data checking procedures developed in this project should facilitate the prompt detection of apparent data anomalies and the application of appropriate connective action. In the process, the amount of poor data can be reduced, with a corresponding reduction in the need for data imputation. 


\section{LIST OF REFERENCES}

American Association of State Highway and Transportation Officials. "Guidelines for Traffic Data Programs". Washington, D.C.:AASHTO, 1992. As cited in Smith et al. (2003).

American Society for Testing and Materials. "Standard Specification for Highway Weigh-In-Motion (WIM) Systems with User Requirements and Test Method". ASTM Designation E 1318-94, 1994. As cited in McCall and Vodrazka (1997).

Bergen, A.T., Lindgren, N., Berthelotc, C. and Woytowich, B. "Preserving Highway Infrastructure Using Weigh-In-Motion". Saskatoon, SK, Canada: IRD, 1998.

Bushman, R. and Pratt A.J. "Weigh In Motion Technology - Economics and Performance". Charlotte, NC: North American Travel Monitoring Exhibition and Conference, 1998.

Federal Highway Administration. "WIM Scale Calibration: A Vital Activity for LTPP Sites". McLean, VA: FHWA, 1998.

Green J., Nichols, A., Allen, E., Nuber, L., Thomaz, J., Bullock, D., Boruff, G., Wasson, J. and Newland M. "Virtual Weigh Station: Final Report". FHWA/IN/JTRP-2001/09, 2002.

Gulen, S., Nagle, J., Weaver, J. and Gallivan, V. "Determination Of Practical ESALs Per Truck Values On Indiana Roads: Final Report". Indianapolis, IN: INDOT, December 2000.

International Road Dynamics, Inc. "Software User's Manual IRD Weigh-In-Motion

Data Collection System". Version 7.4.3. Saskatoon, SK, Canada: IRD, 1993, 33 of section 5 .

Katz J.K. and Rakha, H.A. "Weigh-In-Motion Evaluation: Final Report". Blacksburg, VA: Virginia Tech Transportation Institute, 2002.

Lingras, P.J., Sharma, S,C. and Zhong M. "Effect of Missing Value Imputations on Traffic Parameters Estimations from Permanent Traffic Counts". Washington

DC: Transportation Research Board, 82th Annual Meeting Compendium of Papers CD-ROM, 2003.

Little, R.J.A. and Rubin, D.B. "Statistical Analysis with Missing Data". Hoboken, N.J. : Wiley, 2002. 
Lomax, T., Turner, S. and Margiotta, R. "Monitoring Urban Roadways in 2000: Using Archived Operations Data for Reliability and Mobility Measurement". College Station, TX: Texas Transportation Institute, 2001.

McCall, B. and Vodrazka, W.C. "States' Successful Practices Weigh-In-Motion Handbook". Washington, DC: FHWA, 1997.

Nihan, N.L. and Holmesland, K.O. "Use of the Box and Jenkins Time Series Technique in Traffic Forecasting". Transportation, 9, 1980, 125-143. As cited in Zhong et al. (2002).

Schmoyer, R. and Hu, P.S. "Analysis of Vehicle Classification and Truck Weight Data of The New England States: Is Data Sharing A Good Idea?" Oak Ridge, TN: Oak Ridge National Laboratory, 1997.

Smith, B.L., Scherer, W.T. and Conklin, J.H. "Exploring Imputation Techniques for Missing Data in Transportation Management Systems". Washington, DC: Transportation Research Board, 82th Annual Meeting Compendium of Papers CD-ROM, 2003.

Zhi, X., Shalaby, A., Middleton, D. and Clayton, A. "Evaluation of Weigh-InMotion in Manitoba". Canadian Journal of Civil Engineering, 26, 1999, 655-666.

Zhong, M., Lingras, P.J., and Sharma, S.C. "Updating Missing Values of Traffic Counts: Factor Approaches, Time Series Analysis versus Genetically Designed Regression and Neural Network Models". Halifax, NS, Canada: Saint Mary's University, 2002 


\section{APPENDIX A. FHWA VEHICLE CLASSIFICATION SCHEME}
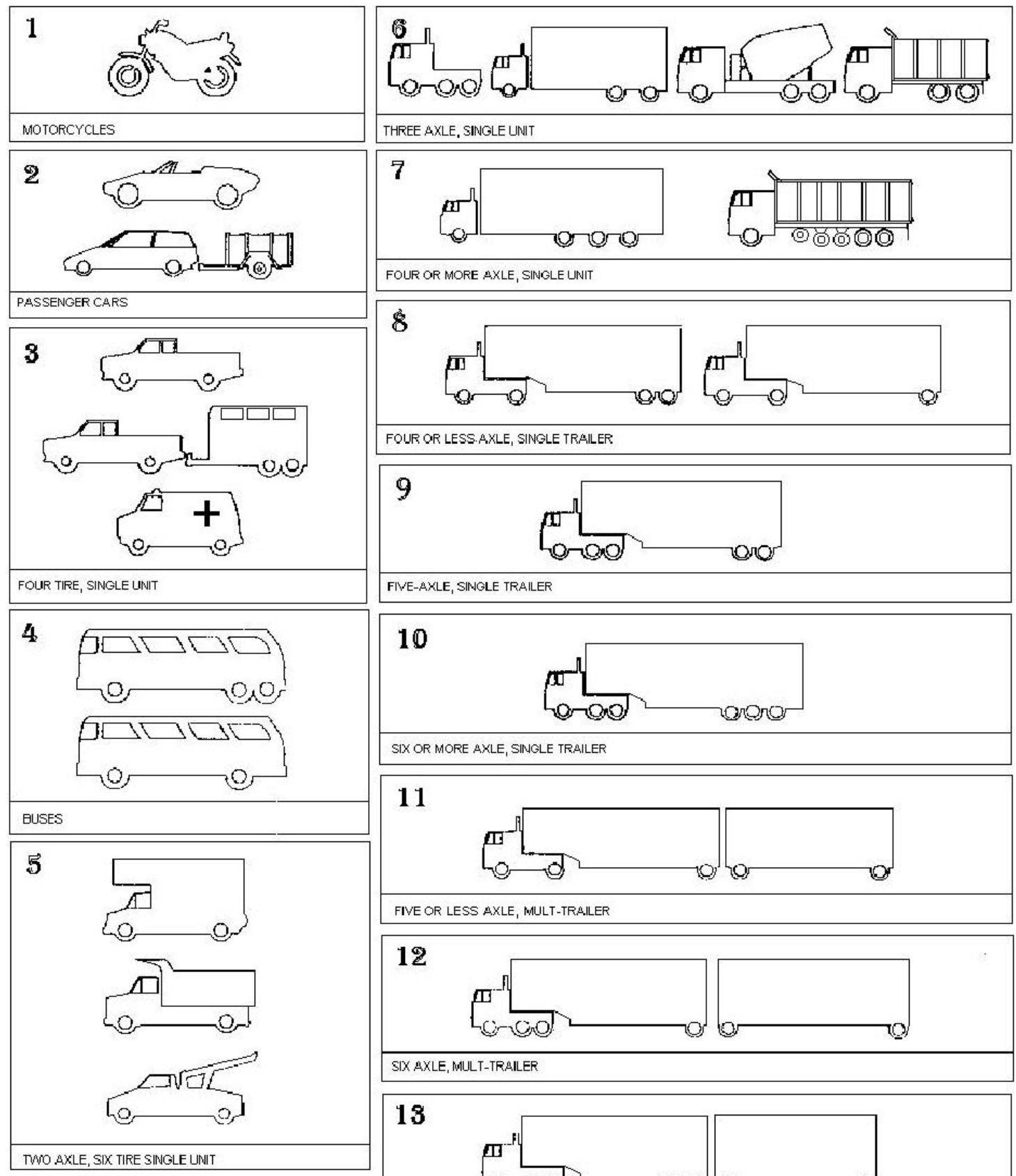

13

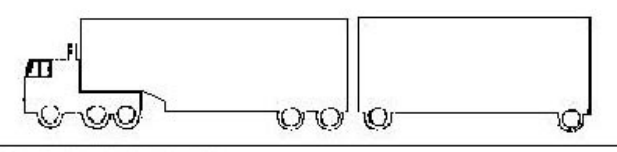

SEVEN OR MORE AXLE, MULTI-TRAILER 
APPENDIX B. DATA USED FOR PATTERN ANALYSIS

\begin{tabular}{|c|c|}
\hline Date & TotalEsal \\
\hline $07-01-99$ & 230.1 \\
\hline $07-02-99$ & 243 \\
\hline $07-03-99$ & 102.2 \\
\hline $07-04-99$ & 68.6 \\
\hline $07-05-99$ & 132.5 \\
\hline $07-06-99$ & 320 \\
\hline $07-07-99$ & 291.3 \\
\hline $07-08-99$ & 268.7 \\
\hline $07-09-99$ & 314.5 \\
\hline $07-10-99$ & 74.9 \\
\hline $07-11-99$ & 51.9 \\
\hline $07-12-99$ & 276.6 \\
\hline $07-13-99$ & 239.1 \\
\hline $07-14-99$ & 251.7 \\
\hline $07-15-99$ & 252.5 \\
\hline $07-16-99$ & 242.6 \\
\hline $07-17-99$ & 64.2 \\
\hline $07-18-99$ & 44.6 \\
\hline $07-19-99$ & 203.7 \\
\hline $07-20-99$ & 202.2 \\
\hline $07-21-99$ & 259.7 \\
\hline $07-22-99$ & 267.4 \\
\hline $07-23-99$ & 278.5 \\
\hline $07-24-99$ & 73.2 \\
\hline $07-25-99$ & 65.4 \\
\hline $07-26-99$ & 274.7 \\
\hline $07-27-99$ & 199.1 \\
\hline $07-28-99$ & 229.8 \\
\hline $07-29-99$ & 291.8 \\
\hline $07-30-99$ & 228.4 \\
\hline $07-31-99$ & 65.2 \\
\hline $08-01-99$ & 43.3 \\
\hline $08-02-99$ & 213.5 \\
\hline $08-03-99$ & 183.1 \\
\hline $08-04-99$ & 247.3 \\
\hline $08-05-99$ & 205 \\
\hline $08-06-99$ & 261.7 \\
\hline & \\
\hline
\end{tabular}




\begin{tabular}{|c|c|}
\hline $08-07-99$ & 78.2 \\
\hline $08-08-99$ & 39.7 \\
\hline $08-09-99$ & 206.5 \\
\hline $08-10-99$ & 255.7 \\
\hline $08-11-99$ & 253.7 \\
\hline $08-12-99$ & 149.3 \\
\hline $08-13-99$ & 225.6 \\
\hline $08-14-99$ & 59.8 \\
\hline $08-15-99$ & 61.6 \\
\hline $08-16-99$ & 216.8 \\
\hline $08-17-99$ & 228.6 \\
\hline $08-18-99$ & 165.7 \\
\hline $08-19-99$ & 158.8 \\
\hline $08-20-99$ & 209 \\
\hline $08-21-99$ & 54.6 \\
\hline $08-22-99$ & 40.4 \\
\hline $08-23-99$ & 171.2 \\
\hline $08-24-99$ & 153.5 \\
\hline $08-25-99$ & 182.3 \\
\hline $08-26-99$ & 162 \\
\hline $08-27-99$ & 216.3 \\
\hline $08-28-99$ & 50.1 \\
\hline $08-29-99$ & 42.3 \\
\hline $08-30-99$ & 179.5 \\
\hline $08-31-99$ & 211.2 \\
\hline $09-01-99$ & 218.2 \\
\hline $09-02-99$ & 279.4 \\
\hline $09-03-99$ & 254.3 \\
\hline $09-04-99$ & 64.6 \\
\hline $09-05-99$ & 32.5 \\
\hline $09-06-99$ & 53.3 \\
\hline $09-07-99$ & 245 \\
\hline $09-08-99$ & 246.2 \\
\hline $09-09-99$ & 247.1 \\
\hline $09-10-99$ & 269.5 \\
\hline $09-11-99$ & 97.6 \\
\hline $09-12-99$ & 72.8 \\
\hline $09-13-99$ & 208.4 \\
\hline $09-14-99$ & 217.7 \\
\hline $09-15-99$ & 210.6 \\
\hline $09-16-99$ & 184.1 \\
\hline $09-17-99$ & 190.6 \\
\hline & \\
\hline
\end{tabular}




\begin{tabular}{|c|c|}
\hline $09-18-99$ & 70.7 \\
\hline $09-19-99$ & 57.6 \\
\hline $09-20-99$ & 219.5 \\
\hline $09-21-99$ & 193.8 \\
\hline $09-22-99$ & 50 \\
\hline $09-23-99$ & 243.1 \\
\hline $09-24-99$ & 209.3 \\
\hline $09-25-99$ & 65.3 \\
\hline $09-26-99$ & 54.6 \\
\hline $09-27-99$ & 246.2 \\
\hline $09-28-99$ & 208 \\
\hline $09-29-99$ & 211.3 \\
\hline $09-30-99$ & 253 \\
\hline $10-01-99$ & 214.5 \\
\hline $10-02-99$ & 66.8 \\
\hline $10-03-99$ & 28.9 \\
\hline $10-04-99$ & 188.5 \\
\hline $10-05-99$ & 256.9 \\
\hline $10-06-99$ & 190.4 \\
\hline $10-07-99$ & 150.3 \\
\hline $10-08-99$ & 215.3 \\
\hline $10-09-99$ & 41.7 \\
\hline $10-10-99$ & 37.1 \\
\hline $10-11-99$ & 222.2 \\
\hline $10-12-99$ & 217.5 \\
\hline $10-13-99$ & 211.1 \\
\hline $10-14-99$ & 215.1 \\
\hline $10-15-99$ & 199.9 \\
\hline $10-16-99$ & 61.6 \\
\hline $10-17-99$ & 22.6 \\
\hline $10-18-99$ & 205.1 \\
\hline $10-19-99$ & 207.2 \\
\hline $10-20-99$ & 186.5 \\
\hline $10-21-99$ & 228.5 \\
\hline $10-22-99$ & 199.3 \\
\hline $10-23-99$ & 65.5 \\
\hline $10-24-99$ & 40.8 \\
\hline $10-25-99$ & 240 \\
\hline $10-26-99$ & 180.5 \\
\hline $10-27-99$ & 199.4 \\
\hline $10-28-99$ & 280.2 \\
\hline $10-29-99$ & 264.5 \\
\hline & \\
\hline
\end{tabular}




\begin{tabular}{|c|c|}
\hline $10-30-99$ & 119.3 \\
\hline $10-31-99$ & 38.1 \\
\hline $11-01-99$ & 245.2 \\
\hline $11-02-99$ & 266.5 \\
\hline $11-03-99$ & 267.5 \\
\hline $11-04-99$ & 257.9 \\
\hline $11-05-99$ & 234.7 \\
\hline $11-06-99$ & 58.4 \\
\hline $11-07-99$ & 32.7 \\
\hline $11-08-99$ & 222.9 \\
\hline $11-09-99$ & 208.3 \\
\hline $11-10-99$ & 260.8 \\
\hline $11-11-99$ & 164.3 \\
\hline $11-12-99$ & 186.7 \\
\hline $11-13-99$ & 62.2 \\
\hline $11-14-99$ & 33.6 \\
\hline $11-15-99$ & 204.2 \\
\hline $11-16-99$ & 183.6 \\
\hline $11-17-99$ & 161.6 \\
\hline $11-18-99$ & 206.1 \\
\hline $11-19-99$ & 191.6 \\
\hline $11-20-99$ & 55.7 \\
\hline $11-21-99$ & 33.8 \\
\hline $11-22-99$ & 237.8 \\
\hline $11-23-99$ & 224 \\
\hline $11-24-99$ & 164.3 \\
\hline $11-25-99$ & 31.9 \\
\hline $11-26-99$ & 85 \\
\hline $11-27-99$ & 43.7 \\
\hline $11-28-99$ & 38.3 \\
\hline $11-29-99$ & 193.6 \\
\hline $11-30-99$ & 224.7 \\
\hline $12-01-99$ & 210 \\
\hline $12-02-99$ & 279.5 \\
\hline $12-03-99$ & 203 \\
\hline $12-04-99$ & 81 \\
\hline $12-05-99$ & 52 \\
\hline $12-06-99$ & 241.5 \\
\hline $12-07-99$ & 232 \\
\hline $12-08-99$ & 224 \\
\hline $12-09-99$ & 221.4 \\
\hline $12-10-99$ & 195 \\
\hline & \\
\hline
\end{tabular}




\begin{tabular}{|c|c|}
\hline $12-11-99$ & 50.3 \\
\hline $12-12-99$ & 51.2 \\
\hline $12-13-99$ & 181.3 \\
\hline $12-14-99$ & 216 \\
\hline $12-15-99$ & 281.5 \\
\hline $12-16-99$ & 246 \\
\hline $12-17-99$ & 201.2 \\
\hline $12-18-99$ & 68.9 \\
\hline $12-19-99$ & 39.1 \\
\hline $12-20-99$ & 245.5 \\
\hline $12-21-99$ & 225.2 \\
\hline $12-22-99$ & 207.6 \\
\hline $12-23-99$ & 159.7 \\
\hline $12-24-99$ & 34.8 \\
\hline $12-25-99$ & 3.3 \\
\hline $12-26-99$ & 18.4 \\
\hline $12-27-99$ & 171.2 \\
\hline $12-28-99$ & 204.2 \\
\hline $12-29-99$ & 263.2 \\
\hline $12-30-99$ & 145.1 \\
\hline $12-31-99$ & 51.3 \\
\hline $01-01-00$ & 15.7 \\
\hline $01-02-00$ & 39.3 \\
\hline $01-03-00$ & 172.2 \\
\hline $01-04-00$ & 187.8 \\
\hline $01-05-00$ & 264.5 \\
\hline $01-06-00$ & 285.5 \\
\hline $01-07-00$ & 223.1 \\
\hline $01-08-00$ & 87.4 \\
\hline $01-09-00$ & 48.9 \\
\hline $01-10-00$ & 272 \\
\hline $01-11-00$ & 243 \\
\hline $01-12-00$ & 184 \\
\hline $01-13-00$ & 214.5 \\
\hline $01-14-00$ & 239.5 \\
\hline $01-15-00$ & 82.7 \\
\hline $01-16-00$ & 54.6 \\
\hline $01-17-00$ & 160.9 \\
\hline $01-18-00$ & 177.8 \\
\hline $01-19-00$ & 215.4 \\
\hline $01-20-00$ & 122.5 \\
\hline $01-21-00$ & 105.6 \\
\hline & \\
\hline
\end{tabular}




\begin{tabular}{|c|c|}
\hline $01-22-00$ & 45.1 \\
\hline $01-23-00$ & 42.6 \\
\hline $01-24-00$ & 204.8 \\
\hline $01-25-00$ & 247.6 \\
\hline $01-26-00$ & 222.6 \\
\hline $01-27-00$ & 245.6 \\
\hline $01-28-00$ & 260.5 \\
\hline $01-29-00$ & 68.2 \\
\hline $01-30-00$ & 45 \\
\hline $01-31-00$ & 298.1 \\
\hline $02-01-00$ & 245.7 \\
\hline $02-02-00$ & 293.8 \\
\hline $02-03-00$ & 258.7 \\
\hline $02-04-00$ & 223.6 \\
\hline $02-05-00$ & 91 \\
\hline $02-06-00$ & 46.7 \\
\hline $02-07-00$ & 255.5 \\
\hline $02-08-00$ & 259.8 \\
\hline $02-09-00$ & 353.3 \\
\hline $02-10-00$ & 199.8 \\
\hline $02-11-00$ & 181.9 \\
\hline $02-12-00$ & 72.3 \\
\hline $02-13-00$ & 38.8 \\
\hline $02-14-00$ & 211.7 \\
\hline $02-15-00$ & 177.7 \\
\hline $02-16-00$ & 267.2 \\
\hline $02-17-00$ & 208.4 \\
\hline $02-18-00$ & 154.8 \\
\hline $02-19-00$ & 54.1 \\
\hline $02-20-00$ & 60.4 \\
\hline $02-21-00$ & 240.9 \\
\hline $02-22-00$ & 235.7 \\
\hline $02-23-00$ & 263.2 \\
\hline $02-24-00$ & 250.5 \\
\hline $02-25-00$ & 227.9 \\
\hline $02-26-00$ & 62.8 \\
\hline $02-27-00$ & 57.9 \\
\hline $02-28-00$ & 245.1 \\
\hline $02-29-00$ & 207.6 \\
\hline $03-01-00$ & 242.6 \\
\hline $03-02-00$ & 221 \\
\hline $03-03-00$ & 286.1 \\
\hline & \\
\hline
\end{tabular}




\begin{tabular}{|c|c|}
\hline $03-04-00$ & 72.9 \\
\hline $03-05-00$ & 50.4 \\
\hline $03-06-00$ & 238.9 \\
\hline $03-07-00$ & 321.8 \\
\hline $03-08-00$ & 317.9 \\
\hline $03-09-00$ & 271.3 \\
\hline $03-10-00$ & 227.7 \\
\hline $03-11-00$ & 67.2 \\
\hline $03-12-00$ & 58.1 \\
\hline $03-13-00$ & 240.3 \\
\hline $03-14-00$ & 278.4 \\
\hline $03-15-00$ & 281.5 \\
\hline $03-16-00$ & 202.5 \\
\hline $03-17-00$ & 177.2 \\
\hline $03-18-00$ & 52.8 \\
\hline $03-19-00$ & 45.1 \\
\hline $03-20-00$ & 176.8 \\
\hline $03-21-00$ & 231.6 \\
\hline $03-22-00$ & 225.1 \\
\hline $03-23-00$ & 232 \\
\hline $03-24-00$ & 187.5 \\
\hline $03-25-00$ & 64.5 \\
\hline $03-26-00$ & 63.5 \\
\hline $03-27-00$ & 228.7 \\
\hline $03-28-00$ & 203.7 \\
\hline $03-29-00$ & 258.7 \\
\hline $03-30-00$ & 268.3 \\
\hline $03-31-00$ & 252.8 \\
\hline $04-01-00$ & 74.6 \\
\hline $04-02-00$ & 27.7 \\
\hline $04-03-00$ & 246.2 \\
\hline $04-04-00$ & 208.7 \\
\hline $04-05-00$ & 242.6 \\
\hline $04-06-00$ & 280.7 \\
\hline $04-07-00$ & 185.9 \\
\hline $04-08-00$ & 58.7 \\
\hline $04-09-00$ & 61.7 \\
\hline $04-10-00$ & 186.3 \\
\hline $04-11-00$ & 219 \\
\hline $04-12-00$ & 240.3 \\
\hline $04-13-00$ & 231.6 \\
\hline $04-14-00$ & 277.7 \\
\hline & \\
\hline 0
\end{tabular}




\begin{tabular}{|c|c|}
\hline $04-15-00$ & 83.4 \\
\hline $04-16-00$ & 53.7 \\
\hline $04-17-00$ & 165.4 \\
\hline $04-18-00$ & 219.7 \\
\hline $04-19-00$ & 188.5 \\
\hline $04-20-00$ & 207.3 \\
\hline $04-21-00$ & 114.9 \\
\hline $04-22-00$ & 37 \\
\hline $04-23-00$ & 24.2 \\
\hline $04-24-00$ & 193.7 \\
\hline $04-25-00$ & 245.1 \\
\hline $04-26-00$ & 291.2 \\
\hline $04-27-00$ & 271.3 \\
\hline $04-28-00$ & 228.5 \\
\hline $04-29-00$ & 81.7 \\
\hline $04-30-00$ & 41.6 \\
\hline $05-01-00$ & 245.7 \\
\hline $05-02-00$ & 250.3 \\
\hline $05-03-00$ & 255.1 \\
\hline $05-04-00$ & 278.7 \\
\hline $05-05-00$ & 241.6 \\
\hline $05-06-00$ & 96.9 \\
\hline $05-07-00$ & 67.2 \\
\hline $05-08-00$ & 283.8 \\
\hline $05-09-00$ & 255.4 \\
\hline $05-10-00$ & 240.1 \\
\hline $05-11-00$ & 229.7 \\
\hline $05-12-00$ & 276.5 \\
\hline $05-13-00$ & 62.7 \\
\hline $05-14-00$ & 39.9 \\
\hline $05-15-00$ & 273.1 \\
\hline $05-16-00$ & 199.5 \\
\hline $05-17-00$ & 217.9 \\
\hline $05-18-00$ & 238.3 \\
\hline $05-19-00$ & 170 \\
\hline $05-20-00$ & 42.7 \\
\hline $05-21-00$ & 43.2 \\
\hline $05-22-00$ & 268.3 \\
\hline $05-23-00$ & 252 \\
\hline $05-24-00$ & 311.6 \\
\hline $05-25-00$ & 291.1 \\
\hline $05-26-00$ & 212.4 \\
\hline & \\
\hline
\end{tabular}




\begin{tabular}{|c|c|}
\hline $05-27-00$ & 41.7 \\
\hline $05-28-00$ & 15.5 \\
\hline $05-29-00$ & 41.3 \\
\hline $05-30-00$ & 229 \\
\hline $05-31-00$ & 239.6 \\
\hline $06-01-00$ & 287.7 \\
\hline $06-02-00$ & 244 \\
\hline $06-03-00$ & 94 \\
\hline $06-04-00$ & 31.9 \\
\hline $06-05-00$ & 150.9 \\
\hline $06-06-00$ & 273.7 \\
\hline $06-07-00$ & 343.9 \\
\hline $06-08-00$ & 342 \\
\hline $06-09-00$ & 343 \\
\hline $06-10-00$ & 85.8 \\
\hline $06-11-00$ & 58 \\
\hline $06-12-00$ & 214 \\
\hline $06-13-00$ & 236.2 \\
\hline $06-14-00$ & 242.9 \\
\hline $06-15-00$ & 298.2 \\
\hline $06-16-00$ & 276.4 \\
\hline $06-17-00$ & 77.6 \\
\hline $06-18-00$ & 51.6 \\
\hline $06-19-00$ & 254.3 \\
\hline $06-20-00$ & 210.2 \\
\hline $06-21-00$ & 331 \\
\hline $06-22-00$ & 323.9 \\
\hline $06-23-00$ & 277 \\
\hline $06-24-00$ & 71.4 \\
\hline $06-25-00$ & 68.1 \\
\hline $06-26-00$ & 245.7 \\
\hline $06-27-00$ & 238 \\
\hline $06-28-00$ & 264.9 \\
\hline $06-29-00$ & 307.2 \\
\hline $06-30-00$ & 280.6 \\
\hline & \\
\hline 0
\end{tabular}


APPENDIX C. DATA USED FOR IMPUTATION METHODS

\begin{tabular}{|c|c|}
\hline Date & TotalESAL \\
\hline $\begin{array}{c}08-01- \\
00\end{array}$ & 336.3 \\
\hline $\begin{array}{c}08-02- \\
00\end{array}$ & 301 \\
\hline $\begin{array}{c}08-03- \\
00\end{array}$ & 245.3 \\
\hline $\begin{array}{c}08-04- \\
00\end{array}$ & 198.7 \\
\hline $\begin{array}{c}08-05- \\
00\end{array}$ & 63.4 \\
\hline $\begin{array}{c}08-06- \\
00\end{array}$ & 50.8 \\
\hline $\begin{array}{c}08-07- \\
00\end{array}$ & 256.4 \\
\hline $\begin{array}{c}08-08- \\
00\end{array}$ & 289.5 \\
\hline $\begin{array}{c}08-09- \\
00\end{array}$ & 263.9 \\
\hline $\begin{array}{c}08-10- \\
00\end{array}$ & 289.6 \\
\hline $\begin{array}{c}08-11- \\
00\end{array}$ & 220.6 \\
\hline $\begin{array}{c}08-12- \\
00\end{array}$ & 43.6 \\
\hline $\begin{array}{c}08-13- \\
00\end{array}$ & 48.2 \\
\hline $\begin{array}{c}08-14- \\
00\end{array}$ & 251.6 \\
\hline $\begin{array}{c}08-15- \\
00\end{array}$ & 282.8 \\
\hline $\begin{array}{c}08-16- \\
00\end{array}$ & 252.7 \\
\hline $\begin{array}{c}08-17- \\
00\end{array}$ & 211 \\
\hline $\begin{array}{c}08-18- \\
00\end{array}$ & 208.4 \\
\hline $\begin{array}{c}08-19- \\
00\end{array}$ & 58.5 \\
\hline 08-20- & 51.1 \\
\hline
\end{tabular}




\begin{tabular}{|c|c|}
\hline 00 & \\
\hline $\begin{array}{c}08-21- \\
00\end{array}$ & 209.1 \\
\hline $\begin{array}{c}08-22- \\
00\end{array}$ & 304.3 \\
\hline $\begin{array}{c}08-23- \\
00\end{array}$ & 241.3 \\
\hline $\begin{array}{c}08-24- \\
00\end{array}$ & 262.6 \\
\hline $\begin{array}{c}08-25- \\
00\end{array}$ & 242.1 \\
\hline $\begin{array}{c}08-26- \\
00\end{array}$ & 68.3 \\
\hline $\begin{array}{c}08-27- \\
00\end{array}$ & 48.1 \\
\hline $\begin{array}{c}08-28- \\
00\end{array}$ & 204.1 \\
\hline $\begin{array}{c}08-29- \\
00\end{array}$ & 259.2 \\
\hline $\begin{array}{c}08-30- \\
00\end{array}$ & 263.7 \\
\hline $\begin{array}{c}08-31- \\
00\end{array}$ & 243.8 \\
\hline $\begin{array}{c}09-01- \\
00\end{array}$ & 225.5 \\
\hline $\begin{array}{c}\text { 09-02- } \\
00\end{array}$ & 50.9 \\
\hline $\begin{array}{c}09-03- \\
00\end{array}$ & 26.3 \\
\hline $\begin{array}{c}\text { 09-04- } \\
00\end{array}$ & 42.2 \\
\hline $\begin{array}{c}\text { 09-05- } \\
00\end{array}$ & 205.7 \\
\hline $\begin{array}{c}\text { 09-06- } \\
00\end{array}$ & 245.7 \\
\hline $\begin{array}{c}\text { 09-07- } \\
00\end{array}$ & 284 \\
\hline $\begin{array}{c}\text { 09-08- } \\
00\end{array}$ & 276.2 \\
\hline $\begin{array}{c}\text { 09-09- } \\
00\end{array}$ & 88.1 \\
\hline $\begin{array}{c}09-10- \\
00\end{array}$ & 44.8 \\
\hline 09-11- & 287.4 \\
\hline
\end{tabular}




\begin{tabular}{|c|c|}
\hline 00 & \\
\hline $\begin{array}{c}09-12- \\
00\end{array}$ & 275.8 \\
\hline $\begin{array}{c}09-13- \\
00\end{array}$ & 333.9 \\
\hline $\begin{array}{c}\text { 09-14- } \\
00\end{array}$ & 213.6 \\
\hline $\begin{array}{c}09-15- \\
00\end{array}$ & 233.5 \\
\hline $\begin{array}{c}09-16- \\
00\end{array}$ & 71.5 \\
\hline $\begin{array}{c}09-17- \\
00\end{array}$ & 59.9 \\
\hline $\begin{array}{c}09-18- \\
00\end{array}$ & 239.6 \\
\hline $\begin{array}{c}09-19- \\
00\end{array}$ & 276.5 \\
\hline $\begin{array}{c}09-20- \\
00\end{array}$ & 273.4 \\
\hline $\begin{array}{c}09-21- \\
00\end{array}$ & 301.4 \\
\hline $\begin{array}{c}09-22- \\
00\end{array}$ & 216.1 \\
\hline $\begin{array}{c}09-23- \\
00\end{array}$ & 70.3 \\
\hline $\begin{array}{c}\text { 09-24- } \\
00\end{array}$ & 40.8 \\
\hline $\begin{array}{c}09-25- \\
00\end{array}$ & 182.4 \\
\hline $\begin{array}{c}\text { 09-26- } \\
00\end{array}$ & 243.1 \\
\hline $\begin{array}{c}09-27- \\
00\end{array}$ & 303.9 \\
\hline $\begin{array}{c}\text { 09-28- } \\
00\end{array}$ & 274.5 \\
\hline $\begin{array}{c}\text { 09-29- } \\
00\end{array}$ & 214.4 \\
\hline $\begin{array}{c}\text { 09-30- } \\
00\end{array}$ & 94.1 \\
\hline $\begin{array}{c}10-01- \\
00\end{array}$ & 62.3 \\
\hline $\begin{array}{c}10-02- \\
00\end{array}$ & 310.5 \\
\hline 10-03- & 276.5 \\
\hline
\end{tabular}




\begin{tabular}{|c|c|}
\hline 00 & \\
\hline $\begin{array}{c}10-04- \\
00\end{array}$ & 214.4 \\
\hline $\begin{array}{c}10-05- \\
00\end{array}$ & 191.7 \\
\hline $\begin{array}{c}10-06- \\
00\end{array}$ & 191.6 \\
\hline $\begin{array}{c}10-07- \\
00\end{array}$ & 79.9 \\
\hline $\begin{array}{c}10-08- \\
00\end{array}$ & 46.2 \\
\hline $\begin{array}{c}10-09- \\
00\end{array}$ & 219.7 \\
\hline $\begin{array}{c}10-10- \\
00\end{array}$ & 268.1 \\
\hline $\begin{array}{c}10-11- \\
00\end{array}$ & 234.5 \\
\hline $\begin{array}{c}10-12- \\
00\end{array}$ & 276.1 \\
\hline $\begin{array}{c}10-13- \\
00\end{array}$ & 299 \\
\hline $\begin{array}{c}10-14- \\
00\end{array}$ & 82.5 \\
\hline $\begin{array}{c}10-15- \\
00\end{array}$ & 51.4 \\
\hline $\begin{array}{c}10-16- \\
00\end{array}$ & 220.4 \\
\hline $\begin{array}{c}10-17- \\
00\end{array}$ & 260.3 \\
\hline $\begin{array}{c}10-18- \\
00\end{array}$ & 262.4 \\
\hline $\begin{array}{c}10-19- \\
00\end{array}$ & 281.2 \\
\hline $\begin{array}{c}10-20- \\
00\end{array}$ & 276.2 \\
\hline $\begin{array}{c}10-21- \\
00\end{array}$ & 95.2 \\
\hline $\begin{array}{c}10-22- \\
00\end{array}$ & 42.6 \\
\hline $\begin{array}{c}10-23- \\
00\end{array}$ & 278.2 \\
\hline $\begin{array}{c}10-24- \\
00\end{array}$ & 238.5 \\
\hline 10-25- & 265 \\
\hline
\end{tabular}




\begin{tabular}{|c|c|}
\hline 00 & \\
\hline $\begin{array}{c}10-26- \\
00\end{array}$ & 244 \\
\hline $\begin{array}{c}10-27- \\
00\end{array}$ & 287.6 \\
\hline $\begin{array}{c}10-28- \\
00\end{array}$ & 79 \\
\hline $\begin{array}{c}10-29- \\
00\end{array}$ & 55.2 \\
\hline $\begin{array}{c}10-30- \\
00\end{array}$ & 212 \\
\hline $\begin{array}{c}10-31- \\
00\end{array}$ & 218.7 \\
\hline
\end{tabular}

